\title{
Usability-Supporting Architectural Patterns
}

\author{
Len Bass \\ Software Engineering Institute \\ Carnegie Mellon University \\ Natalia Juristo \\ School of Computing \\ Technical University of Madrid
}

Bonnie E. John

Human-Computer Interaction Institute

Carnegie Mellon University

Maribel Sanchez-Segura

Computer Science Department

Carlos III University of Madrid

Sponsored by the U.S. Department of Defense, NASA, and the European Union.

USAP Tutorial ICSE 2004 - page 1

Bonnie E. John

Human-Computer Interaction Institute

Carnegie Mellon University

Pittsburgh PA 15213

USA

1-412-268-7182

bej@cs.cmu.edu

Natalia Juristo

School of Computing

Technical University of Madrid

Campus de Montegancedo s/n

28660 Boadilla del Monte

Spain

34-91-3366922

natalia@fi.upm.es
Len Bass

Software Engineering Institute

Carnegie Mellon University

Pittsburgh PA 15213

USA

1-412-268-6763

ljb@sei.cmu.edu

Maribel Sanchez-Segura

Computer Science Department

Universidad Carlos III de Madrid

Avda. de la Universidad, 30

28911 Leganes

Spain

34-91-6249421

Mariaisabel.sanchez@uc3m.es 


\section{Schedule}

\begin{tabular}{|l|l|}
\hline Time & Topic \\
\hline 9:00-9:15 & Instructor introduction \& tutorial objectives \\
\hline $9: 15-9: 30$ & $\begin{array}{l}\text { What is Software Architecture \& What is Usability? } \\
\text { ? Basic Concepts of each }\end{array}$ \\
\hline $9: 30-9: 45$ & $\begin{array}{l}\text { How software architecture and usability techniques fit } \\
\text { into a software development activities }\end{array}$ \\
\hline $9: 45-10: 30$ & $\begin{array}{l}\text { Separation based architectural patterns and their } \\
\text { motivation } \\
\text { ? J2EE-MVC } \\
\text { ? PAC } \\
\text { Why separation is inadequate for interactive systems }\end{array}$ \\
\hline 10:30-11:00 & BREAK \\
\hline
\end{tabular}




\section{Schedule}

\begin{tabular}{|l|l|}
\hline Time & Topic \\
\hline 11:00-11:30 & $\begin{array}{l}\text { Usability-Supporting Architectural Patterns (USAP) } \\
\text { ? Introduction to the parts of a USAP } \\
\text { ? Example of a USAP - problem statement, forces, and } \\
\text { general responsibilities }\end{array}$ \\
\hline 11:30-12: 30 & $\begin{array}{l}\text { Small Group Exercise: } \\
\text { ? Applying the problem statement and forces to a real- } \\
\text { world problem brought by the members of the } \\
\text { breakout group (one group per instructor) } \\
\text { ? Report-out to the entire group }\end{array}$ \\
\hline LUNCH \\
\hline $12: 30-2: 00$ & \\
\hline
\end{tabular}




\section{Schedule}

\begin{tabular}{|l|l|}
\hline Time & Topic \\
\hline 2:00-2:30 & Sample solution for example problem. \\
\hline $2: 30-3: 30$ & $\begin{array}{l}\text { Small Group Exercise: } \\
\text { ? Apply sample solution to real-world problem } \\
\text { introduced in prior break out } \\
\text { ? Report-out to entire group }\end{array}$ \\
\hline $3: 30-4: 00$ & BREAK \\
\hline $4: 00-5: 15$ & $\begin{array}{l}\text { A second USAP: } \\
\text { ?Example with Observing System State USAP }\end{array}$ \\
\hline $5: 15-5: 30$ & Tutorial wrap-up \\
\hline
\end{tabular}

USAP Tutorial ICSE 2004 - page 4 


\title{
Introductions
}

\author{
Who are we? \\ - Len Bass \\ - Bonnie John \\ - Natalia Juristo \\ - Maribel Sanchez-Segura
}

Who are you?

What do you want to get out of this tutorial?

Bonnie John is an engineer (B.Engr., The Cooper Union, 1977; M. Engr. Stanford, 1978) and cognitive psychologist (M.S. Carnegie Mellon, 1984; Ph. D. Carnegie Mellon, 1988) who has worked both in industry (Bell Laboratories, 1977-1983) and academe (Carnegie Mellon University,1988-present). She is an Associate Professor in the HumanComputer Interaction Institute and the Director of the Masters Program in HCI. Her research includes human performance modeling, usability evaluation methods, and the relationship between usability and software architecture. She consults for many industrial and government organizations.

Len Bass is an expert in software architecture \& architecture design methods. Author of six books including two textbooks on software architecture \& UI development, Len consult s on large-scale software projects in his role as Senior MTS on the Architecture Trade-off Analysis Initiative at the Software Engineering Institute. His research area is the achievement of various software quality attributes through software architecture and he is the developer of software architecture analysis and design methods. Len is also the past chair of the International Federation of Information Processing Working Group on User Interface Engineering.

Dr. Natalia Juristo is a professor of software engineering with the Computing School at the Universidad Politecnica de Madrid. From 1992 until 2002 she was the Director of the MSc in Software Engineering. Dr. Juristo has a B.S. and a Ph.D. in Computing. She was fellow of the European Centre for Nuclear Research (CERN) in Switzerland in 1988, and staff of the European Space Agency (ESA) in Italy in 1989 and 1990. During 1992 she was a resident affiliate of the Software Engineering Institute at Carnegie Mellon University. She was program chair for SEKE97 and general chair for SEKE01 and SNPD02. Prof. Juristo has been the keynote speaker for CSEET03. She has been the guest editor of special issues in several journals, including the Journal of Software and Systems, Data and Knowledge Engineering and the International Journal of Software Engineerin $g$ and Knowledge Engineering Dr. Juristo has been a member of several editorial boards, including IEEE Software and the Journal of Empirical Software Engineering. She is a senior member of IEEE.

Maribel Sanchez-Segura has been a faculty member of the Computer Science Department in the Carlos III Technical University of Madrid since 1998. Her research interests include software engineering, interactive systems, and usability. Maribel holds a B.S. in Computer Science, a M.S. in Software Engineerin g and a Ph.D. in Computer Science from the Technical University of Madrid. 


\section{Tutorial objectives: The scene}

The usability analyses or user test data are in; the development team is poised to respond. The software had been carefully modularized so that modifications to the UI would be fast and easy. When the usability problems are presented, someone around the table exclaims, "Oh, no, we can't change THAT!"

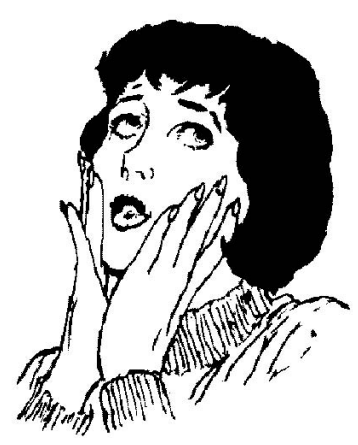

USAP Tutorial ICSE 2004 - page 6 


\section{Tutorial objectives: The scene}

The usability analyses or user test data are in; the development team is poised to respond. The software had been carefully modularized so that modifications to the UI would be fast and easy. When the usability problems are presented, someone around the table exclaims, "Oh, no, we can't change THAT!"

The requested modification, feature, functionality, reaches too far in to the architecture of the system to allow economically viable and timely changes to be made.

- Even when the functionality is right,

- Even when the UI is separated from that functionality,

- Architectural decisions made early in development can preclude the implementation of a usable system. 


\section{Tutorial objectives:}

- Understand basic principles of software architecture for interactive systems and its relationship to the usability of that system

- Be able to evaluate whether common usability scenarios will arise in the systems you are developing and what implications these usability scenarios have for software architecture design

- Understand patterns of software architecture that facilitate usability, and recognize architectural decisions that preclude usability of the end-product, so that you can effectively bring usability considerations into early architectural design. 


\section{What is Software Architecture?}

Enumeration of all major software components

Each component has enumeration of responsibilities

Interaction among components specified

- Control and data flow

- Sequencing information

- Protocols of interaction

- Allocation to hardware

There are many ways to document this information (Clements, et. al. 2003)

USAP Tutorial ICSE 2004 - page 9

Clements, P., Bachmann, F., Bass, L., Garlan, D., Ivers, J., Little, R., Nord, R., \& Stafford J., (2003) Documenting Software Architectures:

Views and Beyond, Addison Wesley. 


\section{Purposes of Software Architecture}

Communication among stakeholders

- An educational purpose

- A managerial purpose

Artifact for analysis

- Embeds early design decisions

Set of blueprints for implementation

USAP Tutorial ICSE 2004 - page 10 


\section{What does usability mean?}

As many definitions as there are authors!

What's important depends on context of use

Some commonly-seen aspects

- efficiency of use

- time to learn to use efficiently

- support for exploration and problem-solving

- user satisfaction (e.g., trust, pleasure, acceptance by discretionary users)

Our concern is which of these can be influenced by architectural decisions

USAP Tutorial ICSE 2004 - page 11 


\section{A usability benefits hierarchy}

Increases individual user effectiveness

- Expedites routine performance

- Accelerates error-free portion of routine performance

- Reduces the impact of routine user errors (slips)

- Improves non-routine performance

- Supports problem-solving

- Facilitates learning

- Reduces the impact of user errors caused by lack of knowledge (mistakes)

- Prevents mistakes

- Accommodates mistakes

Reduces the impact of system errors

- Prevents system errors

- Tolerates system errors

Increases user confidence and comfort

USAP Tutorial ICSE 2004 - page 12 


\section{Activities in software development}

System Formulation

Requirements

Architecture Design

Detailed Design

Implementation

System Test and Deployment

USAP Tutorial ICSE 2004 - page 13 


\section{Activities in software development $+\mathrm{HCl}$ techniques}

System Formulation - $\mathrm{HCl}$ techniques: Interviewing, questionnaires, Contextual Inquiry

Requirements - $\mathrm{HCl}$ techniques: Interviewing, questionnaires, Contextual Inquiry

Architecture Design - $\mathrm{HCl}$ techniques:

What we'll learn today

Detailed Design - $\mathrm{HCl}$ techniques:

Heuristic Evaluation, Cognitive Walkthrough, GOMS, PICTIVE,

Rapid prototyping+user testing, etc.

Implementation - $\mathrm{HCl}$ techniques:

UI Toolkits

System Test and Deployment - $\mathrm{HCl}$ techniques:

User testing in the field, Log analysis, etc.

USAP Tutorial ICSE 2004 - page 14 


\section{Detailed Design - Common Practice for Interactive Systems}

System Formulation - $\mathrm{HCl}$ techniques: Interviewing, questionnaires, Contextual Inquiry

Requirements - $\mathrm{HCl}$ techniques: Interviewing, questionnaires, Contextual Inquiry

Architecture Design - $\mathrm{HCl}$ techniques:

What we'll learn today

Detailed Design - $\mathrm{HCl}$ techniques:

Heuristic Evaluation, Cognitive Walkthrough, GOMS, PICTIVE,

Rapid prototyping+user testing, etc.

Implementation - $\mathrm{HCl}$ techniques:

UI Toolkits

System Test and Deployment - $\mathrm{HCl}$ techniques:

Think-aloud Usability Testing, Log analysis, etc.

USAP Tutorial ICSE 2004 - page 15 


\section{Detailed Design - Common Practice for Interactive Systems}

The $\mathrm{HCl}$ techniques supporting detailed design of the user interface are all based on iterative design

- i.e., design, test (analyze or measure), change, and re-test.

Once software has been designed, iteration implies change.

Software engineers plan for change through isolating section to be changed (separation).

In detailed design, the items to be separated are those relating to presentation, input, possibly dialog.

USAP Tutorial ICSE 2004 - page 16 


\section{Separation Based Architectural Patterns for Usability}

Presentation-Abstraction-Control (PAC)

- Developed in 1980s by group at the University of Grenoble

- Reaction to shortcomings of Smalltalk Model-ViewController (MVC)

J2EE Model-View-Controller (J2EE MVC)

- Developed by Sun to support J2EE

- Adaptation of Smalltalk MVC to web environment

Separation based patterns are commonly used in practice and have proven quite successful

USAP Tutorial ICSE 2004 - page 17

PAC is documented in:

Buschmann, F., Meuneir, R, Rohnert, H., Sommerlad, P. and Stal, M., (1996) Pattern-Oriented Software Architecture, A System of Patterns, Chichester, Eng: John Wiley and Sons.

J2EE-MVC is documented at http://java.sun.com/blueprints/patterns/MVCdetailed.html 


\section{Presentation-Abstraction-Control}

(PAC)

Hierarchical series of agents

- Top-level agent provides functional core

- Bottom level agents are self contained semantic concepts such as spread sheets or forms.

- Intermediate level agents act as intermediaries between top level and bottom level agents and determines which bottom level agents are active.

Each agent has three portions:

- Presentation - Input/output manager (unlikely to occur except in bottom level)

- Abstraction - Application functionality

- Control - Mediator between Presentation \& Abstraction and communicator to controls at other levels

USAP Tutorial ICSE 2004 - page 18 


\section{Presentation-Abstraction-Control (PAC)}

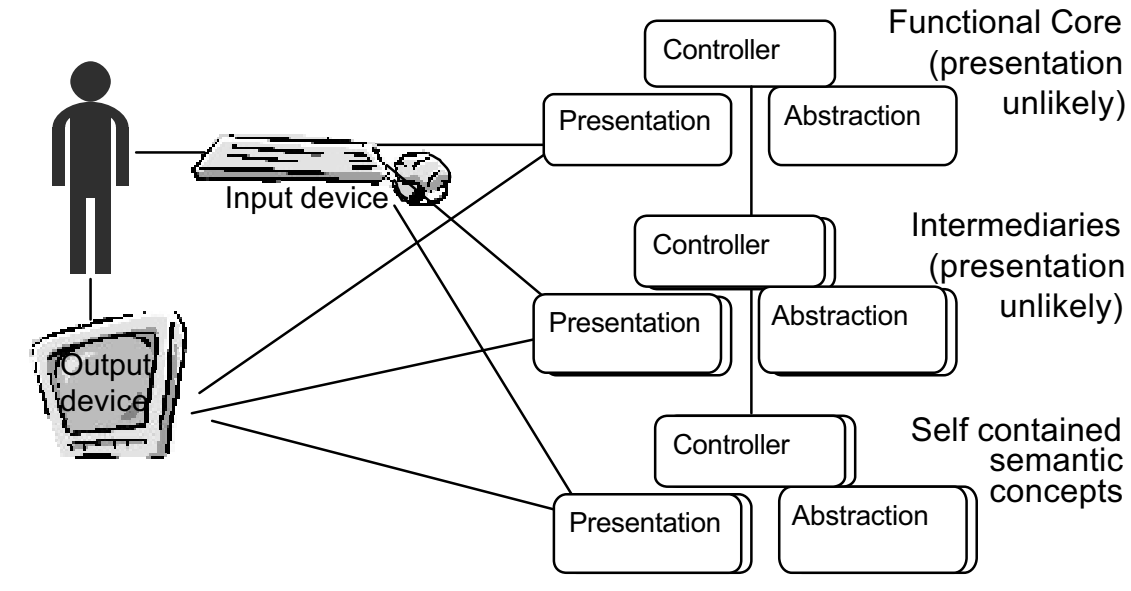

USAP Tutorial ICSE 2004 - page 19 


\section{J2EE Model-View-Controller}

Object-oriented

Model - Application state and functionality

View - Renders models, sends user gestures to Controller

Controller - Updates model, selects view, defines application behavior

Differences from PAC

- Separates management of the input from the output

- View updates itself directly from the model

- PAC hierarchical concept managed outside of J2EE-MVC

USAP Tutorial ICSE 2004 - page 20 


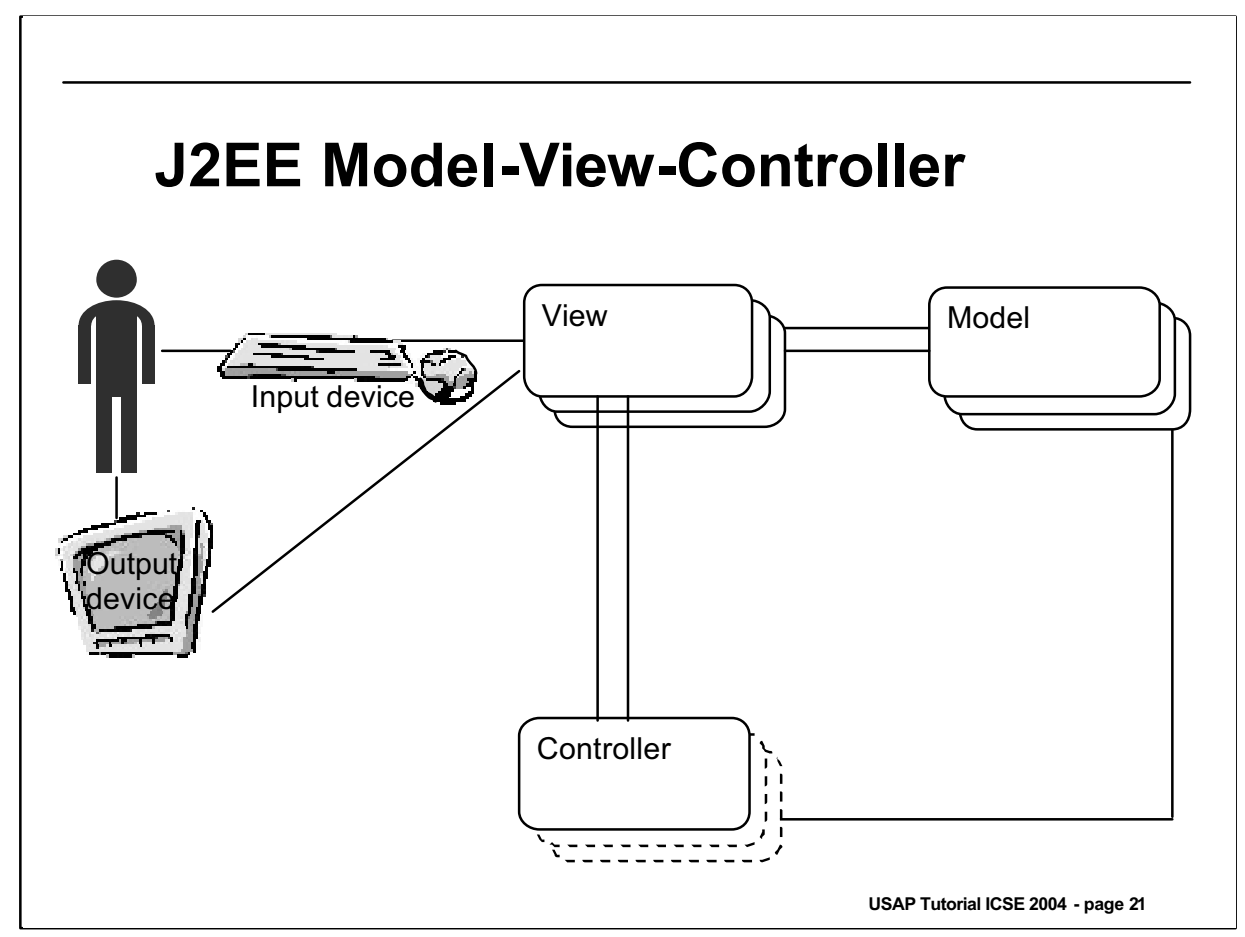




\section{Software architectural patterns}

PAC and J2EE MVC are "software architectural patterns" (Buschmann, et. al., 1996)

Independent of application

Provides some indication of assignment of responsibilities to components

Much left unspecified:

- Allocation to processes

- Synchronous/asynchronous communication

- Decomposition of components

- Class structure

- Other responsibilities of components

- Exceptions

Sufficient to give overall guidance for design approach

USAP Tutorial ICSE 2004 - page 22

Buschmann, F., Meuneir, R, Rohnert, H., Sommerlad, P. and Stal, M., (1996) Pattern-Oriented Software Architecture, A System of Patterns, Chichester, Eng: John Wiley and Sons. 


\section{Software architectural patterns - 2}

Patterns community has a variety of styles and levels of detail for writing about patterns

- Buschmann, et. al., (1996) provide prose descriptions, architecture-level diagrams, and sample code.

- Gamma, et. al., (1995) provide prose descriptions, class diagrams, and code samples

- Hillside Group advocates mainly prose and emphasizes pattern languages above individual patterns

USAP Tutorial ICSE 2004 - page 23

Buschmann, F., Meuneir, R, Rohnert, H., Sommerlad, P. and Stal, M., (1996) Pattern-Oriented Software Architecture, A System of Patterns, Chichester, Eng: John Wiley and Sons.

Gamma, E., Helm, R., Johnson, R., Vlissides, J. (1995). Design Patterns. Boston, Massachusetts: Addison-Wesley.

Information about the Hillside Group and patterns and pattern languages can be found at http://www.hillside.net/ 


\section{Why separation-based}

architectural patterns are not sufficient for interactive systems

Remember iterative design? 


\section{How does J2EE MVC support}

iterative design?

Change color of font

- Modify only View

- View contains all display logic; font changes only require modifying the display

Change order of dialogs

- Modify only Controller

- Controller defines the presentation flow, so changing dialog order involves modifying the controller logic

USAP Tutorial ICSE 2004 - page 25 


\section{What happens to other usability changes?}

Add the ability to cancel a long-running command

- Requires modification of all three modules

- View - must have cancel button or other means for user to specify cancel

- Controller - logic to respond to the View's menu selection and execute the appropriate Model function

- Model - free allocated resources, etc. 


\section{Shortcomings of separation patterns for solving the "We can't change THAT!" problem}

With respect to adding the ability to cancel

- Involved all components

- Not much localization

- If requirement for cancel discovered late, then will require extensive modification to the architecture.

USAP Tutorial ICSE 2004 - page 27 
After the break, we'll start addressing these shortcomings with usability-supporting architectural patterns 


\section{Beyond separation-based architectural patterns}

Our goal is to provide software designers and usability specialist tools to recognize and prevent common usability problems that are not supported by separation.

We are doing this by:

- Identifying those aspects of usability that are "architecturally sensitive" and embodying them in small scenarios

- Providing a way to reason about the forces acting on architecture design in these scenarios

- Providing checklist of important software responsibilities and possible architecture patterns to satisfy these scenarios 


\section{What does architecturally- sensitive mean?}

A scenario is architecturally-sensitive if it is difficult to add the scenario to a system after the architecture has been designed.

Solution may:

- Insure that multiple components interact in particular ways

- Insure that related information and actions can be found in a single component and easily changed

Separation patterns intended to localize changes to presentation. Therefore,

- Changing color of font - NOT architecturally-sensitive

- Adding cancellation - IS architecturally-sensitive 


\section{An architecturally-sensitive scenario: Canceling commands}

The user issues a command then changes his or her mind, wanting to stop the operation and return the software to its pre-operation state. It doesn't matter why the user wants to stop; he or she could have made a mistake, the system could be unresponsive, or the environment could have changed. 
What other architecturallysensitive scenarios can you think of? 


\section{Here are some others we have thought of}

Aggregating Data

Aggregating Commands

Alert

Canceling Commands

Checking for Correctness

Evaluating the System

Form/Field Validation

History Logging

Maintaining Device Independence

(Different Access Methods)

Maintaining Compatibility with

Other Systems

Making Views Accessible

Modifying Interfaces

Navigating Within a Single View

Observing System State

Operating Consistently Across

Views

Providing Good Help

(Context-Sensitive Help)

Predicting Task Duration

Recovering from Failure
Reusing Information

Retrieving Forgotten Passwords

Shortcuts

Status indication

Supporting Comprehensive Searching

Supporting International Use (Different Languages)

Supporting Multiple Activities

Supporting Personalization

(User Profile)

Supporting Undo

Supporting Visualization

Tour

Using Applications Concurrently (Multi-Tasking)

Verifying Resources

Wizard

Workflow mode

Working at the User's Pace

Working in an Unfamiliar Context

USAP Tutorial ICSE 2004 - page 33

This list of architecturally-sensitive usability scnearios is compiled from

Bass, L., John, B. E., \& Kates, J. (2001). Achieving usability through software architecture (CMU/SEl2001-TR-005). Pittsburgh, PA:

Software Engineering Institute.

http://www.sei.cmu.edu/publications/documents/01.re ports/01tr005.html

And

Juristo , N., Moreno, A. M., \& Sanchez, M. (2003) Deliverable D.3.4.

Techniques, patterns and styles for architecture-level usability improvement. ESPRIT project (IST-2001-32298)

http://www.ls. fi. upm.es/status/results/deliverables.html 


\section{Need more than just architecturally sensitive scenario}

Architecturally sensitive scenarios are potential requirements for a particular system to support usability

Need

- to determine whether the benefit of supporting the scenario outweighs the cost

- to provide guidance to the development team as to the issues associated with implementing a solution 


\section{Systems exist in a context}

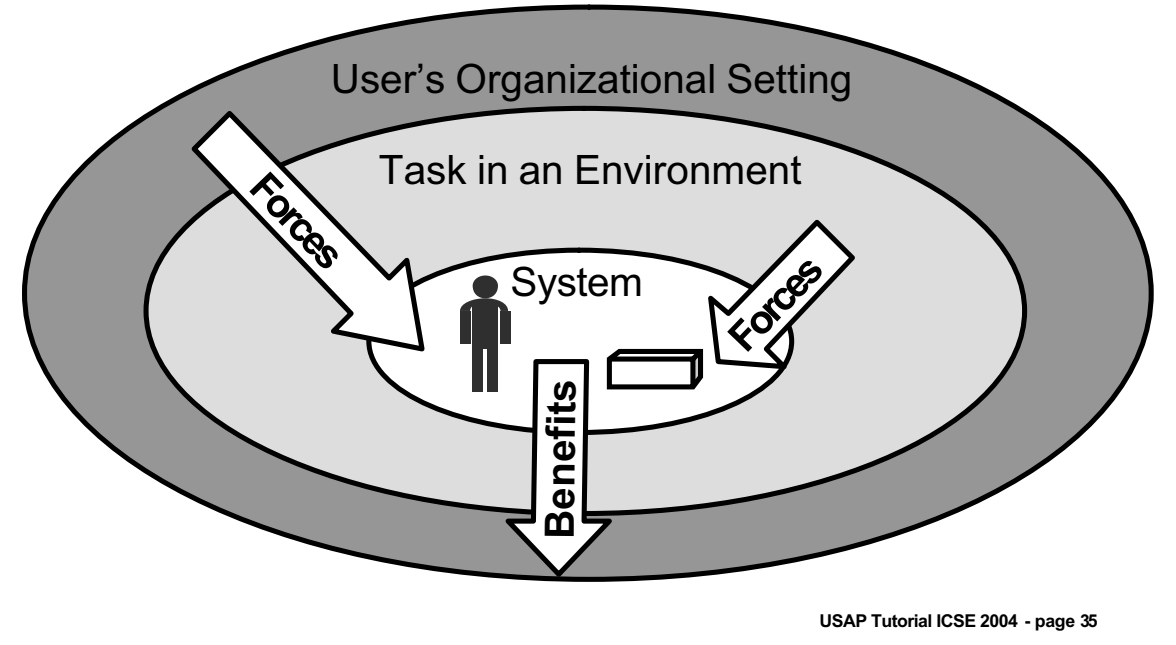




\section{Context for computer system}

Computer systems fulfill "business" goals

- "Business goals" could be mission, academic, entertainment, etc.

- User using the system creates certain benefits for the "organization" that created it

- Creating system has costs.

Cost/Benefit

- Implementation support for total scenario

- Implementation support for pieces of the scenario

But more detail is necessary to be able to understand cost/benefit and implications of implementation

USAP Tutorial ICSE 2004 - page 36 


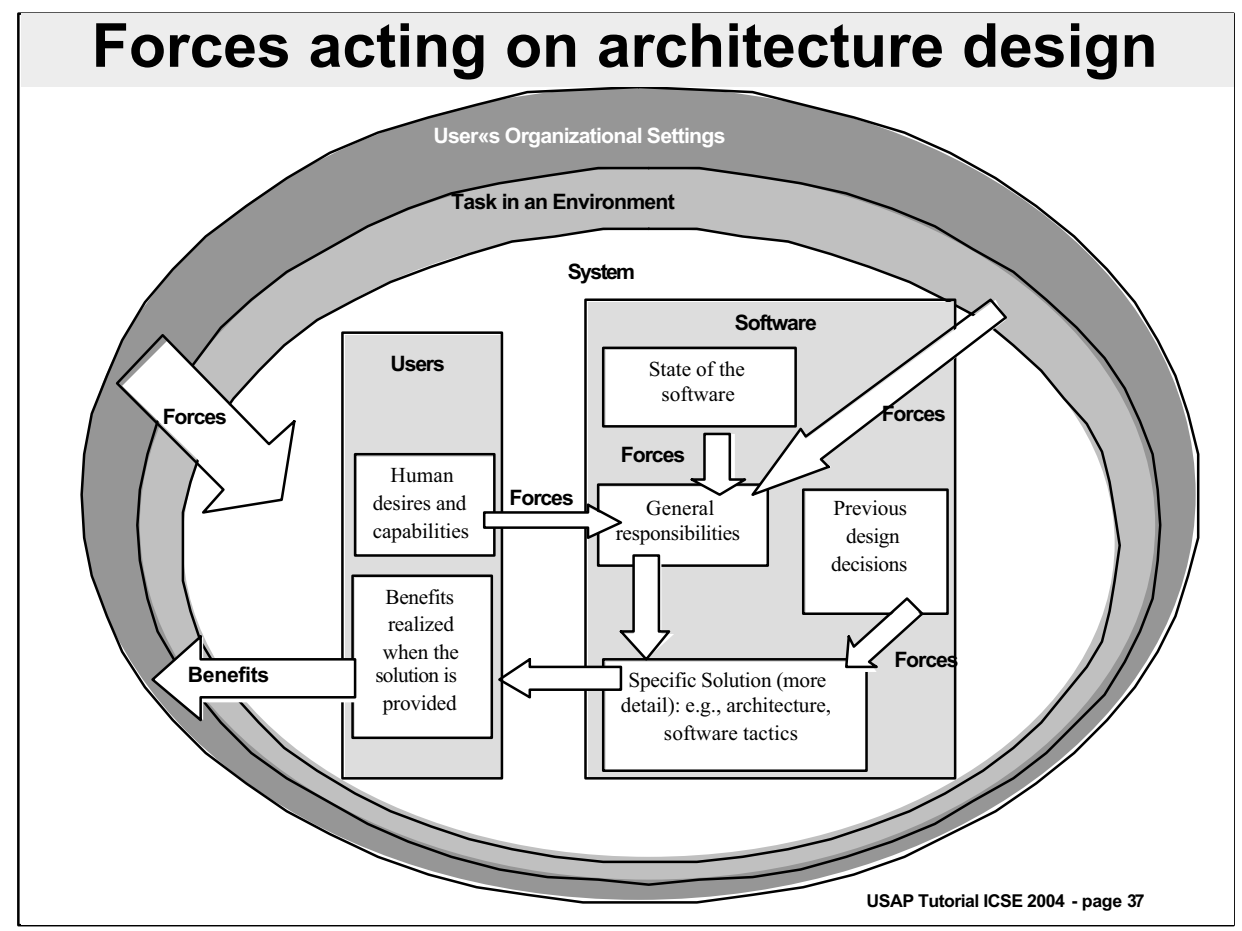




\section{Reasoning about architecture design}

Differing forces motivate particular aspects of solution.

Forces come from three sources:

- Task and environment in which user is operating.

- E.g., Cancel is only useful if operation is long running.

- Human desires and capabilities.

- E.g., User makes mistakes, Cancel allows one type of correction of mistake.

- State of the software.

- E.g., Networks fail. Giving the user the ability to cancel may prevent the user from being blocked because of this failure.

USAP Tutorial ICSE 2004 - page 38 


\section{Architecture Design}

Many different methods for satisfying a particular scenario.

Most systems use separation based architectural pattern as a basis for overall design of system.

We provide two different solutions:

- General solution - responsibilities of the software that must be fulfilled by any solution

- Specific solution. An architectural pattern that shows how to implement the general solution in the context of a separation based pattern. For example, we'll assume J2EE-MVC as an overarching separation based pattern.

USAP Tutorial ICSE 2004 - page 39 


\section{Software Architectural Patterns}

We have given you two examples of architectural patterns (PAC and J2EE-MVC)

These are examples of the solution portion of an architectural pattern

The patterns community has developed a set of common concepts that should be included in descriptions of a pattern.

We embody these concepts in Usability-Supporting Architectural Patterns (USAPs)

USAP Tutorial ICSE 2004 - page 40 


\section{Usability-Supporting Architectural Patterns - 1}

Context

- Situation - architecturally sensitive usability scenarios

- Conditions - constraints on when the situation is relevant

- Usability benefits - enumeration of benefits to the user from supporting this scenario

Problem - Forces in conflict

- Forces exerted by the task and environment

- Forces exerted by human desires and capabilities

- Forces exerted by the state of the software when the user wishes to apply the architecturally sensitive usability scenario

USAP Tutorial ICSE 2004 - page 41 


\section{Usability-Supporting Architectural}

Patterns - 2

General solution - set of responsibilities that any solution to situation must satisfy

Specific solution - architectural pattern to solve situation assuming an overarching separation based pattern

- In our slides, we'll assume J2EE-MVC 


\section{USAP Context template}

Situation: A brief description of the situation from the user's perspective that makes this pattern useful

Conditions on the Situation: Any conditions on the situation constraining when the pattern is useful

Potential Usability Benefits: A brief description of the benefits to the user if the solution is implemented. We use the usability benefit hierarchy given earlier

USAP Tutorial ICSE 2004 - page 43 


\section{USAP Context for Cancel - 1}

Situation: The user issues a command then changes his or her mind, wanting to stop the operation and return the software to its pre-operation state. It doesn't matter why the user wants to stop; he or she could have made a mistake, the system could be unresponsive, or the environment could have changed.

Conditions on the Situation: A user is working in a system where the software has long-running commands, i.e., more than one second.

The cancellation command could be explicitly issued by the user, or through some sensing of the environment (e.g., a child's hand in a power car window).

USAP Tutorial ICSE 2004 - page 44 


\section{Benefits of Cancel - 1}

Potential Usability Benefits:

A. Increases individual user effectiveness

A. 1 Expedites routine performance

A.1.2 Reduces the impact of routine user errors (slips) by allowing users to revoke accidental commands and return to their task faster than waiting for the erroneous command to complete.

A.2 Improves non-routine performance

A.2.1 Supports problem-solving by allowing users to apply commands and explore without fear, because they can always abort their actions.

USAP Tutorial ICSE 2004 - page 45 


\section{Benefits of Cancel - 2}

Potential Usability Benefits:

A. Increases individual user effectiveness

A.3 Reduces the impact of user errors caused by lack of knowledge (mistakes)

A.3.2 Accommodates mistakes by allowing users to abort commands they invoke through lack of knowledge and return to their task faster than waiting for the erroneous command to complete.

B. Reduces the impact of system errors

B.2 Tolerates system errors by allowing users to abort commands that aren't working properly (for example, a user cancels a download because the network is jammed).

C.Increases user confidence and comfort by allowing users to perform without fear because they can always abort their actions.

USAP Tutorial ICSE 2004 - page 46 


\section{Cost/Benefit}

There is a cost to implementing cancel. The software engineer can calculate this.

There is a benefit to the organization (as we explained) from implementing cancel.

- Benefit to current user immediately from recovered time

- Benefit to current user later from cleaning up local resources so system will not subsequently crash

- Benefit to other users from cleaning up shared resources.

Development team (or project manager) can do cost/benefit analysis to determine whether to implement cancel.

USAP Tutorial ICSE 2004 - page 47 


\section{First row of problem/general solution template always scenario}

The first row provides the rationale for the scenario in terms of the forces.

This enables the development team to decide whether to implement the scenario at all.

It may be that forces are not applicable to current development.

It may also be that forces cause consideration of scenario when it may be have been overlooked.

USAP Tutorial ICSE 2004 - page 48 


\section{USAP Problem/General Solution}

Template

\begin{tabular}{|l|l|l|l|}
\hline \multicolumn{2}{|c|}{ Problem } & \multicolumn{1}{|c|}{$\begin{array}{l}\text { General } \\
\text { Solution }\end{array}$} \\
\hline $\begin{array}{l}\text { Forces } \\
\text { exerted by the } \\
\text { environment } \\
\text { and the task. } \\
\text { Each row } \\
\text { contains a } \\
\text { different force }\end{array}$ & $\begin{array}{l}\text { Forces } \\
\text { exerted by } \\
\text { human } \\
\text { desires and } \\
\text { capabilities. } \\
\text { Each row } \\
\text { contains a } \\
\text { different } \\
\text { force. }\end{array}$ & $\begin{array}{l}\text { Forces } \\
\text { exerted by } \\
\text { the state of } \\
\text { the software. } \\
\text { Each row } \\
\text { contains a } \\
\text { different force. }\end{array}$ & $\begin{array}{l}\text { Responsibilities } \\
\text { of the general } \\
\text { solution that } \\
\text { resolve the forces } \\
\text { in the row. }\end{array}$ \\
\hline
\end{tabular}




\section{Cancel Problem/General Solution:}

Responsibility $R 1$ is essentially the scenario itself

\begin{tabular}{|l|l|l|l|}
\hline \multicolumn{2}{|c|}{ Problem } & \multicolumn{1}{|l|}{$\begin{array}{l}\text { General } \\
\text { Solution }\end{array}$} \\
\hline $\begin{array}{l}\text { Networks are } \\
\text { sometimes } \\
\text { unresponsive. }\end{array}$ & $\begin{array}{l}\text { Users slip or } \\
\text { make mistakes, } \\
\text { or explore } \\
\text { commands and } \\
\text { then change } \\
\text { their minds, but } \\
\text { do not want to } \\
\text { wait for the } \\
\text { Sometimes } \\
\text { changes in the } \\
\text { environment } \\
\text { require the } \\
\text { system to } \\
\text { terminate. }\end{array}$ & $\begin{array}{l}\text { Software is } \\
\text { sometimes } \\
\text { unresponsive }\end{array}$ & $\begin{array}{l}\text { R1. } \\
\text { Must provide } \\
\text { a means to } \\
\text { concel a } \\
\text { command }\end{array}$ \\
\hline
\end{tabular}

USAP Tutorial ICSE 2004 - page 50 


\section{Template Problem/General Solution - other rows}

Each subsequent row of the problem general solution template provides rationale for one or more responsibilities.

Usually one row per responsibility, but sometimes rationale for multiple responsibilities are the same and so multiple responsibilities are included in one row.

Allows development team to understand reason for responsibility and make cost/benefit decisions about:

- Necessity

- Utility 


\section{Cancel Problem/General Solution: Responsibility R2}

\begin{tabular}{|l|l|l|l|}
\hline \multicolumn{2}{|c|}{ Problem } & General Solution \\
\hline & $\begin{array}{l}\text { Users have to } \\
\text { communicate } \\
\text { their intentions } \\
\text { to the software } \\
\text { through overt } \\
\text { acts (e.g., finger } \\
\text { movements) }\end{array}$ & $\begin{array}{l}\text { Software } \\
\text { has to } \\
\text { receive an } \\
\text { action from } \\
\text { the user to } \\
\text { do } \\
\text { something }\end{array}$ & $\begin{array}{l}\text { R2. } \\
\text { Provide a button, } \\
\text { menu item, } \\
\text { keyboard shortcut } \\
\text { and/or other means } \\
\text { to cancel the active } \\
\text { command. }\end{array}$ \\
\hline
\end{tabular}

USAP Tutorial ICSE 2004 - page 52 


\section{Cancel Problem/General Solution: Responsibilities R3 and R4}

\begin{tabular}{|c|c|c|}
\hline & Problem & General Solution \\
\hline $\begin{array}{l}\text { No one can } \\
\text { predict when } \\
\text { the } \\
\text { environment } \\
\text { will change }\end{array}$ & $\begin{array}{l}\text { No one can } \\
\text { predict when the } \\
\text { users will want to } \\
\text { cancel } \\
\text { commands }\end{array}$ & $\begin{array}{l}\text { R3. } \\
\text { Must always listen for the } \\
\text { cancel command or } \\
\text { environmental changes } \\
\text { R4. } \\
\text { Must be always gathering } \\
\text { information (state, resource } \\
\text { usage, actions, etc.) that } \\
\text { allow for recovery of the } \\
\text { state of the system prior to } \\
\text { the execution of the current } \\
\text { command }\end{array}$ \\
\hline
\end{tabular}




\section{Appendix contains the full table of forces and general responsibilities for canceling commands.}

- We have enumerated 21 responsibilities

- Some are conditional

- on aspects of the task

- or state of the software 


\section{Summary of responsibilities that any implementation of cancel must consider}

R1. Must provide a means to cancel a command

R2. Provide a button, menu item, keyboard shortcut and/or other means to cancel the active command.

R3. Must always listen for the cancel command or environmental changes

R4. Must always gather information (state, resource usage, actions, etc.) that allow for recovery of the state of the system prior to the execution of the current command

R5. Must acknowledge receipt of the cancellation command appropriately within $150 \mathrm{msec}$. The acknowledgement must be appropriate to the manner in which the command was issued. For example, if the user pressed a cancel button, changing the color of the button will be seen. If the user used a keyboard shortcut, flashing the menu that contains that command might be appropriate.

... to R21 (see Tutorial Notes)

USAP Tutorial ICSE 2004 - page 55

Either the command itself is responsive

R6. The command must have the ability to cancel itself (I.e., it must fulfill Responsibilities R10 to R21 (e.g., an object-oriented system would have a cancel method in each object)

Or the command itself is not responsive

R7. An active portion of the application must ask the infrastructure to cancel the command, or

R8. The infrastructure itself must provide a means to request the cancellation of the application (e.g., task manager on Windows, force quit on MacOS)

R9. If either R7 or R8, then the infrastructure must have the ability to cancel the active command (I.e., it must fulfill Responsibilities R10 to R21)

If the command has invoked collaborating processes

R10. The collaborating processes have to be informed of the cancellation of the invoking command (these processes have their own responsibilities that they must perform in response to this information, possibly treat it as a cancellation.). The information given to collaborating processes may include the request for cancellation, the progress of cancellation, and/or the completion of cancellation. 


\section{Continuation of responsibilities that any implementation of cancel must consider}

Either the system is capable of rolling back all changes to the state prior to execution of the command.

R11. Restore the system back to its state prior to execution of the command.

Or the system is not capable of rolling back all changes to the state prior to execution of the command.

R12. Restore the system back to as close to the state prior to execution of the command as possible

R13. Inform the user of the difference between the prior state and the restored state.

Either all resource can be restored

R14. Resources must be freed

Or some resources has been irrevocably consumed and cannot be restored

R15. Inform the user of the partially-restored resources in a manner that they will see it.

For critical tasks with incomplete state or resource restoration,

R16. Require acknowledgement from the user that they are aware of the partiallyrestored nature of the cancellation.

R17. Return control to the user, or not, depending on the forces from the task

R18. If control cannot be returned to the user, inform the user of this fact (and ideally, why that is the case)

R19. Estimate the time it will take to cancel within $20 \%$

R20. Inform the user of this estimate.

- If the estimate is between 1 and 10 seconds, changing the cursor shape is sufficient.

- If the estimate is more than 10 seconds, and time estimate is with $20 \%$, then a progress indicator is better.

- If estimate is more than 10 seconds but cannot be estimated accurately, consider other alternatives (see TN, footnote 8)

R21. Once the cancellation has finished the system must provide feedback to the user that cancellation is finished, e.g., if cursor was changed to busy indicator, change it back to normal; if progress bar was displayed was displayed, remove it; if dialog box was provided, close it. 


\section{Observations on general responsibilities}

Many details might be overlooked by implementer

- Free resources

- Provide feedback if not able to completely cancel

- Inform collaborators

Table provides rationale which enables cost/benefit possibilities. e.g. "return control to the user immediately"

- Benefit is that user wants to multi-task - increased efficiency

- Cost may be too high depending on system environment.

USAP Tutorial ICSE 2004 - page 5 


\section{Small Group Exercise:}

Apply the problem statement and forces to a real-world problem brought by the members of the breakout group. (one group per instructor)

Report-out to the entire group 


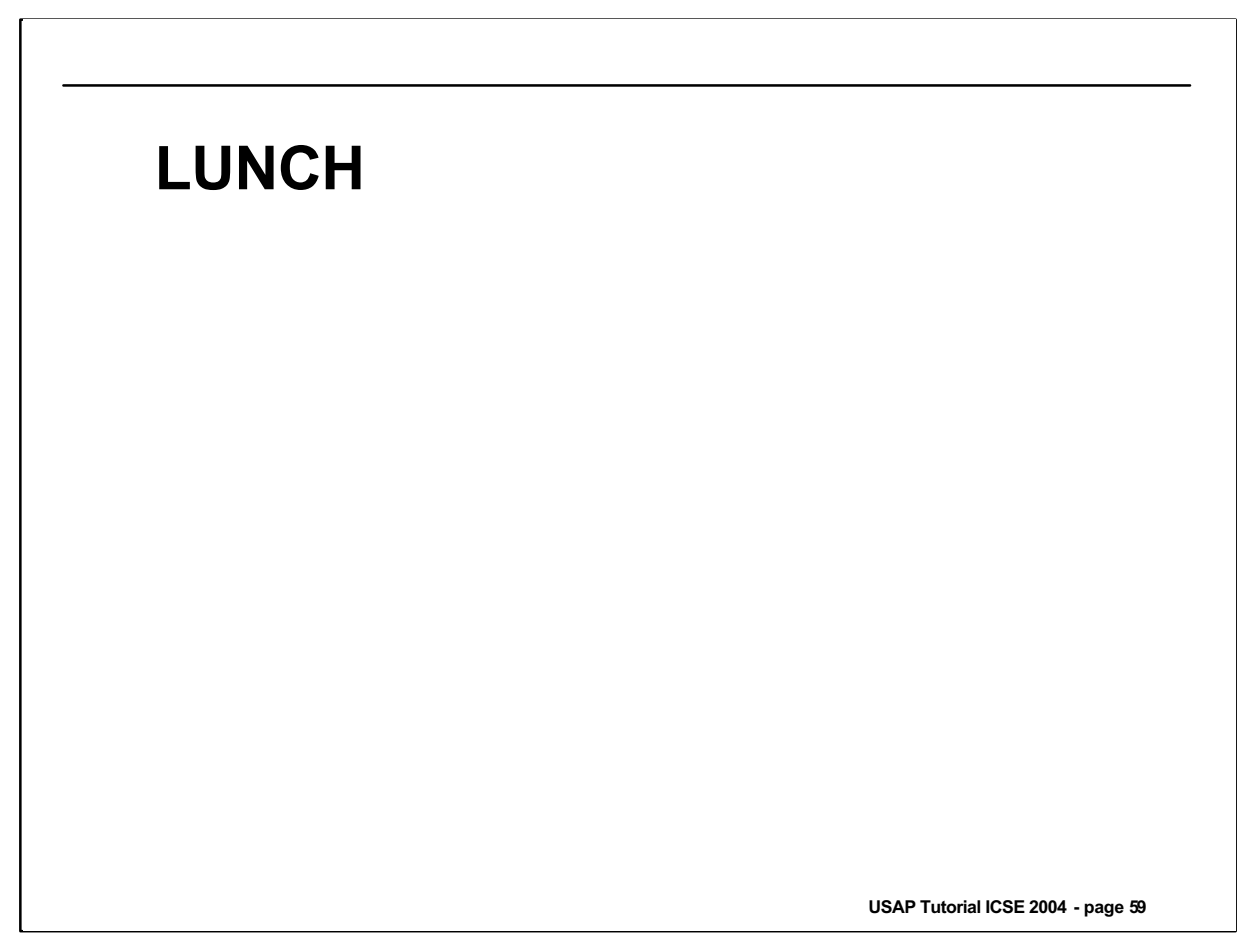




\section{Overarching patterns}

Designers do not build system design around desire for architecturally sensitive usability scenarios.

Designers have some overarching pattern that they use. e.g. PAC or J2EE-MVC

This overarching pattern introduces additional software forces on specific solution.

Consider "inform collaborating processes" responsibility when canceling web-based data base application.

Notice the difference in communication from PAC to J2EEMVC

USAP Tutorial ICSE 2004 - page 60 


\section{Presentation-Abstraction-Control (PAC)}

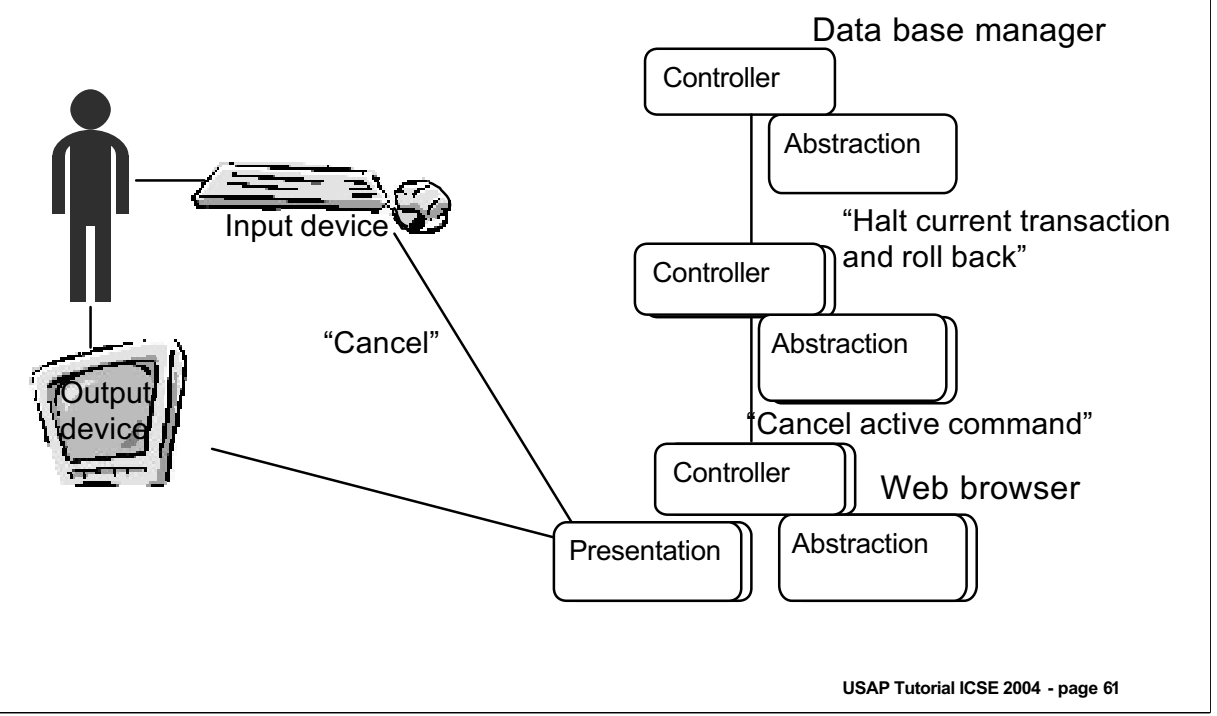




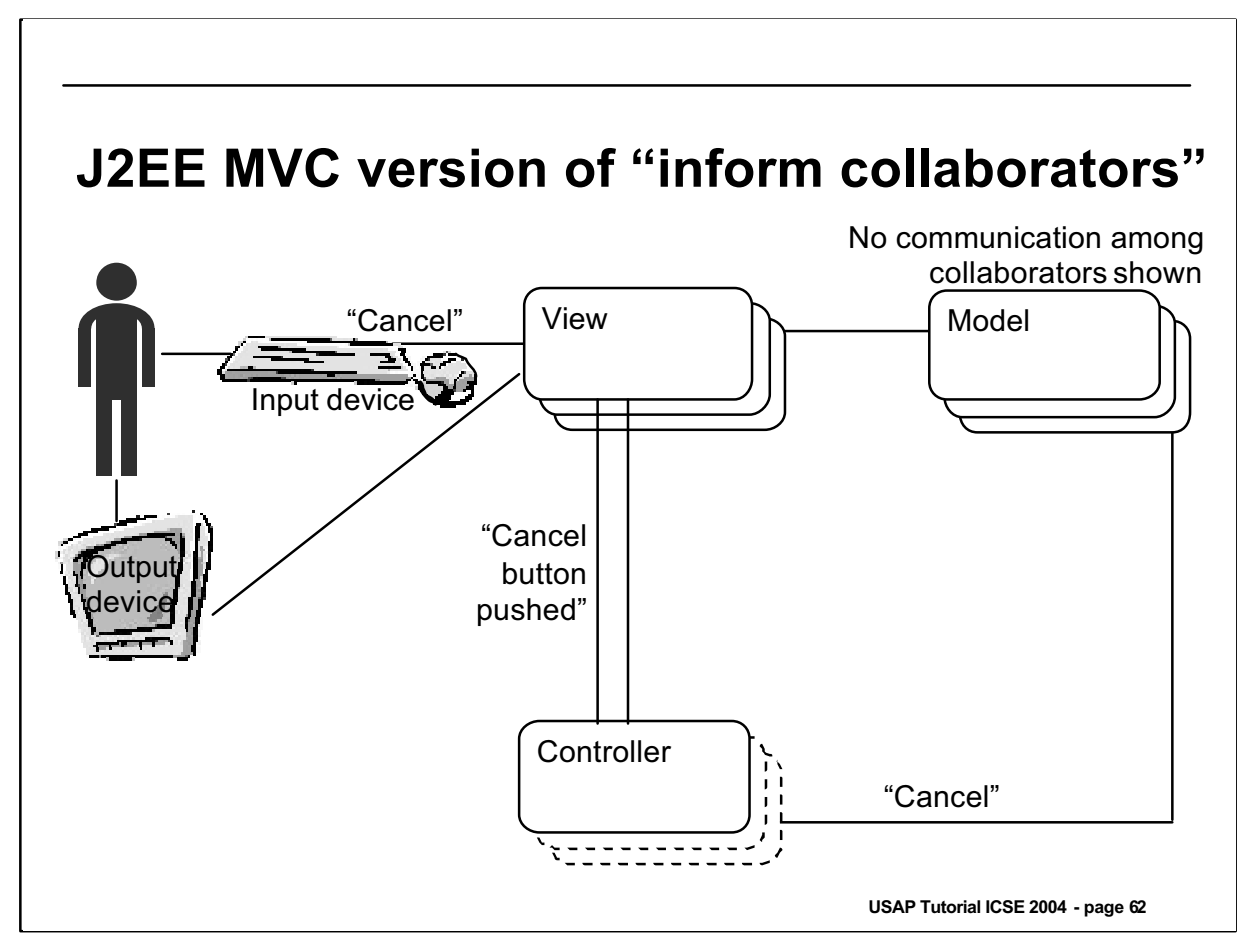




\section{We'll use J2EE-MVC as overarching pattern to illustrate our USAPs}

Overarching pattern will affect specific solution in our USAPs

We'll use J2EE-MVC as overarching pattern because it is widely used in web applications.

Open question as to how, in general, choice of a different overarching pattern would affect specific solutions

USAP Tutorial ICSE 2004 - page 63 


\section{We'll use a non-critical task for the example}

This implies that

- The user can have control while the cancellation is happening

- The user need not acknowledge the results of the cancellation 


\section{Specific Solution}

Architectural view: Presentation of one (or more) aspects of the architecture.

Common views:

- Component Diagram - shows major units of software but does not show dynamic behavior or assignment of units to various processors.

- Sequence Diagram - shows sequence of activities for a single thread through the system

USAP Tutorial ICSE 2004 - page 65 


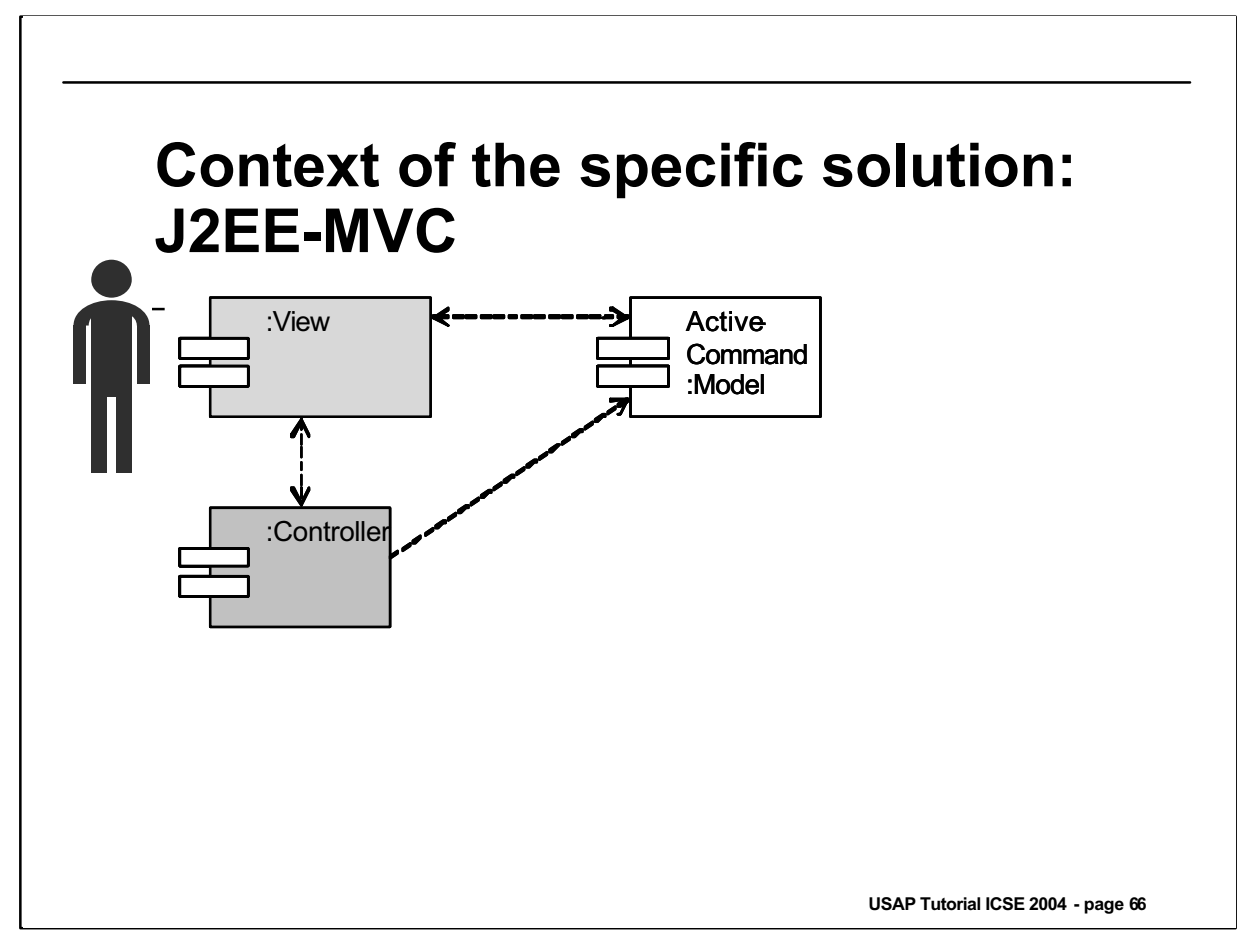




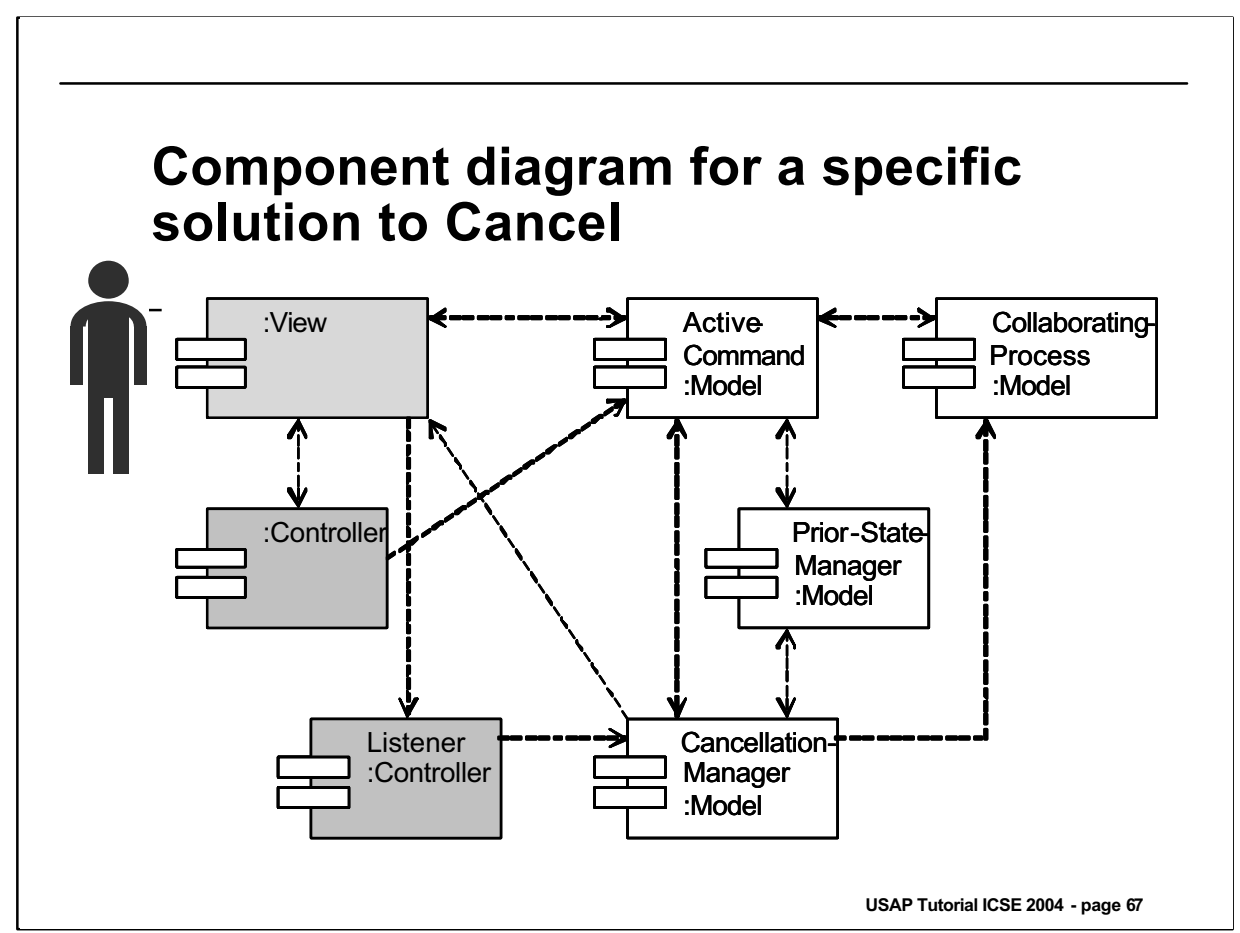




\section{Responsibilities of new component - Listener}

- Type Controller

- Must always listen for the cancel command or environmental changes (R3) 


\section{Responsibilities of new component - Cancellation Manager}

- Type Model

- Always listen and gather information (R3, R4)

- If the Active Command is not responding, handle the cancellation (R7, R10, R11, R12)

- Free resources (R14)

- Estimate time to cancel (R19)

- Inform the user of Progress of the cancellation (R13, $\mathrm{R} 15, \mathrm{R} 20, \mathrm{R} 21$ )

USAP Tutorial ICSE 2004 - page 69

Full text of responsibilities assigned to the Cancellation Manager in this example solution

R3. Must always listen for the cancel command or environmental changes

R4. Must always gather information (state, resource usage, actions, etc.) that allow for recovery of the state of the system prior to the execution of the current command

R7. An active portion of the application must ask the infrastructure to cancel the command,

If R7, then R10. The collaborating processes have to be informed of the cancellation of the invoking command (these processes have their own responsibilities that they must perform in response to this information, possibly treat it as a cancellation.). The information given to collaborating processes may include the request for cancellation, the progress of cancellation, and/or the completion of cancellation.

If R7, then R11. Restore the system back to its state prior to execution of the command. OR $\mathrm{R} 12$. Restore the system back to as close to the state prior to execution of the command as possible

If R12, then R13. Inform the user of the difference between the prior state and the restored state.

R14. All resources that can be freed must be freed.

If any resources are not capable of being freed, then R15. Inform the user of the partiallyrestored resources in a manner that they will see it.

R19. Estimate the time it will take to cancel within $20 \%$

R20. Inform the user of this estimate.

R21. Once the cancellation has finished the system must provide feedback to the user that cancellation is finished, e.g., if cursor was changed to busy in dicator, change it back to normal; if progress bar was displayed was displayed, remove it; if dialog box was provided, close it. 


\section{Responsibilities of new component - Prior State Manager}

- Type Model

- Must always gather information (state, resource usage, actions, etc.) that allow for recovery of the state of the system prior to the execution of the current command (R4)

- If the Active Command is not responding (R7), work with the Cancellation Manager to restore the system back to its state prior to execution of the command (R11) or as close as possible to that state (R12) 


\section{New responsibilities for old components - View}

- Type View

- Provide a button, menu item, keyboard shortcut and/or other means to cancel the active command (R2)

- Must always listen for the cancel command or environmental changes (R3)

- Provide feedback to the user about the progress of the cancellation (R5, R13, R15, R20, R21)

Full text of responsibilities assigned to the View in this examp le solution

R2. Provide a button, menu item, keyboard shortcut and/or other means to cancel the active command

R3. Must always listen for the cancel command or environmental changes

R5. Must acknowledge receipt of the cancellation command appropriately within $150 \mathrm{msec}$.

If any module did R12, then R13. Inform the user of the difference between the prior state and the restored state.

If any module did R14, then R15. Inform the user of the partially-restored resources in a manner that they will see it.

R20. Inform the user of the time estimate.

$\mathrm{R} 21$. Once the cancellation has finished the system must provide feedback to the user that cancellation is finished, e.g., if cursor was changed to busy in dicator, change it back to normal; if progress bar was displayed was displayed, remove it; if dialog box was provided, close it. 


\section{New responsibilities for old components - Active Command}

- Type Model

- Always gather information (R4)

- Handle the cancellation by terminating processes, and restoring state and resources (R6, R10, R11, R12, R14)

- Provide appropriate feedback to the user (R13, R15, R19, R20, R21)

USAP Tutorial ICSE 2004 - page 72

Full text of responsibilities assigned to the Active Command in this example solution

R4. Must always gather information (state, resource usage, actions, etc.) that allow for recovery of the state of the system prior to the execution of the current command

R6. The command must respond by canceling itself (I.e., it must fulfill Responsibilities R10 to R21 (e.g., an object-oriented system would have a cancel method in each object)

If R6 then R10. The collaborating processes have to be informed of the cancellation of the invoking command (these processes have their own responsibilities that they must perform in response to this information, possibly treat it as a cancellation.). The information given to collaborating processes may include the request for cancellation, the progress of cancellation, and/or the completion of cancellation.

If R6, then R11. Restore the system back to its state prior to execution of the command. Or R12. Restore the system back to as close to the state prior to execution of the command as possible

If R12, then R13. Inform the user of the difference between the prior state and the restored state.

R14. Resources that can be freedmust be freed

If any resources are not capable of being freed, then R15. Inform the user of the partiallyrestored resources in a manner that they will see it.

R19. Estimate the time it will take to cancel within $20 \%$

R20. Inform the user of this estimate.

R21. Once the cancellation has finished the system must provide feedback to the user that cancellation is finished, e.g., if cursor was changed to busy in dicator, change it back to normal; if progress bar was displayed was displayed, remove it; if dialog box was provided, close it. 


\section{Responsibilities not assigned or shown in our diagrams and why.}

-We are not considering a "critical task" where the progress and results of the cancellation must effect user behavior, therefore R16 and R18 are not assigned.

- J2EE-MVC implicitly returns control to the user during cancellation, so R17is not assigned.

- Our diagram does not show the infrastructure in which the application runs, therefore responsibilities assigned to the infrastructure are not shown (R8, R9)

USAP Tutorial ICSE 2004 - page 73

List of responsibilities not assigned to our components or not shown in the diagrams.

R8. The infrastructure itself must provide a means to request the cancellation of the application (e.g., task manager on Windows, force quit on MacOS)

R9. If either R7 or R8, then the infrastructure must have the ability to cancel the active command (I.e., it must fulfill Responsibilities R10 to R21)

R16 Require acknowledgement from the user that they are aware of the partiallyrestored nature of the cancellation. (we're not doing a "critical task" in this example)

R17. Return control to the user, or not, depending on the forces from the task (implicit in J2EE-MVC)

R18. If control cannot be returned to the user, inform the user of this fact (and ideally, why that is the case) (we're not doing a "critical task" in this example) 


\section{Sequence diagram of activities prior to issuing cancel command}

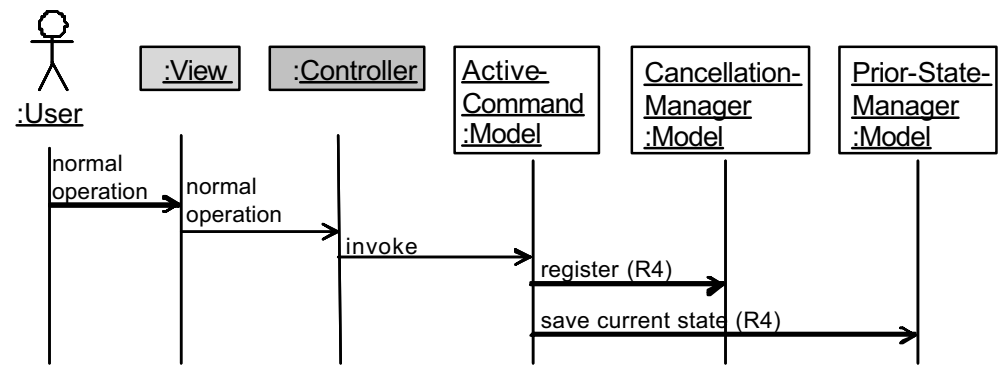

USAP Tutorial ICSE 2004 - page 74

Xxx put in note about the components that don't show up in this sequence 


\section{Sequence diagram of activities after issuing cancel command}

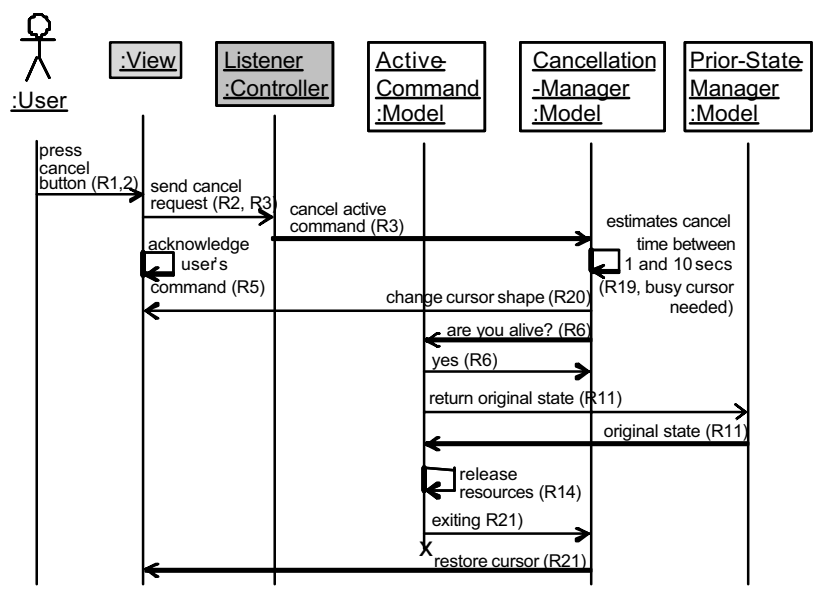

USAP Tutorial ICSE 2004 - page 75

Xxx put in note about the components that don't show up in this sequence 


\section{Comment on sequence diagrams}

Important portion of cancel is that listener is on separate thread of control (otherwise listener may be blocked because command is not responding and command owns the active thread).

Sequence diagram does not make this explicit. It is implicit in fact that listener responds regardless of state of active command.

Sequence diagram is UML (standard). Difficult to show threads in UML. 


\section{Small Group Exercise}

Apply sample solution to real-world problem introduced in prior break out

Report-out to entire group

USAP Tutorial ICSE 2004 - page $\pi$ 


\section{BREAK}

USAP Tutorial ICSE 2004 - page 78 


\section{Schedule}

\begin{tabular}{|l|l|}
\hline Time & Topic \\
\hline $4: 00-5: 15$ & $\begin{array}{l}\text { A second USAP: } \\
\text { ?Example with Observing System State USAP }\end{array}$ \\
\hline
\end{tabular}

USAP Tutorial ICSE 2004 - page 79 


\section{A Second USAP}

\section{Observing System State}




\section{Types of Feedback}

- Observing System state: To inform users of the internal system state and state changes.

- Progress indicator: To inform users that the system is processing an action that will take some time to complete.

- Interaction Feedback: To inform users that the system has registered a user interaction, that is, that the system has heard users.

- Warning: To inform users of any irreversible action. 


\section{USAP Template}

- Context

- Situation

- Conditions

- Potential usability benefits

- Problem and General Solution

- Specific Solution 


\section{Observing System State:}

\section{Situation}

Situation: When some change in system state occurs, the user should be notified, specially when the state change affects to state information that is displayed.

Conditions

Potential Usability Benefits 


\section{Observing System State:}

\section{Conditions}

Situation: When some change in system state occurs, the user should be notified.

\section{Conditions:}

- A user may not be given the system state data necessary to operate the system (e.g., uninformative error messages, no file size given for folders).

- The system state may be given in a way that violates human tolerances (e.g., displayed too quickly for people to read).

- The system state may also be given unclearly, thereby confusing the user.

- System designers should account for human needs and capabilities when deciding what aspects of a system state to display and how to do so.

Potential Usability Benefits

USAP Tutorial ICSE 2004 - page 84 


\section{Observing System State: Potential Usability Benefits}

Situation: When some change in system state occurs, the user should be notified.

Conditions:

- A user may not be given the system state data necessary to...

Potential Usability Benefits:

A. Increase individual user effectiveness

A.1 Expedite routine performance

A.1.2 Reduce the impact of routine user errors (slips)

A.2 Improve non-routine performance

A.2.1 Support problem-solving

A.2.2 Facilitate learning

A.3 Reduce the impact of user mistakes

A.3.2 Accommodate mistakes

C. Increase user confidence and comfort 


\section{USAP Template}

- Context

- Problem and General Solution

- Specific Solution 


\section{USAP Template}

- Context

\section{- Problem and General Solution}

- Forces exerted by the environment and the task

- Forces exerted by human desires and capabilities

- Forces exerted by the state of the software

- Responsibilities of the general solution that resolve the forces

- Specific Solution 


\section{Observing System State:}

\section{Human Forces (1/2)}

1. When some change in system state occurs, the user should be notified (HF01)

2. If the system fails, the user should be notified (HF02)

3. Users need to be alerted of the fact that a command does not respond (HF03) 


\section{Observing System State:}

\section{Environmental Forces}

1. Resources, be it the network, a database, etc., can become not operational (EF01) 


\section{Observing System State:}

System Forces (1/2)

1. System state changes (SF01)

2. Systems sometimes fail (SF02)

3. Commands sometimes die (SF03) 


\section{Observing System State:}

Problem - Responsibilities

\begin{tabular}{|l|l|l|l|}
\hline \multicolumn{3}{|c|}{ Problem } & \multicolumn{1}{|c|}{ General Solution } \\
\hline $\begin{array}{l}\text { Forces } \\
\text { exerted by } \\
\text { the } \\
\text { environment } \\
\text { and the task }\end{array}$ & $\begin{array}{l}\text { Forces } \\
\text { exerted by } \\
\text { human } \\
\text { desires and } \\
\text { capabilities }\end{array}$ & $\begin{array}{l}\text { Forces } \\
\text { exerted by } \\
\text { the state of } \\
\text { the software }\end{array}$ & $\begin{array}{l}\text { Responsibilities of the } \\
\text { software system that } \\
\text { resolve the forces }\end{array}$ \\
\hline
\end{tabular}




\section{Observing System State: Problem - Responsibilities}

\section{Problem/Forces:}

- SF01. The software changes

- HF01. When some change in system state occurs, the user should be notified.

\section{Solution/Responsibilities:}

- R01. The software should be able to listen to active commands, because they can provide information about the state of the system. If this information is useful to the user, the system should be able to provide this information to the user in the appropriate manner and in the proper location. 


\section{Observing System State: Problem - Responsibilities}

\section{Problem/Forces:}

- SF03. Commands sometimes fail to be operational

- R02: As active commands can fail, the software system should be able to check at any time whether a given command is being executed and, if the command fails, inform users that

- HF03: To alert users of the fact that the command is not operational. a command does not respond 


\section{Observing System State:}

Problem - Responsibilities

Problem/Forces:

Solution/Responsibilities:

- R03: The software should be able to

- EF1: Resources, be it the network, a database, etc., can become not operational listen to or query external resources, like networks or databases, about their state, to inform properly the user if any resource is not performing properly. 


\section{Observing System State: Problem - Responsibilities}

Problem/Forces:

- HF01. When some change in system state occurs, the user should be notified.
Solution/Responsibilities:

- R04: The software should be able to check the system resources and inform the user about their use. 


\section{USAP Template}

- Context

- Problem and General Solution

- Specific Solution

- General responsibilities

- Forces exerted by previous design decisions

- Allocation of responsibilities to specific components

- Rationale 


\section{Observing System State:}

General Responsibilities

- R01: Listen to active commands

- R02: Ascertain the state of active commands

- R03: Listen to or query external sources

-R04: Check the state of system resources 


\section{Observing System State:}

Forces from design decisions

- Architectural styles for the system will affect specific solution

- We have used J2EE-MVC as an architectural style for designing a specific solution 


\section{Context of the specific solution:}

J2EE-MVC 


\section{Observing System State: Allocation of responsibilities}

R1. The software should be able to listen to active commands. If this information is useful to the user, the system should be able to provide this information to the user in the appropriate manner not only through the display.
- Model: Should include an element that listens to active commands and, if the info is useful, sends it to the controller.

- View: Should be able to inform the user in the appropriate manner.

- Controller: Should be able to select the appropriate view to show the information to the user. 


\section{Observing System State: Allocation of responsibilities}

- Model: Should include an element that listens to active commands and, if the info is useful, sends it to the controller.

R1

- View: Should be able to inform the user in the appropriate manner.

- Controller: Should be able to select the appropriate view to show the information to the user.
- Active Command: Represents the command in progress and should inform the appropriate feedbacker if the user is to be notified of something

-Feedbacker: Receives the information to be displayed from the model or a change of view from the controller

- Controller: Should be listening to the Viewer and, if the user requests an action creates the required command, an instance of active command
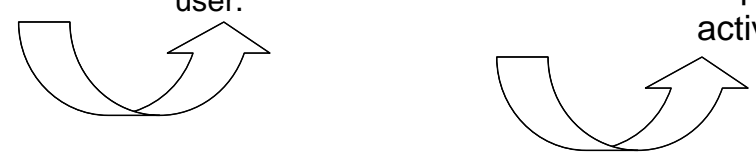

USAP Tutorial ICSE 2004 - page 101 


\section{Observing System State: Allocation of responsibilities}

\begin{tabular}{|c|c|c|}
\hline $\begin{array}{l}\text { General Responsibilities of } \\
\text { the software }\end{array}$ & $\begin{array}{l}\text { Forces exerted by previous } \\
\text { design decisions }\end{array}$ & $\begin{array}{l}\text { Allocation of responsibilities } \\
\text { to specific components }\end{array}$ \\
\hline \multirow{3}{*}{$\begin{array}{l}\text { R01:The software should be able to } \\
\text { listen to active commands, because } \\
\text { they can provide information about } \\
\text { the state of the system. If this } \\
\text { information is useful to the user, the } \\
\text { system should be able to provide this } \\
\text { information to the user in the } \\
\text { appropriate manner and in the } \\
\text { appropriate location, not only through } \\
\text { the display. }\end{array}$} & $\begin{array}{l}\text { Model: The model should include an } \\
\text { element that listens to active } \\
\text { commands and, if the information is } \\
\text { useful, sends the information to be } \\
\text { passed on to the user (see model } \\
\text { decomposition) }\end{array}$ & $\begin{array}{l}\text { Active command: Represents the } \\
\text { command in progress and should } \\
\text { inform appropriate feedbacker if the } \\
\text { user is to be notified of something }\end{array}$ \\
\hline & $\begin{array}{l}\text { View: Should be able to inform the } \\
\text { user in the appropriate manner. }\end{array}$ & $\begin{array}{l}\text { Feedbacker: Receives the } \\
\text { information to be displayed from the } \\
\text { model or a change of view from the } \\
\text { controller }\end{array}$ \\
\hline & $\begin{array}{l}\text { Controller: Should be able to select } \\
\text { the appropriate view to show the } \\
\text { information to the user. }\end{array}$ & $\begin{array}{l}\text { Controller: Should be listening to the } \\
\text { Viewer and, if the user requests an } \\
\text { action creates the required command, } \\
\text { an instance of active command }\end{array}$ \\
\hline
\end{tabular}




\section{Observing System State:}

Specific Solution

- Check whether or not the ongoing command is dead.

- Check whether or not external resources are dead.

- Check whether or not the system has enough resources to execute the ongoing command. 


\section{Observing System State:}

Specific Solution

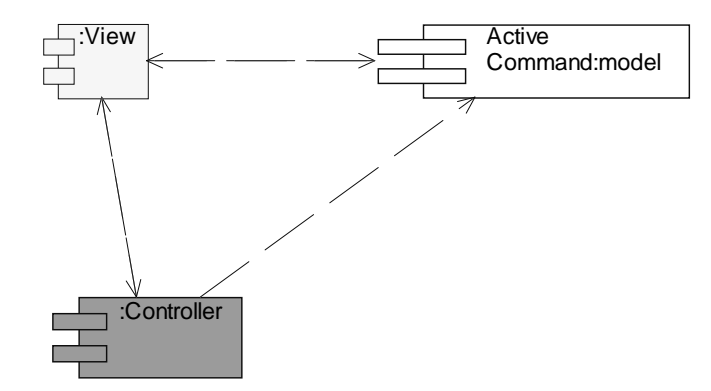




\section{Observing System State:}

Specific Solution

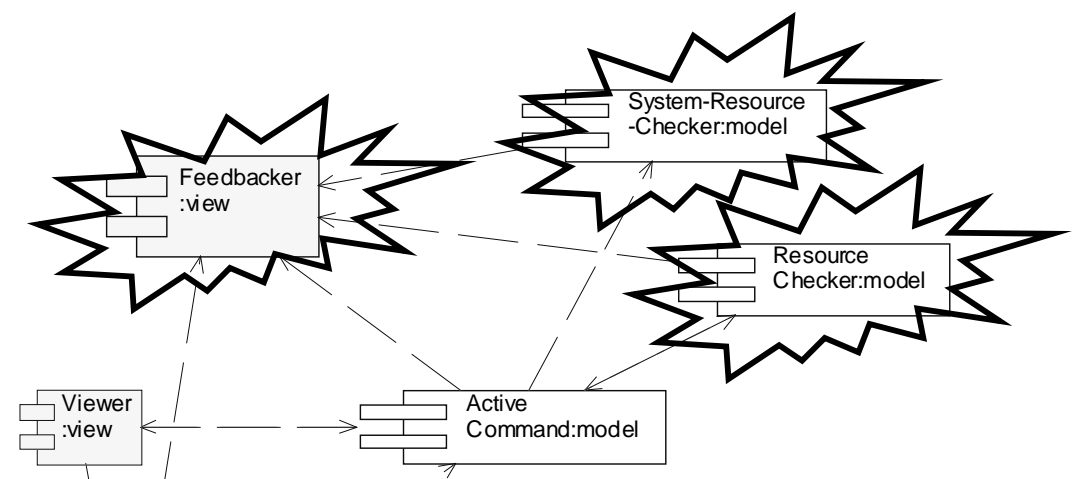

$5^{\text {:Controller }}$ 


\section{Observing System State: Responsibilities of new components}

\begin{tabular}{|l|l|}
\hline NEW COMPONENT & RESPONSIBILITIES \\
\hline $\begin{array}{c}\text { Feedbacker } \\
\text { (Type Model) }\end{array}$ & $\begin{array}{l}\text { Receive info from Resource Checker and select the } \\
\text { appropriate feedback (R02, R03, R04) }\end{array}$ \\
\hline $\begin{array}{l}\text { Resource Checker } \\
\text { (Type Model) }\end{array}$ & $\begin{array}{l}\text { Must be able to check whether or not the ongoing } \\
\text { command is alive (R02) } \\
\text { Must be able to check whether or not the external } \\
\text { resources are alive (R03) }\end{array}$ \\
\hline $\begin{array}{l}\text { System Resource } \\
\text { Checker } \\
\text { (Type Model) }\end{array}$ & $\begin{array}{l}\text { Must be able to check whether or not the system can } \\
\text { provide enough resources to properly execute the } \\
\text { ongoing command (R04) }\end{array}$ \\
\hline \multicolumn{2}{|c|}{} \\
\hline
\end{tabular}




\section{Observing System State:}

Specific Solution
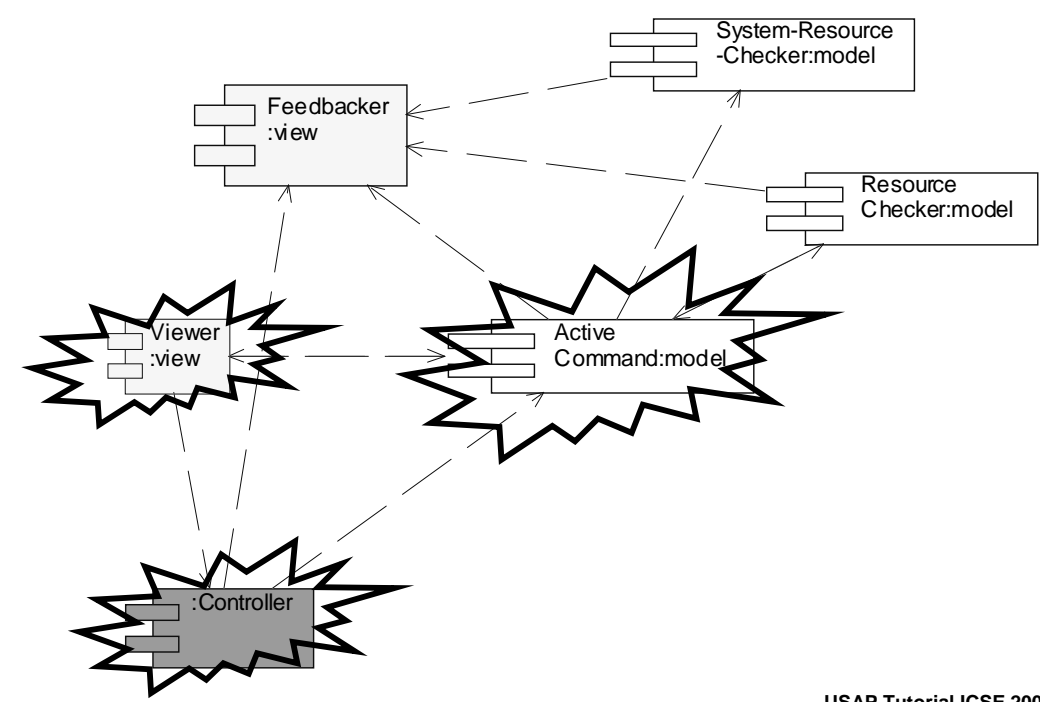


\section{Observing System State: Responsibilities of old components}

\begin{tabular}{|l|l|}
\hline OLD COMPONENT & RESPONSABILITIES \\
\hline $\begin{array}{l}\text { Viewer } \\
\text { (Type View) }\end{array}$ & Must be able to gather user requests. \\
\hline $\begin{array}{l}\text { Controller } \\
\text { (Type Controller) }\end{array}$ & $\begin{array}{l}\text { Must always listen for the viewer requests to create } \\
\text { the respective active command. }\end{array}$ \\
\hline $\begin{array}{l}\text { Active Command } \\
\text { (Type Model) }\end{array}$ & $\begin{array}{l}\text { Represents the command in progress and should } \\
\text { inform the Feedbacker about any change produced. }\end{array}$ \\
\hline
\end{tabular}




\section{Observing System State:}

Responsibilities related to control

- The Active Command should run in a different thread from the Resource Checker component

- The Active Command should run in a different thread from the System Resource Checker component 


\section{Observing System State:}

Specific Solution

Imagine we are faced with a situation where:

- The ongoing command is dead 


\section{Observing System State:}

Specific Solution

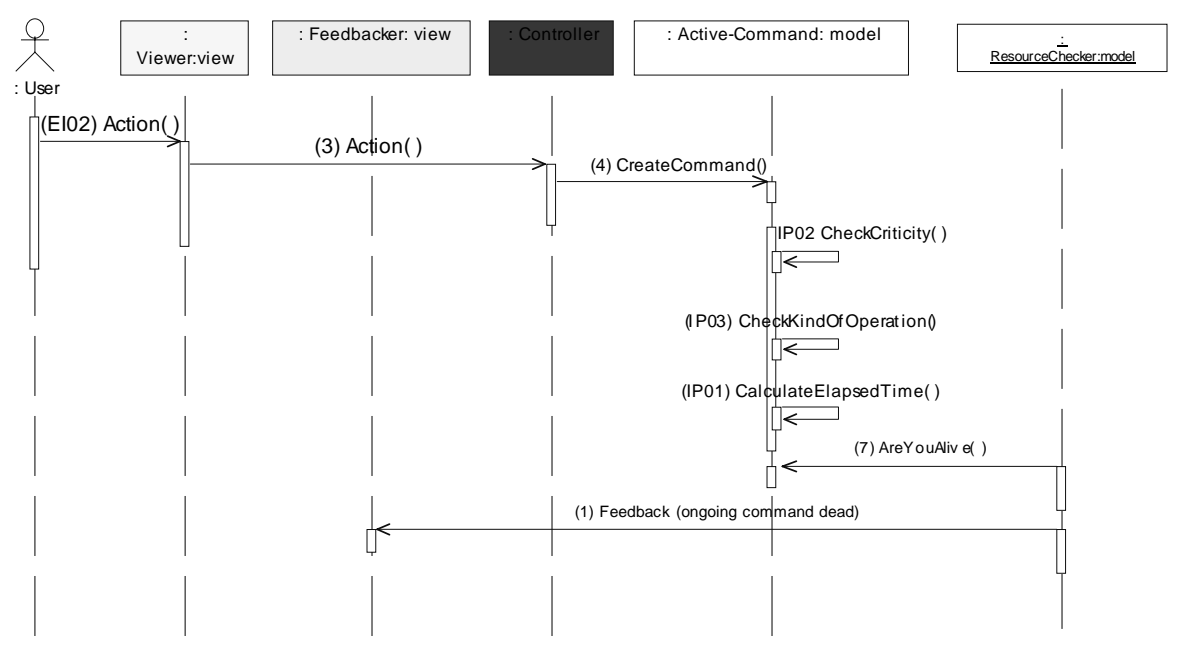




\section{Observing System State:}

Specific Solution

Imagine we are faced with a situation where:

- There are not enough resources to execute the ongoing command 


\section{Observing System State:}

Specific Solution

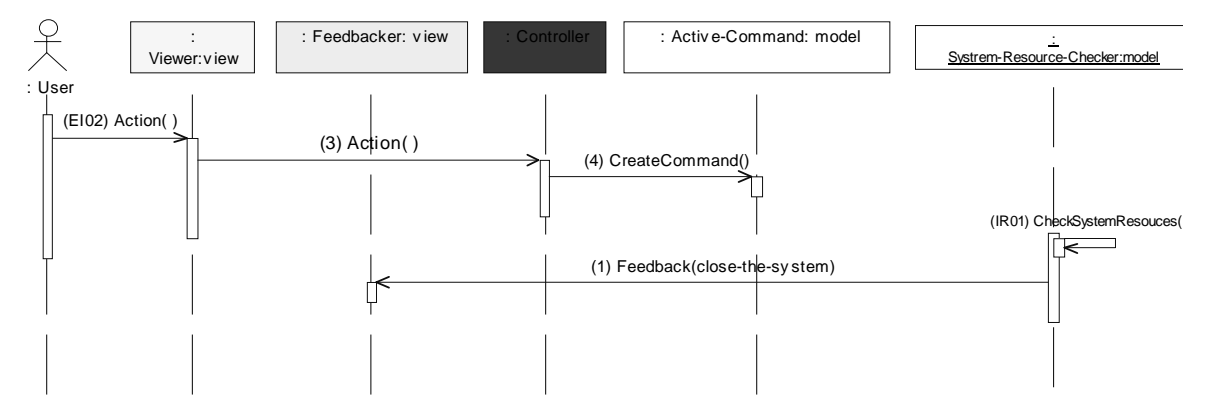




\section{Observing System State:}

Specific Solution

Imagine we are faced with a situation where:

- The external resources are performing properly 


\section{Observing System State:}

Specific Solution

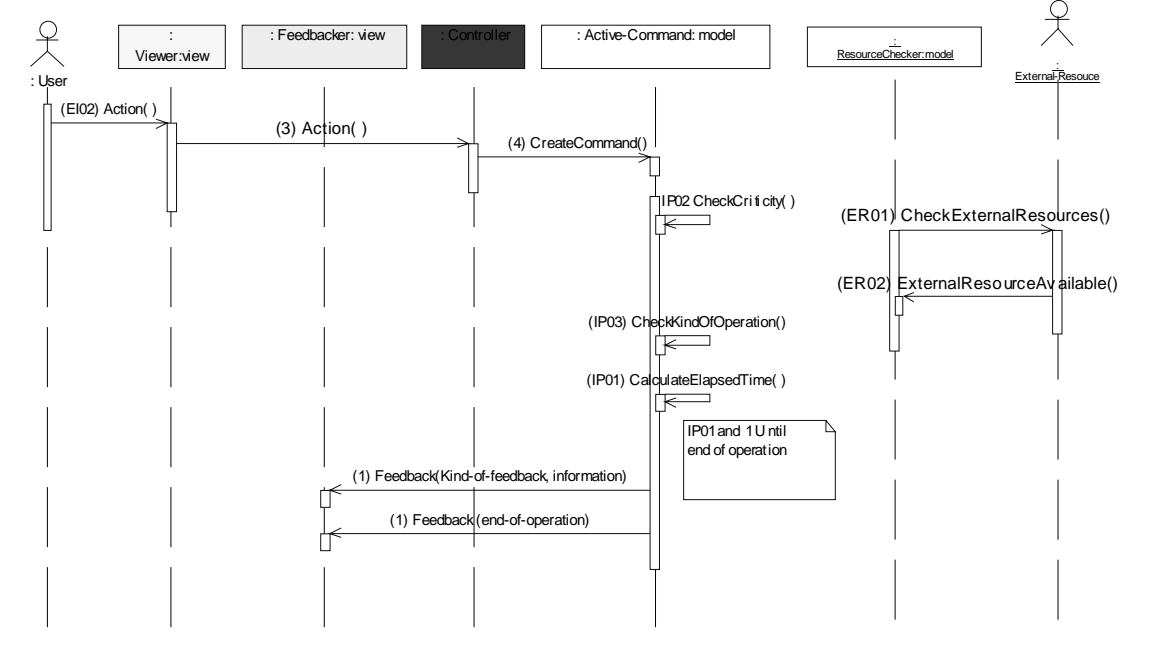




\section{Current status of USAPs}

We have about two dozen architecturally sensitive scenarios

Four of these have been elaborated into force $=>$ general responsibilities

We are elaborating additional scenarios.

We are also looking for additional scenarios.

Goal is to produce a handbook. 


\section{Experiences of USAPs in development}

Several Architectural Tradeoff Analyses conducted by the SEI used some of the architecturally-sensitive usability scenarios

NASA's MERBoard, a large-screen collaborative tool used in the Mars Exploration Rover mission this winter, redesigned their architecture using the scenarios and USAPs 


\section{Tutorial Summary}

Software architectural design can support iterative design through separation based patterns, but some usability issues are difficult to resolve through iterative design.

Architecturally sensitive scenarios are examples of problems that are difficult to implement once architecture is designed.

USAPs are an attempt to capture some of these problems, provide rationale to support cost/benefit analysis, provide general set of responsibilities for any solution, and provide sample specific solution to further guide software designer.

Currently have about two dozen architecturally sensitive scenarios and are in process of turning these into USAPs. 


\section{Appendix I General Usability Scenarios}

(excerpt of Bass, L., John, B. E., \& Kates, J. (2001). Achieving usability through software architecture (CMU/SEl-2001-TR-005). Pittsburgh, PA: Software Engineering Institute, Carnegie Mellon University)

This section enumerates the usability scenarios that we have identified as being architecturally sensitive. A general usability scenario describes an interaction that some stakeholder (e.g., end user, developer, system administrator) has with the system under consideration from a usability point of view.

We generated the list of usability scenarios by surveying the literature, by personal experience, and by asking colleagues [Gram 1996, Newman 1995, Nielsen 1993]. We also screened the list so that all entries have explicit software architectural implications and solutions. Section 5 provides an architectural pattern that implements each scenario given in this report.

\section{Aggregating Data}

A user may want to perform one or more actions on more than one object. For example, an Adobe ${ }^{\circledR}$ Illustrator ${ }^{\circledR}$ user may want to enlarge many lines in a drawing. It could become tedious to perform these actions one at a time. Furthermore, the specific aggregations of actions or data that a user wishes to perform cannot be predicted; they result from the requirements of each task. Systems, therefore, should allow users to select and act upon arbitrary combinations of data.

\section{Aggregating Commands}

A user may want to complete a long-running, multi-step procedure consisting of several commands. For example, a psychology researcher may wish to execute a batch of commands on a data file during analysis. It could become tedious to invoke these commands one at a time, or to provide parameters for each command as it executes. If the computer is unable to accept the required inputs for this procedure up front, the user will be forced to wait for each input to be requested. Systems should provide a batch or macro capability to allow users to aggregate commands.

\section{Canceling Commands}

A user invokes an operation, then no longer wants the operation to be performed. The user now wants to stop the operation rather than wait for it to complete. It does not matter why the user launched the operation. The mouse could have slipped. The user could have mistaken one command for another. The user could have decided to invoke another operation. For these reasons (and many more), systems should allow users to cancel operations.

\section{Using Applications Concurrently}

A user may want to work with arbitrary combinations of applications concurrently. These applications may interfere with each other. For example, some versions of IBM ${ }^{\circledR}$ ViaVoice and Microsoft巴 Word contend for control of the cursor with unpredictable results. 
Systems should ensure that users can employ multiple applications concurrently without conflict. (See: Supporting Multiple Activities)

\section{Checking for Correctness}

A user may make an error that he or she does not notice. However, human error is frequently circumscribed by the structure of the system; the nature of the task at hand, and by predictable perceptual, cognitive, and motor limitations. For example, users often type "hte" instead of "the" in word processors. The frequency of the word "the" in English and the fact that "hte" is not an English word, combined with the frequency of typing errors that involve switching letters typed by alternate hands, make automatically correcting to "the" almost always appropriate. Computer-aided correction becomes both possible and appropriate under such circumstances. Depending on context, error correction can be enforced directly (e.g., automatic text replacement, fields that only accept numbers) or suggested through system prompts.

\section{Maintaining Device Independence}

A user attempts to install a new device. The device may conflict with other devices already present in the system. Alternatively, the device may not function in certain specific applications. For example, a microphone that uses the Universal Serial Bus (USB) may fail to function with older sound software. Systems should be designed to reduce the severity and frequency of device conflicts. When device conflicts occur, the system should provide the information necessary to either solve the problem or seek assistance. (Devices include printers, storage/media, and I/O apparatus.)

\section{Evaluating the System}

A system designer or administrator may be unable to test a system for robustness, correctness, or usability in a systematic fashion. For example, the usability expert on a development team might want to log test users' keystrokes, but may not have the facilities to do so. Systems should include test points and data gathering capabilities to facilitate evaluation.

\section{Recovering from Failure}

A system may suddenly stop functioning while a user is working. Such failures might include a loss of network connectivity or hard drive failure in a user's PC. In these or other cases, valuable data or effort may be lost. Users should be provided with the means to reduce the amount of work lost from system failures.

\section{Retrieving Forgotten Passwords}

A user may forget a password. Retrieving and/or changing it may be difficult or may cause lapses in security. Systems should provide alternative, secure mechanisms to grant users access. For example, some online stores ask each user for a maiden name, birthday, or the name of a favorite pet in lieu of a forgotten password.

\section{Providing Good Help}

A user needs help. The user may find, however, that a system's help procedures do not adapt adequately to the context. For example, a user's computer may crash. After re- 
booting, the help system automatically opens to a general table of contents rather than to a section on restoring lost data or searching for conflicts. Help content may also lack the depth of information required to address the user's problem. For example, an operating system's help area may contain an entry on customizing the desktop with an image, but may fail to provide a list of the types of image files that can be used. Help procedures should be context dependent and sufficiently complete to assist users in solving problems.

\section{Reusing Information}

A user may wish to move data from one part of a system to another. For example, a telemarketer may wish to move a large list of phone numbers from a word processor to a database. Re-entering this data by hand could be tedious and/or excessively timeconsuming. Users should be provided with automatic (e.g., data propagation) or manual (e.g., cut and paste) data transports between different parts of a system. When such transports are available and easy to use, the user's ability to gain insight through multiple perspectives and/or analysis techniques will be enhanced.

\section{Supporting International Use}

A user may want to configure an application to communicate in his or her language or according to the norms of his or her culture. For example, a Japanese user may wish to configure the operating system to support a different keyboard layout. However, an application developed in one culture may contain elements that are confusing, offensive, or otherwise inappropriate in another. Systems should be easily configurable for deployment in multiple cultures.

\section{Leveraging Human Knowledge}

People use what they already know when approaching new situations. Such situations may include using new applications on a familiar platform, a new version of a familiar application, or a new product in an established product line.

New approaches usually bring new functionality or power. When, however, users are unable to apply what they already know, a corresponding cost in productivity and training time is incurred. For example, new versions of applications often assign items to different menus or change their names. As a result, users skilled in the older version are reduced to the level of novices again, searching menus for the function they know exists.

System designers should strive to develop upgrades that leverage users' knowledge of prior systems and allow them to move quickly and efficiently to the new system.

\section{Modifying Interfaces}

Iterative design is the lifeblood of current software development practice, yet a system developer may find it prohibitively difficult to change the user interface of an application to reflect new functions and/or new presentation desires. System designers should ensure that their user interfaces can be easily modified. 


\section{Supporting Multiple Activities}

Users often need to work on multiple tasks more or less simultaneously (e.g., check mail and write a paper). A system or its applications should allow the user to switch quickly back and forth between these tasks.

\section{Navigating Within a Single View}

A user may want to navigate from data visible on-screen to data not currently displayed. For example, he or she may wish to jump from the letter "A" to the letter "Q" in an online encyclopedia without consulting the table of contents. If the system takes too long to display the new data or if the user must execute a cumbersome command sequence to arrive at her or his destination, the user's time will be wasted. System designers should strive to ensure that users can navigate within a view easily and attempt to keep wait times reasonably short. (See: Working at the User's Pace)

\section{Observing System State}

A user may not be presented with the system state data necessary to operate the system (e.g., uninformative error messages, no file size given for folders). Alternatively, the system state may be presented in a way that violates human tolerances (e.g., is presented too quickly for people to read. See: Working at the User's Pace). The system state may also be presented in an unclear fashion, thereby confusing the user. System designers should account for human needs and capabilities when deciding what aspects of system state to display and how to present them.

A special case of Observing System State occurs when a user is unable to determine the level of security for data entered into a system. Such experiences may make the user hesitate to use the system or avoid it altogether.

\section{Working at the User's Pace}

A system might not accommodate a user's pace in performing an operation. This may make the user feel hurried or frustrated. For example, ATMs often beep incessantly when a user "fails" to insert an envelope in time. Also, Microsoft Word's scrolling algorithm does not take system speed into account and becomes unusable on fast systems (the data flies by too quickly for human comfort). Systems should account for human needs and capabilities when pacing the stages in an interaction. Systems should also allow users to adjust this pace as needed.

\section{Predicting Task Duration}

A user may want to work on another task while a system completes a long running operation. For example, an animator may want to leave the office to make copies or to eat while a computer renders frames. If systems do not provide expected task durations, users will be unable to make informed decisions about what to do while the computer "works." Thus, systems should present expected task durations.

\section{Supporting Comprehensive Searching}

A user wants to search some files or some aspects of those files for various types of content. For example, a user may wish to search text for a specific string or all movies for a 
particular frame. Search capabilities may be inconsistent across different systems and media, thereby limiting the user's opportunity to work. Systems should allow users to search data in a comprehensive and consistent manner by relevant criteria.

\section{Supporting Undo}

A user performs an operation, then no longer wants the effect of that operation. For example, a user may accidentally delete a paragraph in a document and wish to restore it. The system should allow the user to return to the state before that operation was performed. Furthermore, it is desirable that the user then be able to undo the prior operation (multi-level undo).

\section{Working in an Unfamiliar Context}

A user needs to work on a problem in a different context. Discrepancies between this new context and the one the user is accustomed to may interfere with the ability to work. For example, a clerk in business office A wants to post a payment for a customer of business unit B. Each business unit has a unique user interface, and the clerk has only used unit A's previously. The clerk may have trouble adapting to business unit B's interface (same system, unfamiliar context.) Systems should provide a novice (verbose) interface to offer guidance to users operating in unfamiliar contexts.

\section{Verifying Resources}

An application may fail to verify that necessary resources exist before beginning an operation. This failure may cause errors to occur unexpectedly during execution. For example, some versions of Adobe ${ }^{\circledR}$ PhotoShop ${ }^{\circledR}$ may begin to save a file only to run out of disk space before completing the operation. Applications should verify that all necessary resources are available before beginning an operation.

\section{Operating Consistently Across Views}

A user may become confused by functional deviations between different views of the same data. Commands that had been available in one view may become unavailable in another or may require different access methods. For example, users cannot run a spell check in the Outline View utility found in a mid-90's version of Microsoft Word. Systems should make commands available based on the type and content of a user's data, rather than the current view of that data, as long as those operations make sense in the current view.

For example, allowing users to perform operations on individual points in a scatter plot while viewing the plot at such a magnification that individual points cannot be visually distinguished does not make sense. A naïve user is likely to destroy the underlying data. The system should prevent selection of single points when their density exceeds the resolution of the screen, and inform the user how to zoom in, access the data in a more detailed view, or otherwise act on single data points. (See: Providing Good Help and Supporting Visualization)

\section{Making Views Accessible}

Users often want to see data from other viewpoints. For example, a user may wish to see the outline of a long document and the details of the prose. If certain views become un- 
available in certain modes of operation, or if switching between views is cumbersome, the user's ability to gain insight through multiple perspectives will be constrained. (See: Supporting Visualization)

\section{Supporting Visualization}

A user wishes to see data from a different viewpoint. Systems should provide a reasonable set of task-related views to enhance users' ability to gain additional insight while solving problems. For example, Microsoft Word provides several views to help users compose documents, including Outline and Page Layout modes.

\section{Supporting Personalization (not in CMU/SEI-2001-TR-005)}

A user wants to work in a particular configuration of features that the system provides. The user may want this configuration to persist over multiple uses of the system (as opposed to having to set it up each time). Systems should enable a user to specify their preferences for features and provide the possibility for these preferences to endure. For example, customizing Netscape's toolbar or saving a hierarchical structure of bookmarks. 


\section{Appendix II \\ Details of the Usability Benefit Hierarchy}

(excerpt from Bass, L., John, B. E., \& Kates, J. (2001). Achieving usability through software architecture (CMU/SEI-2001-TR005). Pittsburgh, PA: Software Engineering Institute, Carnegie Mellon University)

To create usable systems, designers must first ensure that their proposed products provide the functionality their users actually need to perform work as opposed to the functionality that the marketing or development team imagines they need. In other words, systems must provide functionality that fits the individual, organizational, and social structure of the work context. Although specifying and identifying needed functionality are fundamental steps in the development process, these design phases do not typically involve architectural concerns. Thus, we will not discuss them here. (We refer readers interested in these issues to Contextual Design [Beyer 1998].)

Assuming that the functionality needed by a system's users is correctly identified and specified, the usability of such a system can still be seriously compromised by architectural decisions that hinder or even prevent the required benefits. In extreme cases, the resulting system can become virtually unusable.

This section organizes and presents scenarios by their usability benefits. We arrived at the hierarchy of usability benefits presented in Table 1 using a bottom-up process called the affinity process [Beyer 1998]. We took this approach rather than taking an existing definition of usability and sorting the scenarios into it because it was not clear that architecturally sensitive scenarios would cover the typical range of usability benefits. However, the resulting hierarchy does not differ significantly from organizations of usability given by other authors [e.g., Newman 1995; Nielsen 1993; Shneiderman 1998], and we view this as partial confirmation that our set of architecturally sensitive scenarios covers, in some sense, the usability space. Each scenario occurs in one or more positions in the hierarchy.

The entries in this chapter discuss each item of the usability benefit hierarchy. One premise of this work has been that the design of a system embodies tradeoffs between benefits (usability) and cost (software engineering). Hence in each section, we discuss the appropriate messages for each benefit. This will enable the usability engineer to better argue the potential benefits of each scenario and the software engineer to know what instrumentation should be embedded into the system to support the benefit calculations. 


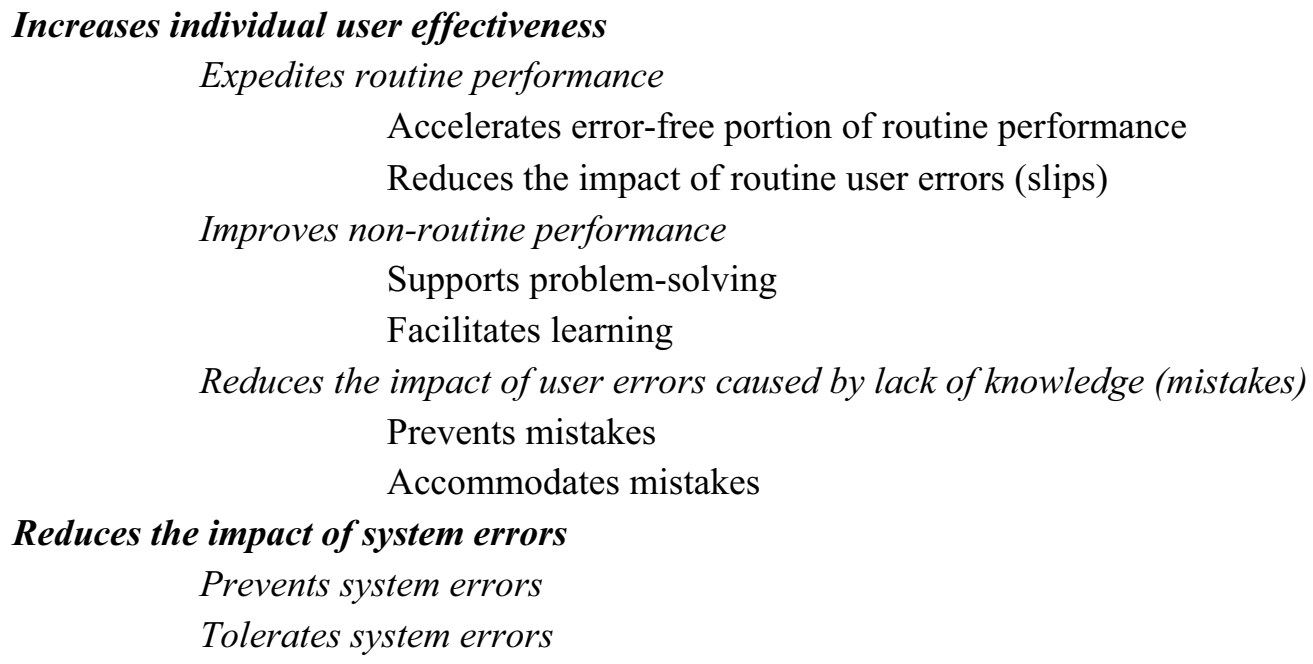

Accelerates error-free portion of routine performance

Reduces the impact of routine user errors (slips)

Improves non-routine performance

Supports problem-solving

Facilitates learning

Reduces the impact of user errors caused by lack of knowledge (mistakes)

Prevents mistakes

Accommodates mistakes

Reduces the impact of system errors

Prevents system errors

Tolerates system errors

Increases user confidence and comfort

\section{$1 \quad$ Increases Individual User Effectiveness}

If addressed properly, the scenarios included in this category will improve the performance of individual users. Such increases in productivity, though seemingly small when considered discretely, can aggregate to produce substantial benefits for an organization as a whole.

\subsection{Expedites routine performance}

In a routine task, a user recognizes a situation, knows what the next goal should be, and knows what to do to accomplish that goal. No problem-solving is necessary. All that remains is for the user to recall and execute the commands necessary to complete the task.

When performing routine tasks, even skilled users will become faster but will probably not develop new methods to complete their tasks [Card 1983]. This is in contrast to a problem-solving or learning situation where the user is likely to discover or learn a new method while performing a task. (For an example of learning and problem-solving behavior, see non-routine performance.)

Although users know what to do to accomplish routine tasks, they will still make errors. In fact, observations of skilled users performing routine tasks reveal that about $20 \%$ of a user's time may be consumed by making, then recovering from, mistakes. These "routine errors" result from "slips" in execution (e.g., hitting the wrong key or selecting the menu item next to the one desired), rather than from a lack of knowledge (i.e., not knowing which command to use). Slips can never be totally prevented if there are multiple actions available to a user, but some system designs accommodate these errors more successfully than others. 


\section{Accelerates error-free portion of routine performance}

Routine tasks take time for a user to recognize the situation, recall the next goal and the method used to accomplish it, and to mentally and/or physically execute the commands to accomplish the goal. We call the minimum required time to accomplish a task, assuming no slips, the error-free portion of routine performance.

In practice, the actual performance time is the sum of this minimum time and the time it takes to make and recover from slips. Systems can be designed to maximize error-free performance time, thereby reducing time to perform routine tasks and increasing individual effectiveness.

\section{Reduces the impact of routine user errors (slips)}

The negative impact of routine user errors can be reduced in two ways. First, since users will always slip, reducing the number of opportunities for error (roughly corresponding to the number and difficulty of steps in a given procedure) will usually reduce its occurrence. Second, systems can be designed to better accommodate user slips by providing adequate recovery methods.

\subsection{Improves non-routine performance}

In a non-routine task, a user does not know exactly what to do. In this situation, the user may experiment within the interface by clicking on buttons either randomly or systematically to observe the effects. The user might guess at actions based on previous experience. He or she might also use a tutorial, a help system, or documentation. Success in these "weak methods" of dealing with a new situation can be helped or hindered through system design.

\section{Supports problem-solving}

Users employ problem-solving behavior when they do not know exactly what to do. This behavior can be described as a search through a problem space [Newell and Simon 1972]. When confronted with a new problem, people guess at solutions based on previous experience, try things at random to see what happens, or search for the desired effect.

For this discussion, we assume that the user understands the goal of the task (e.g., I would like to replace all occurrences of "bush" with "shrub"), but the user may have to search through the system's available commands to achieve the desired outcome.

Measures of how well a system supports problem-solving include

the time it takes to accomplish a novel task

the number of incorrect paths the user takes while accomplishing a novel task

the type of incorrect paths the user takes while accomplishing a novel task (e.g., paths that have unforeseen and permanent side effects or benign paths that change nothing but simply add to the problem-solving time) 
the time necessary to recover from incorrect paths (Systems that support UNDO usually score well on this measure.)

In addition to reducing time spent on incorrect paths, well-designed systems may actually enhance users' problem-solving capabilities, further improving productivity.

\section{Facilitates learning}

Humans continuously learn as they perform tasks. Even in routine situations, humans continue to speed up with each repetition, eventually reaching a plateau where further improvements in performance become nearly imperceptible. In non-routine situations, people learn by receiving training, consulting instructions (using a help system, documentation, or asking a friend), by exploring the system, by applying previous experience to the new situation, and/or by reasoning based on what they know (or think they know) about a system. They may also learn by making a mistake, observing that the erroneous action does not produce the desired result, and by remembering not to perform this action again.

Measures of how well a system supports learning typically include

the number of times a task must be performed by a user before it is completed without error. (Often investigators include a repetition requirement to avoid the "luck" factor; for example, a user must perform a task $n$ times without error.)

the time before a user fulfills the error-free repetition requirement (defined above) incidental learning measures, in which a user first performs a task until some level of mastery is reached. The user then performs a different task that he or she has not practiced. The problem-solving and learning measures associated with this second task are measures of incidental learning.

\subsection{Reduces the impact of user errors caused by lack of knowledge (mistakes)}

In addition to the errors people make even when they know how to accomplish their tasks (slips, discussed above), people make errors when they do not know what to do in the current situation. In a typical scenario, a user does not understand that the current situation differs in important ways from previously encountered situations, and therefore he or she misapplies knowledge of procedures that have worked before. ${ }^{1}$ Errors due to lack of knowledge are called mistakes.

1 It is often difficult to distinguish a mistake from an exploratory problem-solving action. Typically, a mistake is when the user "knows" what to do and is wrong; while problem-solving is when the user doesn't know what to do and is trying to find the correct way. Therefore, the difference can only be detected through means other than the observation of actions - think-aloud protocols or interviews about what a person intended when taking an action, or his or her response when the action does not have the intended result (which indicates a mistake) typically allow observers to make this distinction. However, for architecture design, this distinction is not important; some users may be problem-solving and others making mistakes, but the architecture should support both. 
Design cannot prevent all mistakes, but careful design can prevent some of them. For example, a typical technique to help prevent mistakes is to gray out inapplicable menu items. Since some mistakes will still occur, systems should also be designed to accommodate them.

\section{Prevents mistakes}

The following are typical measures of how well a system helps to prevent mistakes:

the number of mistaken actions that a user could make while completing a task

the type of mistakes the user could make while accomplishing a task (e.g., paths that have unforeseen and permanent side effects, or benign paths that change nothing)

(While these measures appear similar to those associated with problem-solving; that case focuses on how well the system guides the user back to the correct path. Preventing mistakes focuses on how well the system guides the user away from an incorrect path. The difference is subtle.)

\section{Accommodates mistakes}

Since mistakes will occur if the user has the freedom to stray from a correct path, the system should accommodate these errors. The most telling measures of such accommodation are

the degree to which the system can be restored to the state prior to the mistake the time necessary to recover from mistakes (Systems that support UNDO usually score well on this measure.) This duration includes the time needed to restore all data and resources to the state before the error.

\section{Reduces the Impact of System Errors}

Systems will always operate with some degree of error. Networks will go down, power failures will occur, and applications will contend for resources and conflict. Design cannot prevent all system errors, but careful design can prevent some of them. All systems should be designed to tolerate system errors. This section differs from section 3.1. "Reduces the impact of routine user errors" only in the source of the error discussed. Here, we address system

error, not user error. The measures stay the same but the object of measurement becomes the system.

\subsection{Prevents system errors}

As with preventing mistakes, the measures associated with preventing system errors are the number and type of error that occur as a user performs a task. 


\subsection{Tolerates system errors}

Since system errors will occur, systems should be set up to tolerate them. Again, as with accommodating mistakes, the most telling measures of error tolerance are

the degree to which the system state can be restored to the state before the error.

the time necessary to recover from errors. This duration includes the time needed to restore all data and resources to the system state before the error.

\section{Increases user confidence and comfort}

In the scenarios included in this category, the benefits do not involve users' efficiency, problem-solving processes, ability to learn, or propensity to make mistakes. The benefits do involve how they feel about the system; for some architectural decisions do facilitate or inhibit capabilities that increase user confidence and comfort, and this may be of value to an organization. Measures of confidence and comfort are more indirect than the time- and error-based metrics in the preceding categories, and typically involve questionnaires or interviews, or analysis of buying behavior (e.g., return customers and referrals). 


\section{Appendix III: Usability Supporting Architectural Pattern Template}

Bonnie E. John, Len Bass, Maribel Sanchez-Segura, and Rob J. Adams, Sept. 2004

\begin{tabular}{|c|c|c|c|}
\hline \multicolumn{4}{|c|}{$\begin{array}{l}\text { Name: Usability Supporting Architectural Patterns must have suggestive names, which give an idea of the } \\
\text { problem addressed and the solution in a word or two. }\end{array}$} \\
\hline \multicolumn{4}{|c|}{$\begin{array}{l}\text { Usability Context } \\
\text { The context is divided into three parts: the situation (or general usability scenario), the conditions under } \\
\text { which this situation is relevant, and the potential benefits to the users if the problem arising from this } \\
\text { situation is solved. }\end{array}$} \\
\hline \multicolumn{4}{|c|}{$\begin{array}{l}\text { Situation: A brief description of the situation that makes this pattern useful from the user's } \\
\text { viewpoint. }\end{array}$} \\
\hline \multicolumn{4}{|c|}{ Conditions: Any conditions concerning the situation constraining when the pattern is useful } \\
\hline \multicolumn{4}{|c|}{$\begin{array}{l}\text { Potential Usability Benefits: A brief description of the benefits to the user if the solution is } \\
\text { implemented. We use the usability benefit hierarchy taken from Bass \& John to express these } \\
\text { benefits. }\end{array}$} \\
\hline \multicolumn{4}{|c|}{$\begin{array}{l}\text { Problem } \\
\text { The problem is expressed as the requirements arising from human desires and capabilities and the task } \\
\text { versus the constraints deriving from the state of the software or the environment. These forces result in } \\
\text { responsibilities that the software must fulfil to solve the problem. The responsibilities are part of the } \\
\text { solution, but it is valuable to see how they arise. They are, therefore, presented here. }\end{array}$} \\
\hline $\begin{array}{l}\text { Forces exerted by the } \\
\text { environment and task }\end{array}$ & $\begin{array}{c}\text { Forces exerted by } \\
\text { human desires and } \\
\text { capabilities }\end{array}$ & $\begin{array}{l}\text { Forces exerted by the } \\
\text { state of the software } \\
\text { system }\end{array}$ & $\begin{array}{c}\text { Responsibilities of the general } \\
\text { solution }\end{array}$ \\
\hline $\begin{array}{l}\text { This field describes the } \\
\text { state of the } \\
\text { environment and the } \\
\text { task, which may } \\
\text { include issues of task } \\
\text { criticality or control, } \\
\text { among others. }\end{array}$ & $\begin{array}{l}\text { This field describes the } \\
\text { human desires and } \\
\text { needs, which may } \\
\text { include issues of } \\
\text { salience or control, } \\
\text { among others. }\end{array}$ & $\begin{array}{l}\text { This field describes the } \\
\text { state of the software, } \\
\text { which may include } \\
\text { issues of resources and } \\
\text { control, among others. }\end{array}$ & $\begin{array}{l}\text { This field contains the } \\
\text { responsibility of the software } \\
\text { and an argument about why this } \\
\text { responsibility is necessary } \\
\text { given the user/task needs and/or } \\
\text { the system/environment } \\
\text { constraints. }\end{array}$ \\
\hline \multicolumn{4}{|c|}{$\begin{array}{l}\text { Specific Solution } \\
\text { The specific solution is situated in a partial design that reflects requirements that the designer believes are } \\
\text { more important than cancel. The designer will make particular choices of overall architecture, MVC is one } \\
\text { example, we need to present our table as an example of how the general solution is customised for the } \\
\text { overall architecture. }\end{array}$} \\
\hline $\begin{array}{l}\text { General } \\
\text { responsibilities of the } \\
\text { software }\end{array}$ & \begin{tabular}{|c|}
$\begin{array}{c}\text { Forces exerted by } \\
\text { previous design } \\
\text { decisions }\end{array}$ \\
\end{tabular} & \begin{tabular}{|c|} 
Allocation of \\
responsibilities to \\
specific components \\
\end{tabular} & Rationale \\
\hline $\begin{array}{l}\text { This field describes the } \\
\text { general responsibilities } \\
\text { of the software } \\
\text { identified in the } \\
\text { problem description. }\end{array}$ & $\begin{array}{l}\text { This field describes the } \\
\text { forces that come from } \\
\text { design decisions taken } \\
\text { independently of } \\
\text { usability aspects but } \\
\text { that influence the way } \\
\text { in which these aspects } \\
\text { must be designed. }\end{array}$ & $\begin{array}{l}\text { This field describes the } \\
\text { responsibilities of the } \\
\text { software components } \\
\text { involved in the design } \\
\text { of the usability aspects. }\end{array}$ & $\begin{array}{l}\text { Justification of how this } \\
\text { allocation of responsibilities to } \\
\text { specific modules satisfies the } \\
\text { problem. }\end{array}$ \\
\hline \multicolumn{4}{|c|}{ Components diagram of specific solution } \\
\hline \multicolumn{4}{|c|}{ Sequence diagram of specific solution } \\
\hline \multicolumn{4}{|c|}{ Deployment diagram of specific solution (if necessary) } \\
\hline
\end{tabular}




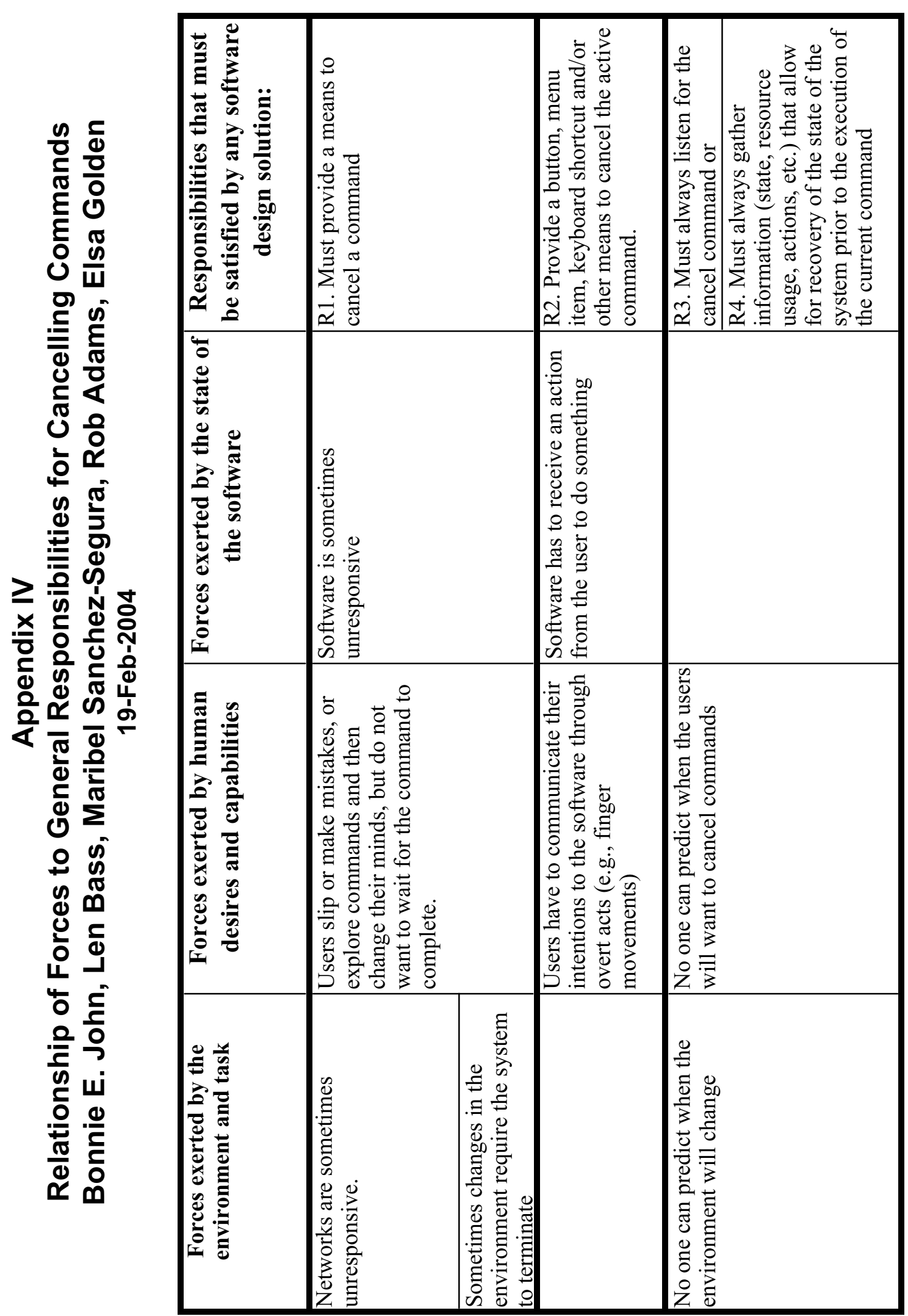

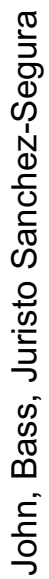


管

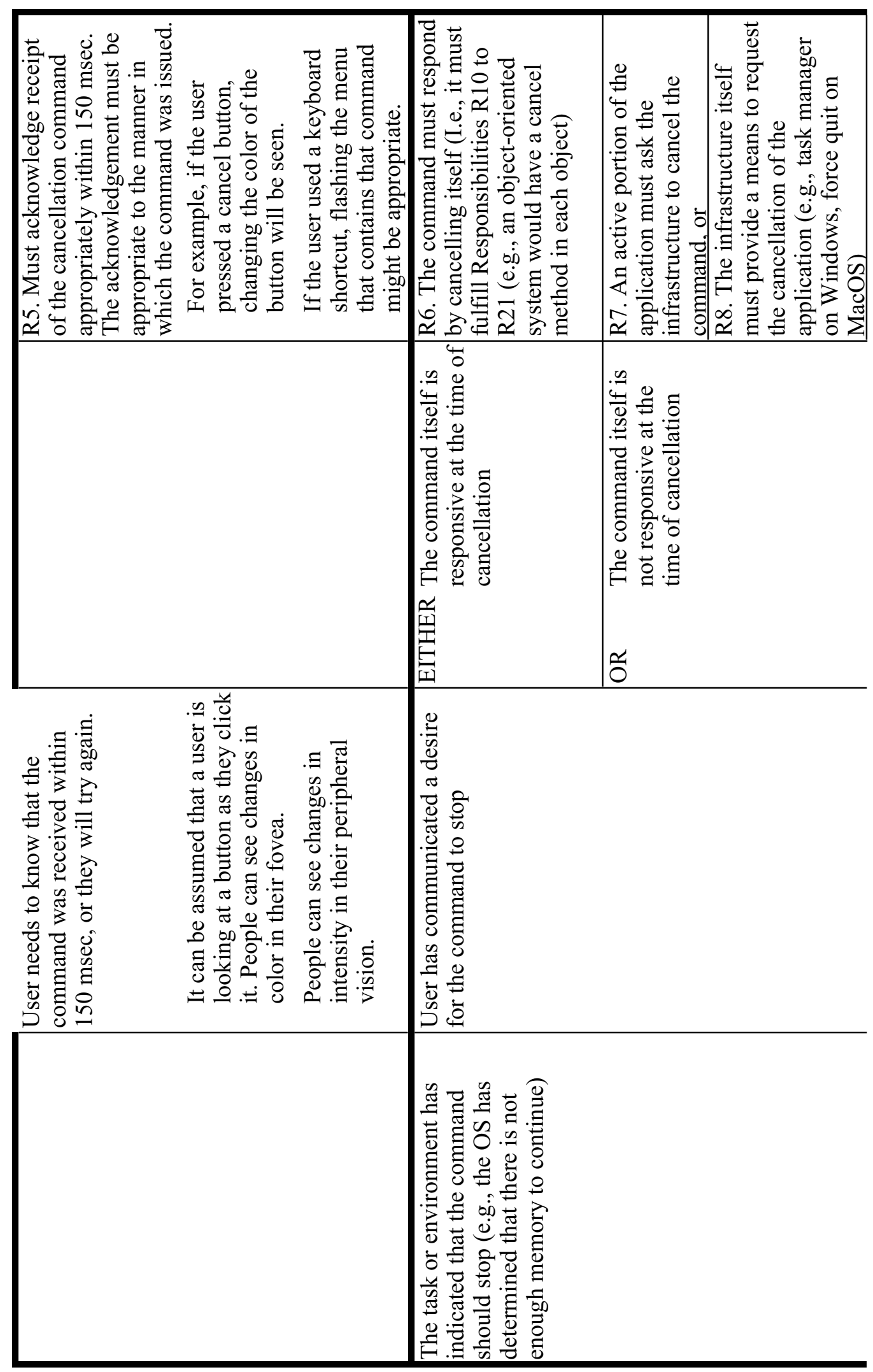

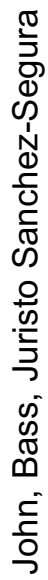


$m$
呈
$\frac{1}{4}$

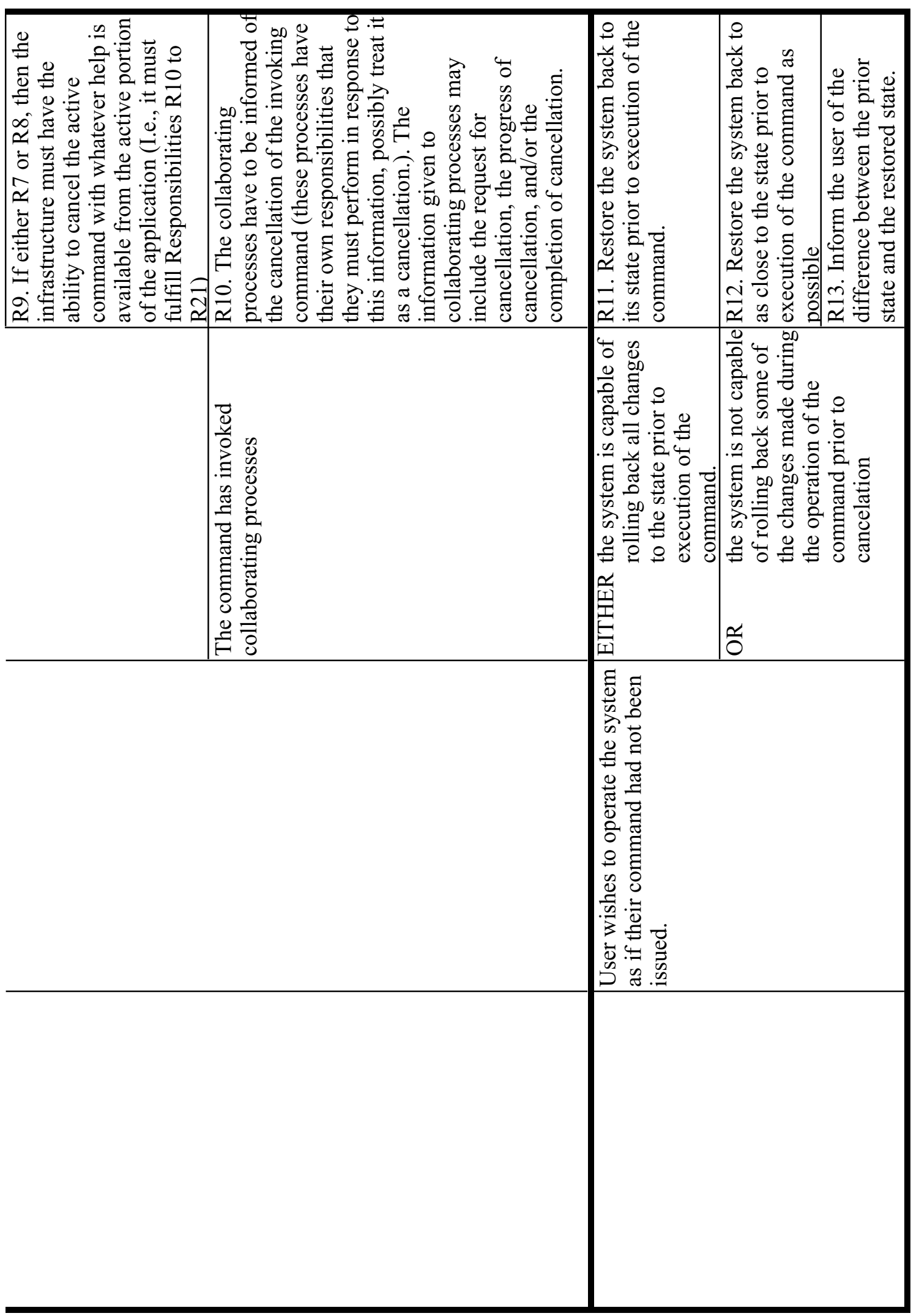

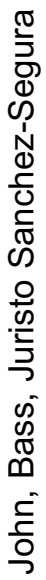




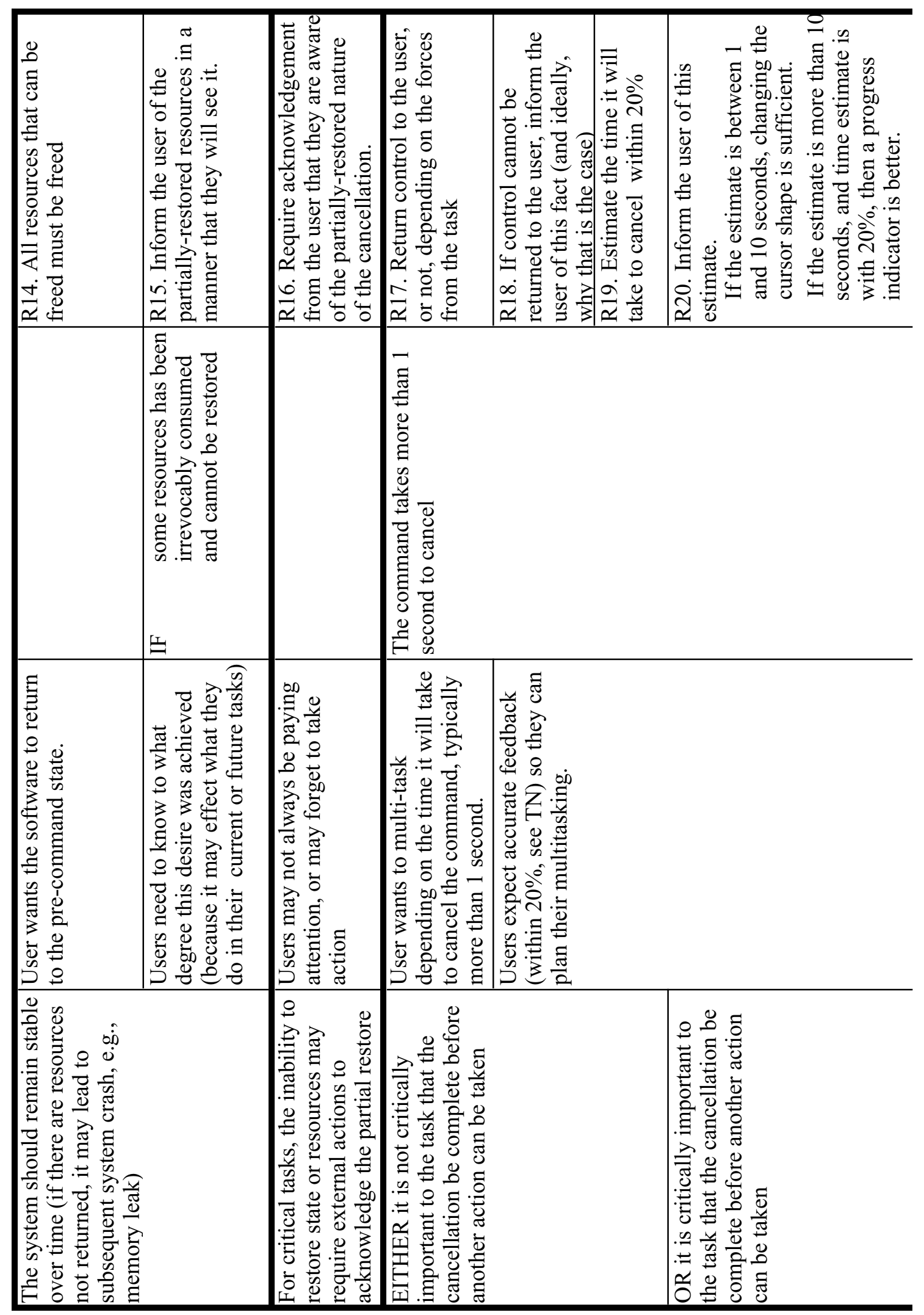

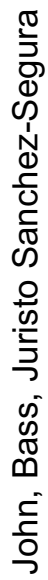


呈

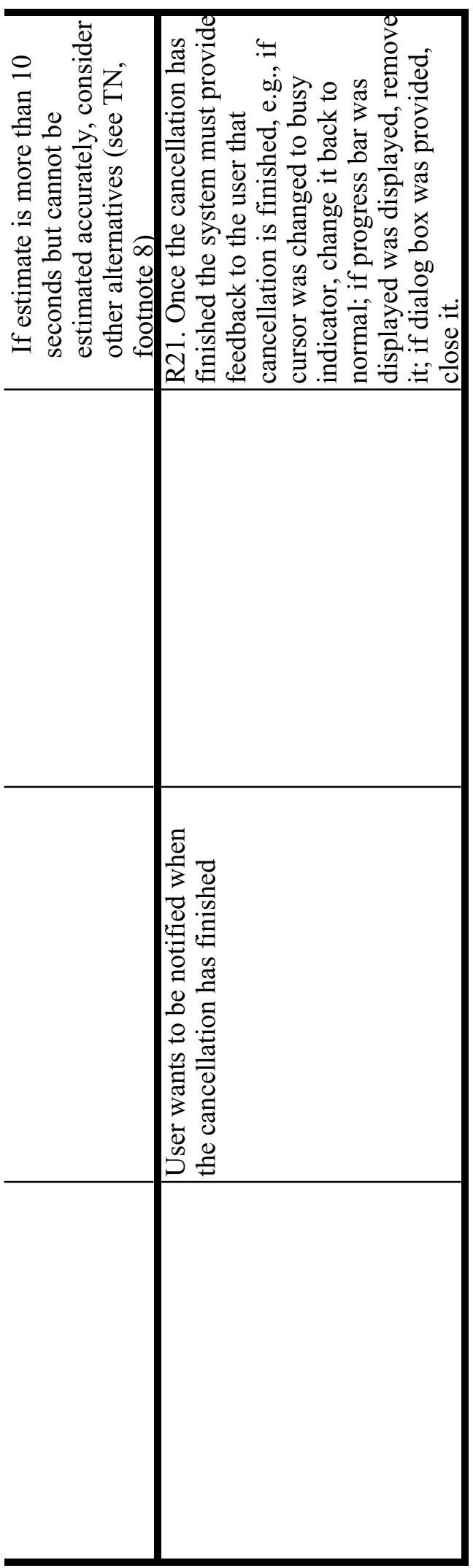

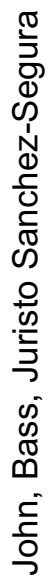




\section{References}

\section{References in Usability and Software Architecture}

Bass, L. J. \& John, B. E. (2000) Achieving Usability Through Software Architectural Styles. Extended Abstracts of CHI, 2000 (The Hague, The Netherlands, April 1-6, 2000) ACM, New York. pp. 502-509.

Bass, L., John, B. E. (2002) Supporting the CANCEL command through software architecture, CMU/SEI-2002-TN-021. Pittsburgh, PA: Software Engineering Institute, Carnegie Mellon University.

http://www.sei.cmu.edu/publications/documents/02.reports/02tn021.html

Bass, L. J. \& John, B. E. (2003) Linking usability to software architecture patterns through general scenarios. Journal of Systems and Software, 66(3), 187-197.

John, B. E. \& Bass, L. J. (2001) Usability and software architecture. Behaviour and Information Technology, 20(5), 329-338.

Bass, L., John, B. E. \& Kates, J. (2000) Achieving usability through software architecture (CMU/SEI-2001-TR-005). Pittsburgh, PA: Software Engineering Institute, Carnegie Mellon University.

http://www.sei.cmu .edu/publications/documents/01. reports/01tr005.html

Juristo , N., Moreno, A. M., \& Sanchez, M. (2003) Deliverable D.3.4. Techniques, patterns and styles for architecture-level usability improvement. - ESPRIT project (IST-2001-32298)

http://www.ls.fi.upm.es/status/results/deliverables.html

\section{References in software engineering and software architec- ture}

Bachmann, F., Bass, L., Chastek, G., Donohoe, P., \& Peruzzi, F. (2000) The architecture based design method (CMU/SEI-2000-TR-001). Pittsburgh, PA: Software Engineering Institute, Carnegie Mellon University. http://www.sei.cmu.edu/publications/documents/00.reports/00tr001.html

Bass, L.; Clements, P. \& Kazman, R. (2003). Software Architecture in Practice. $2^{\text {nd }}$ edition. Reading, MA: Addison Wesley Longman.

Buschmann, F., Meuneir, R, Rohnert, H., Sommerlad, P. and Stal, M., (1996) Pattern-Oriented Software Architecture, A System of Patterns, Chichester, Eng: John Wiley and Sons.

Clements, P., Bachmann, F., Bass, L., Garlan, D., Ivers, J., Little, R., Nord, R., \& Stafford J., (2003) Documenting Software Architectures: Views and Beyond, Addison Wesley.

Clements, P., Kazman, R, \& Klein, M. (2001). Evaluating software architectures: Methods and case studies. Boston: Addison-Wesley. 
Gamma, E., Helm, R., Johnson, R., Vlissides, J., (1995) Design Patterns, Elements of Reusable Object-Oriented Software, Reading, Ma: Addison Wesley Longman.

Hillside Group: Information about patterns and pattern languages can be found at http://www.hillside.net/ (19 February 2004).

J2EE-MVC is documented at

http://java.sun.com/blueprints/patterns/MVC-detailed.html

(19 February 2004).

Klein, M. \& Bachmann, F. (2000). Quality Attribute Design Primitives (CMU/SEI-2000-TN-2000-017). Pittsburgh, PA: Software Engineering Institute, Carnegie Mellon University.

www. sei.cmu.edu/publications/documents/00.reports/00tr017.html

Laprie, J.-C. (1992) Dependability: Basic Concepts and Terminology. Springer-Verlag: Vienna.

McCall, J. (2001) Quality Factors. In Encyclopedia of Software Engineering ( $2^{\text {nd }}$ edition) John Marciniak, ed., John Wiley, New York, pp 10831093

Smith, C. \& Williams, L., (2001) Performance Solutions: A Practical Guide to Creating Responsive, Scalable Software. Reading, Ma.:Addison Wesley Longman.

\section{References in human performance usability}

Beyer, H. \& Holtzblatt, K. (1998) Contextual Design. San Francisco, CA: Morgan Kaufmann Publishers, Inc.

Card, S. K., Moran, T. P. \& Newell, A. (1983) The Psychology of HumanComputer Interaction. Hillsdale, NJ: Erlbaum.

Gram, C. \& Cockton, G. (1996) Design Principles for Interactive Systems. London, England: Chapman and Hall.

Newell, A. \& Simon, H. A. (1972) Human Problem Solving. Englewood Cliffs, NJ: Prentice-Hall.

Newman, W. \& Lamming, M. (1985) Interactive System Design. Wokingham, England: Addison-Wesley Publishing.

Nielsen, J. (1993) Usability Engineering. Boston, MA: Academic Press Inc.

Shneiderman, B. (1998) Designing the User Interface, 3rd ed. Reading, MA: Addison-Wesley. 


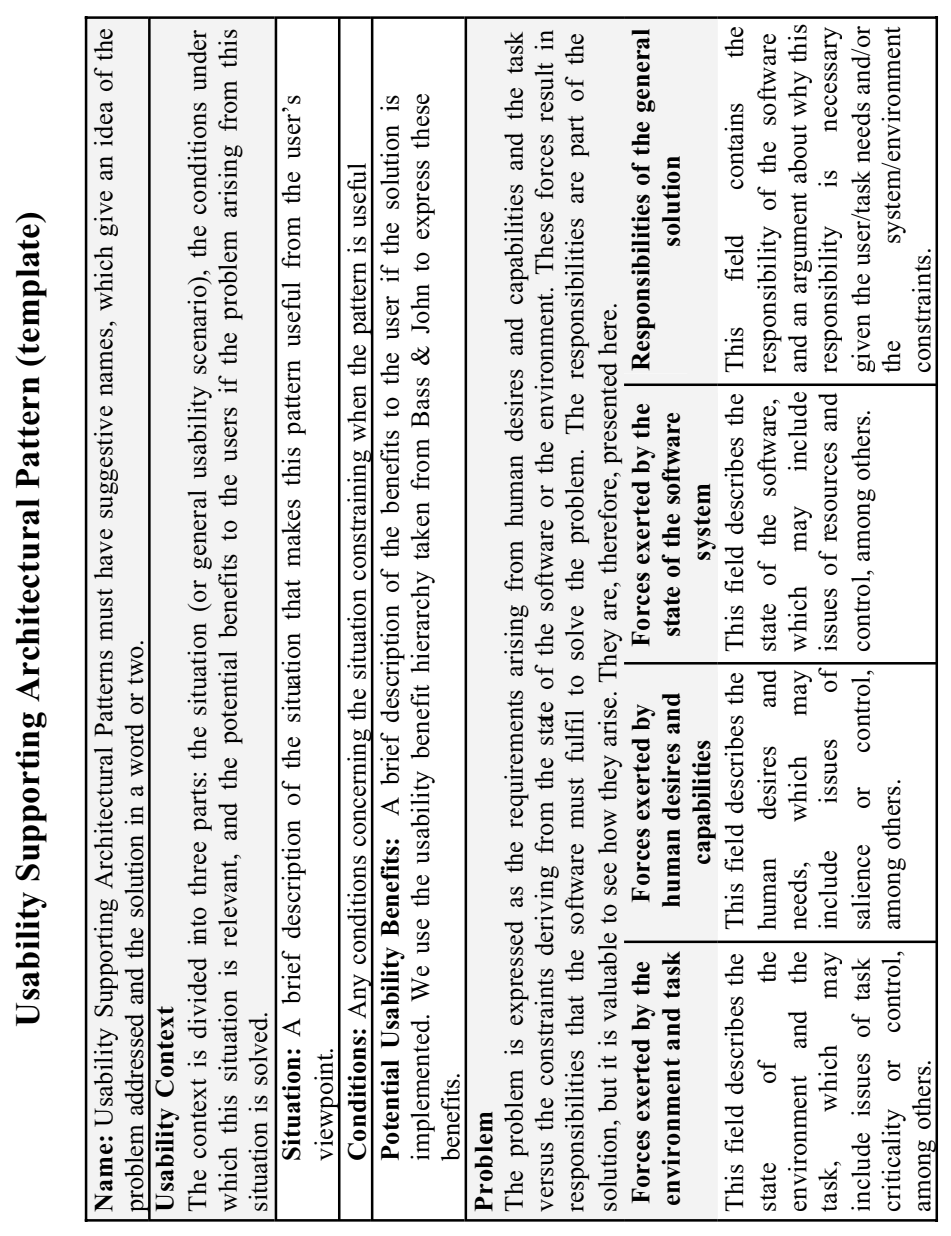




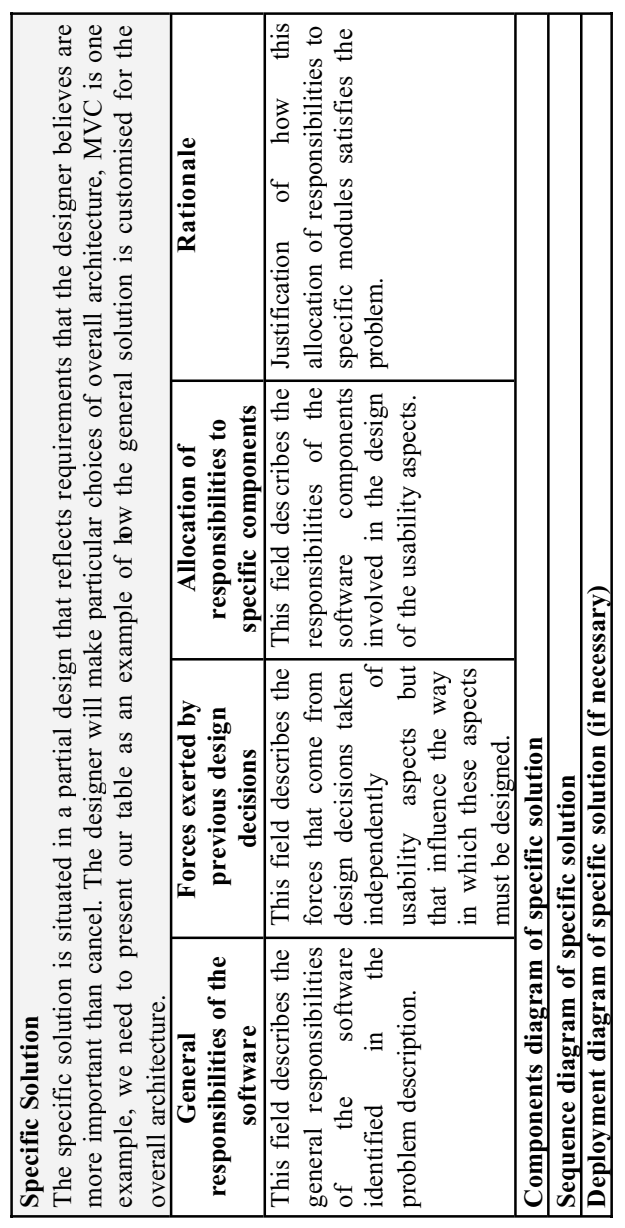




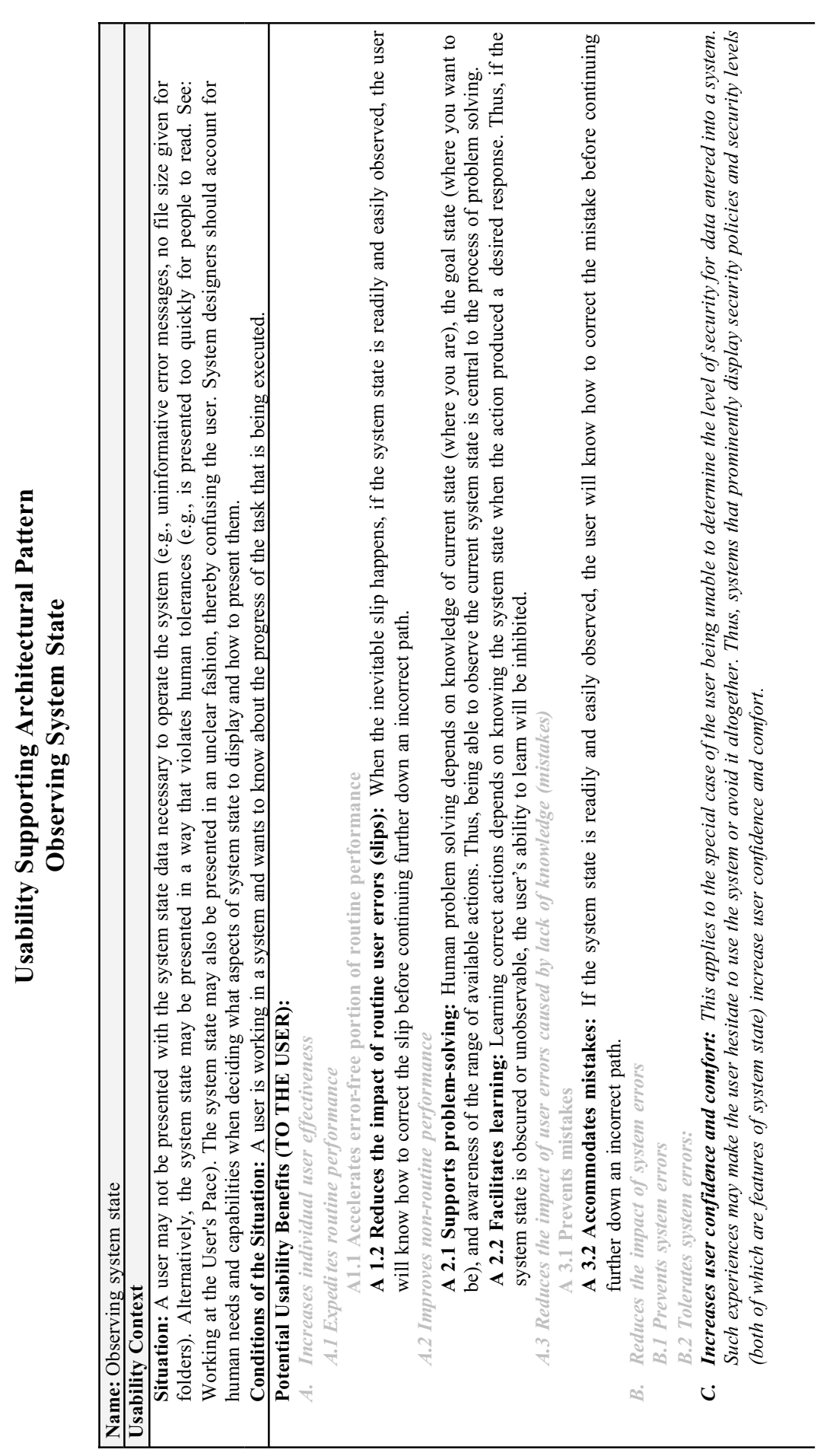




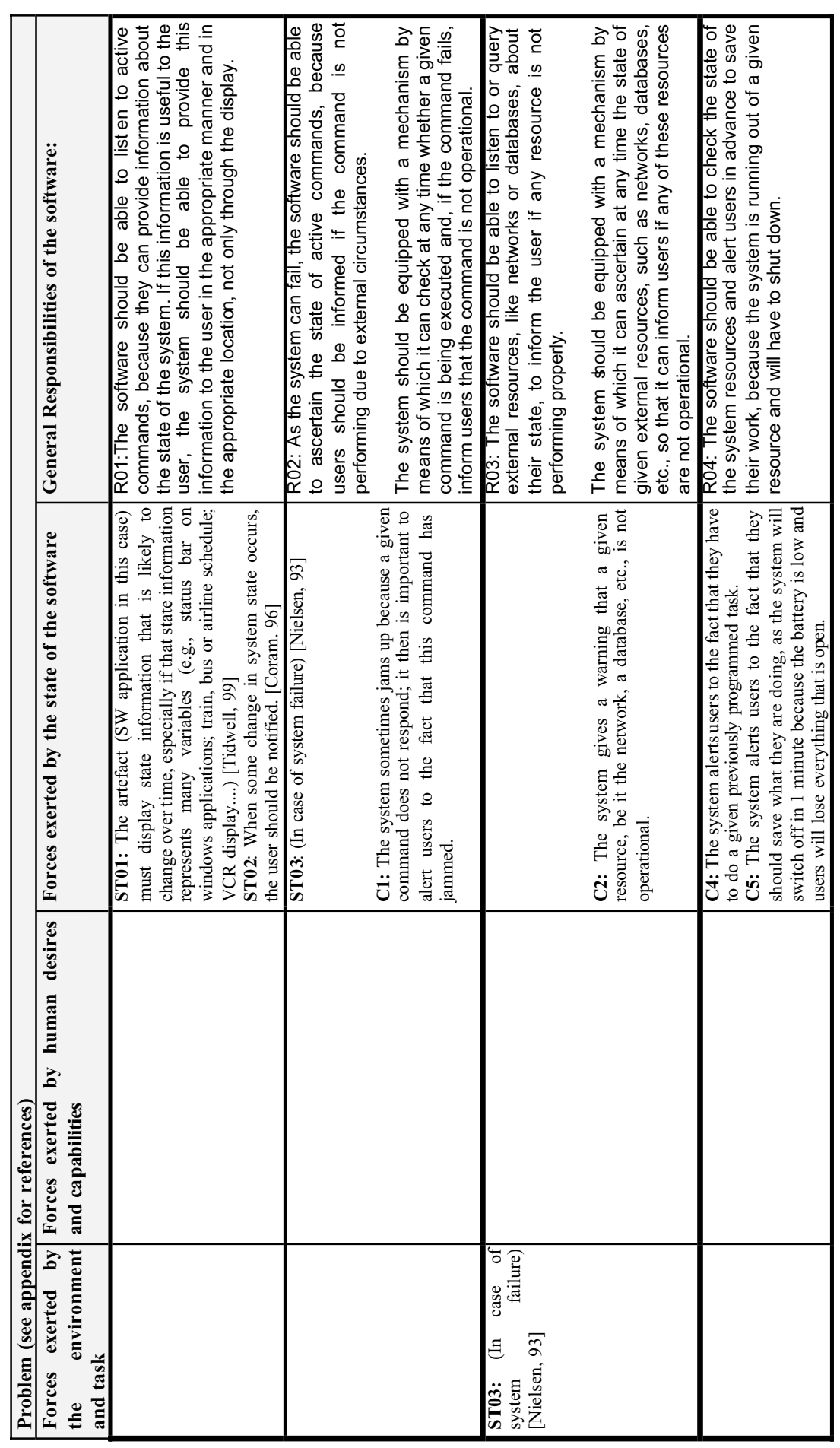




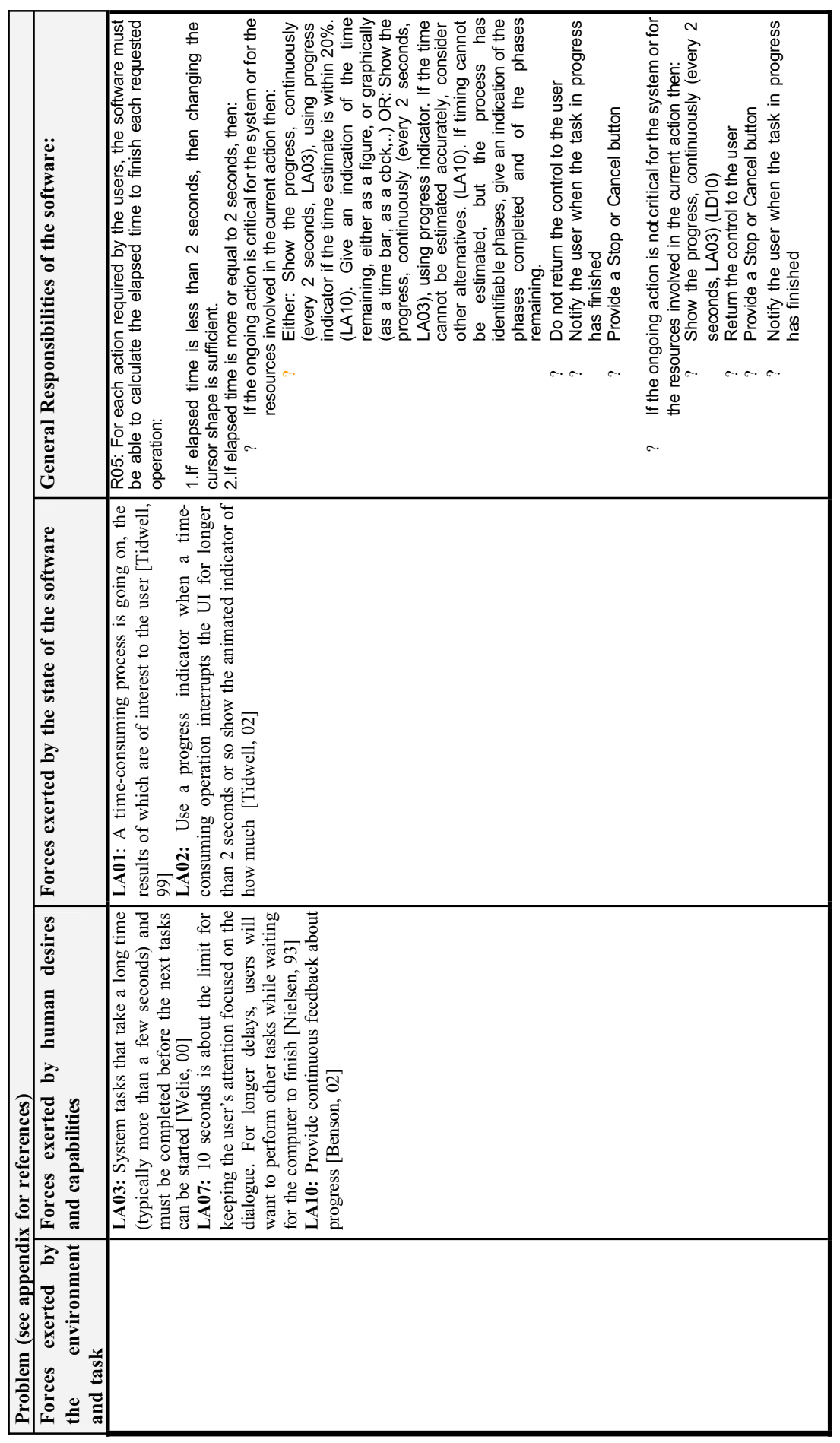




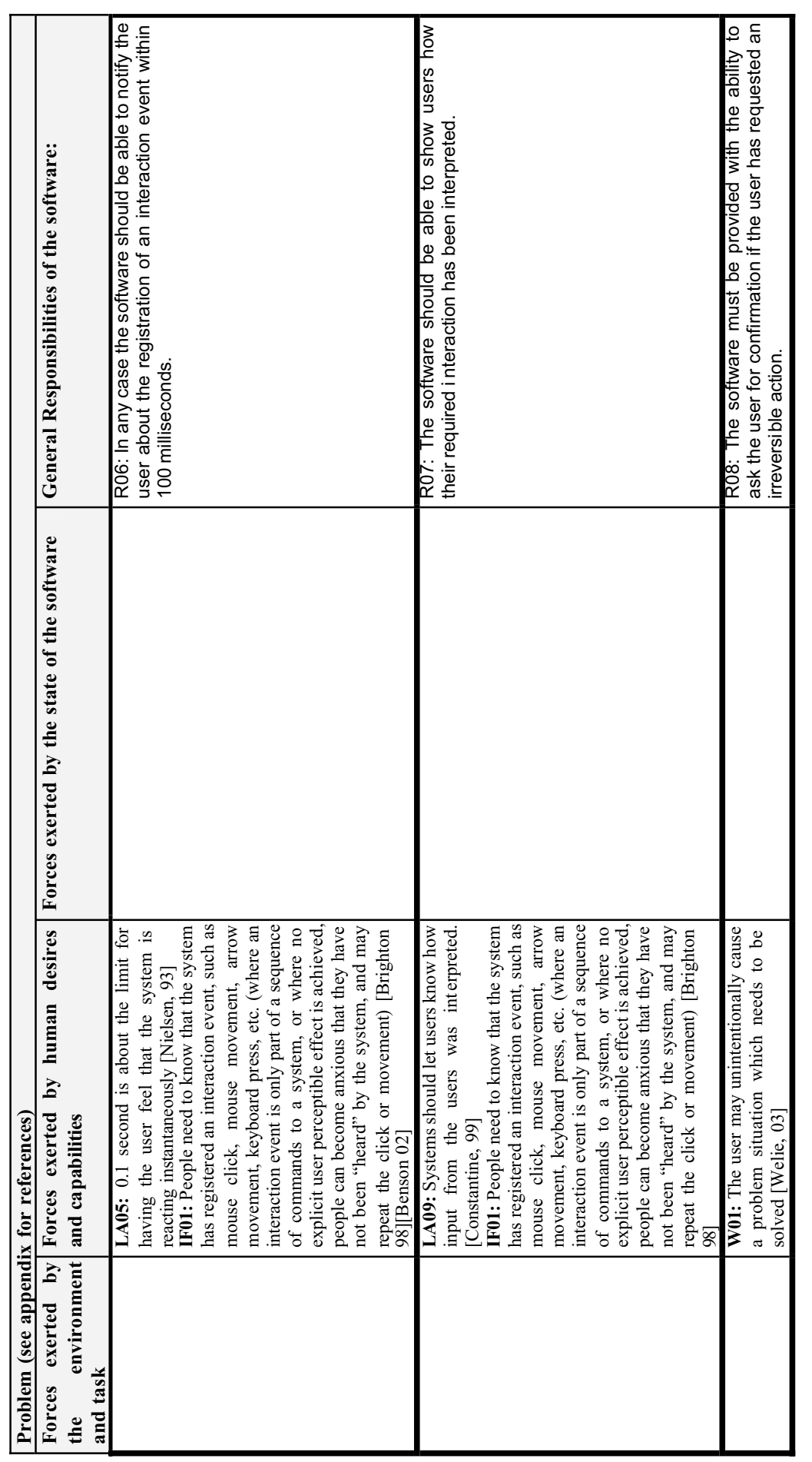




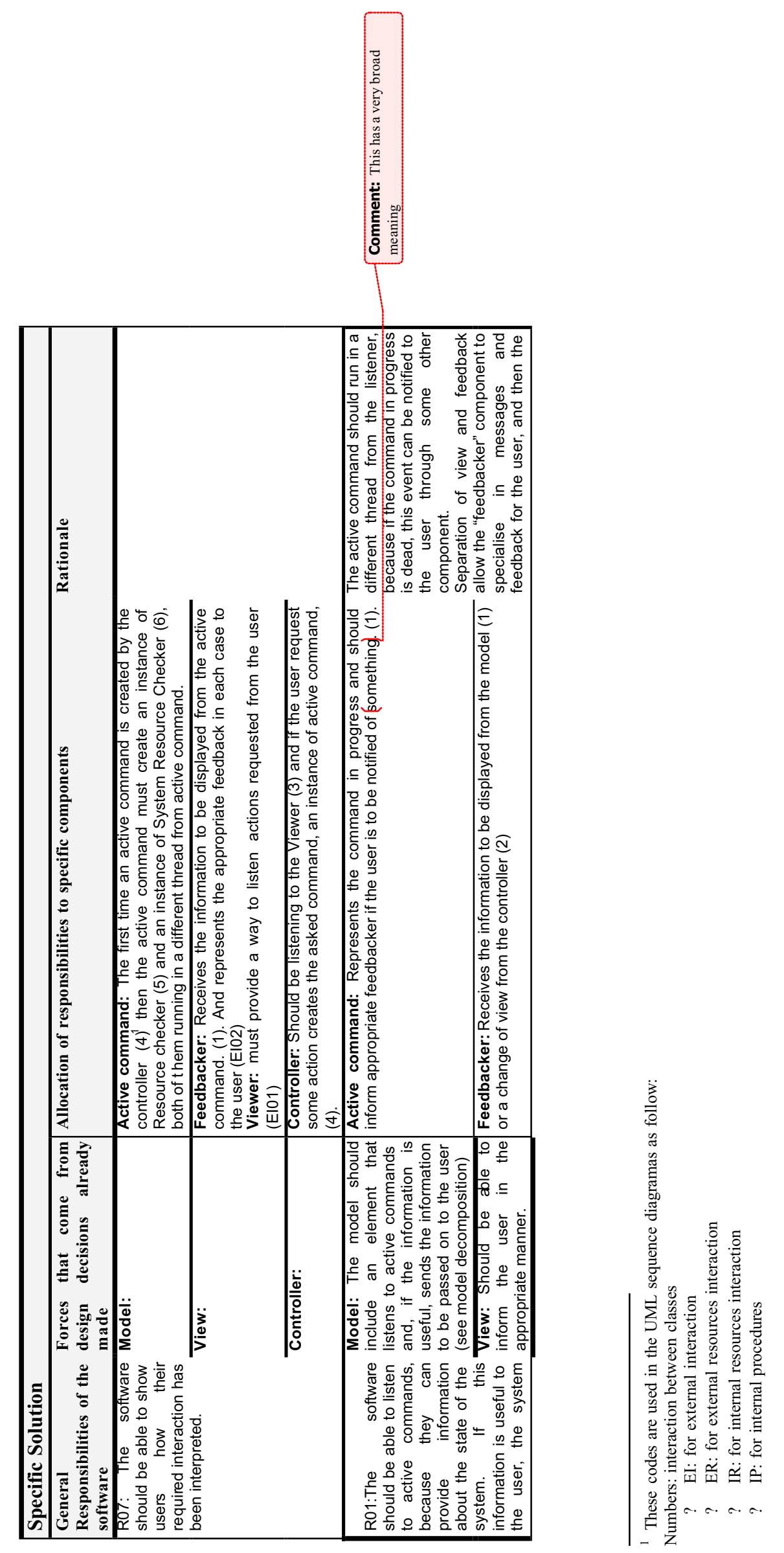




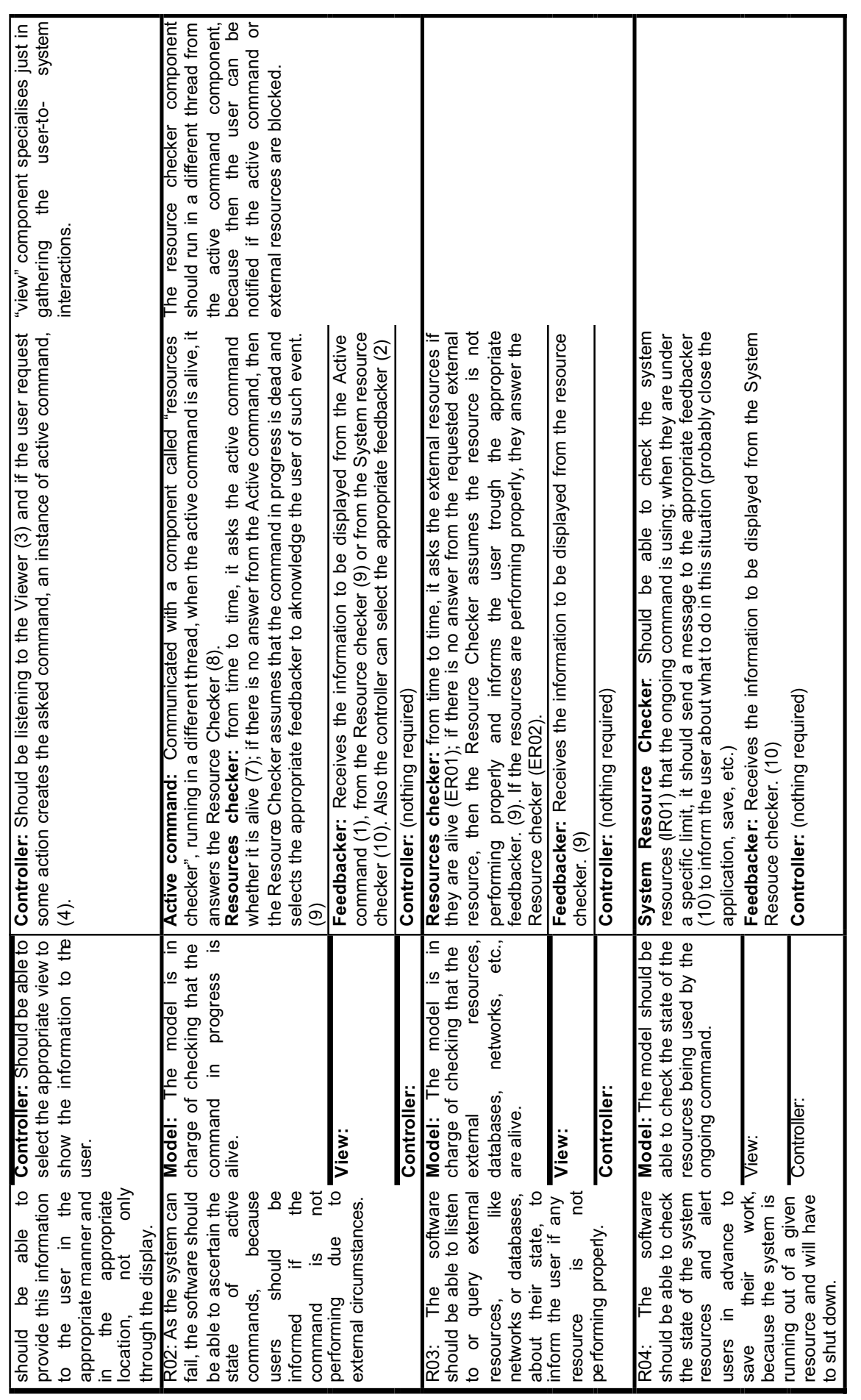




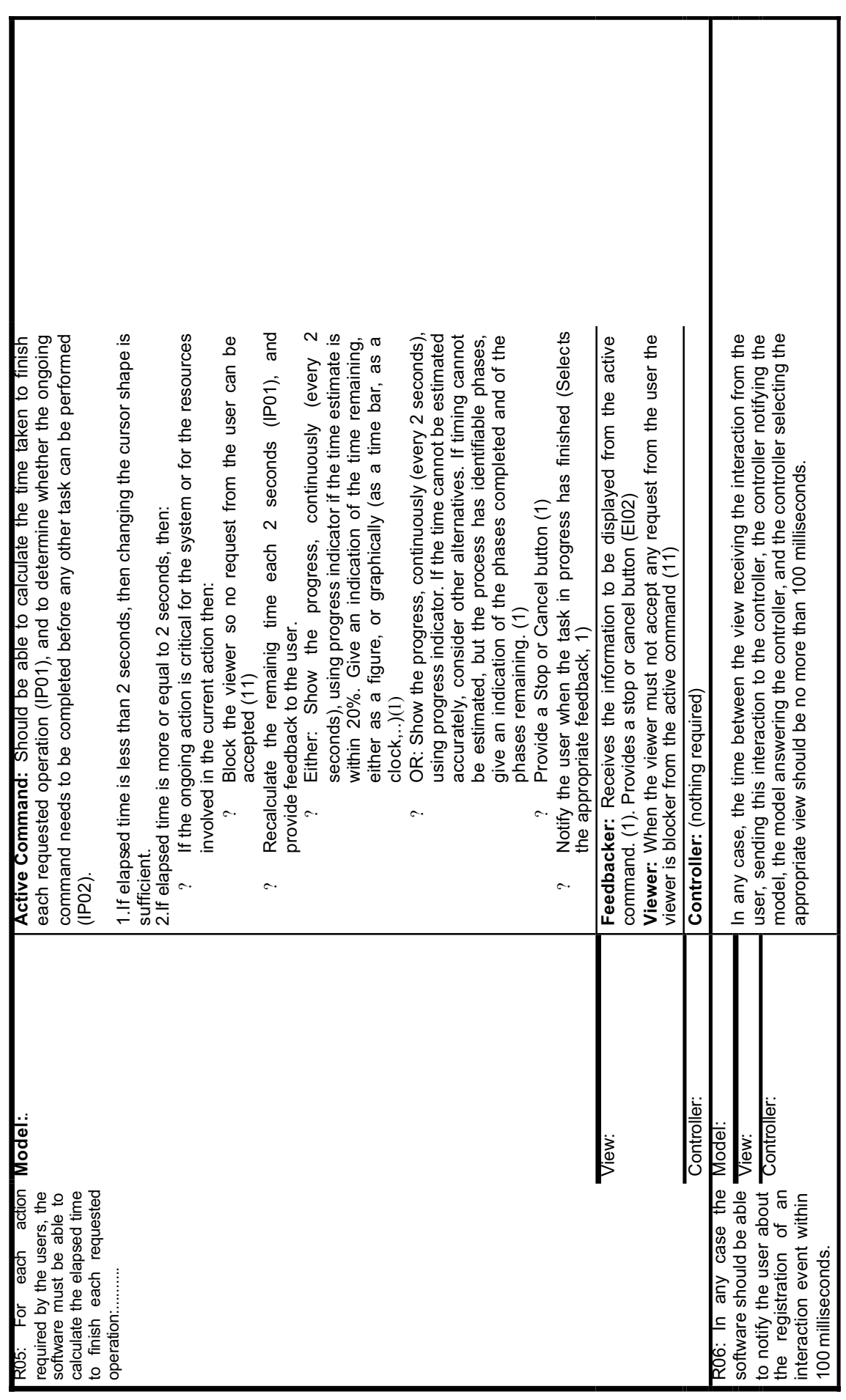



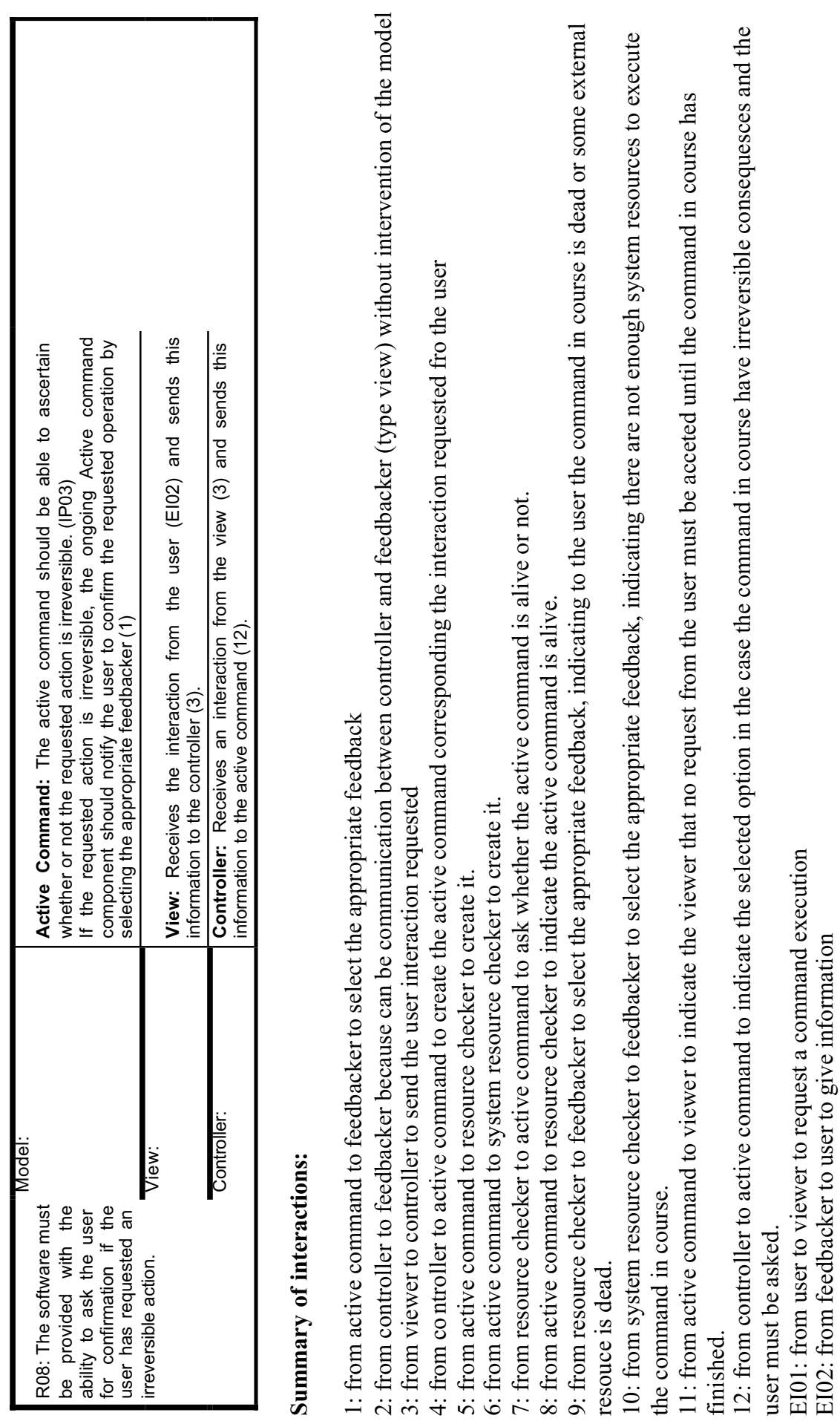

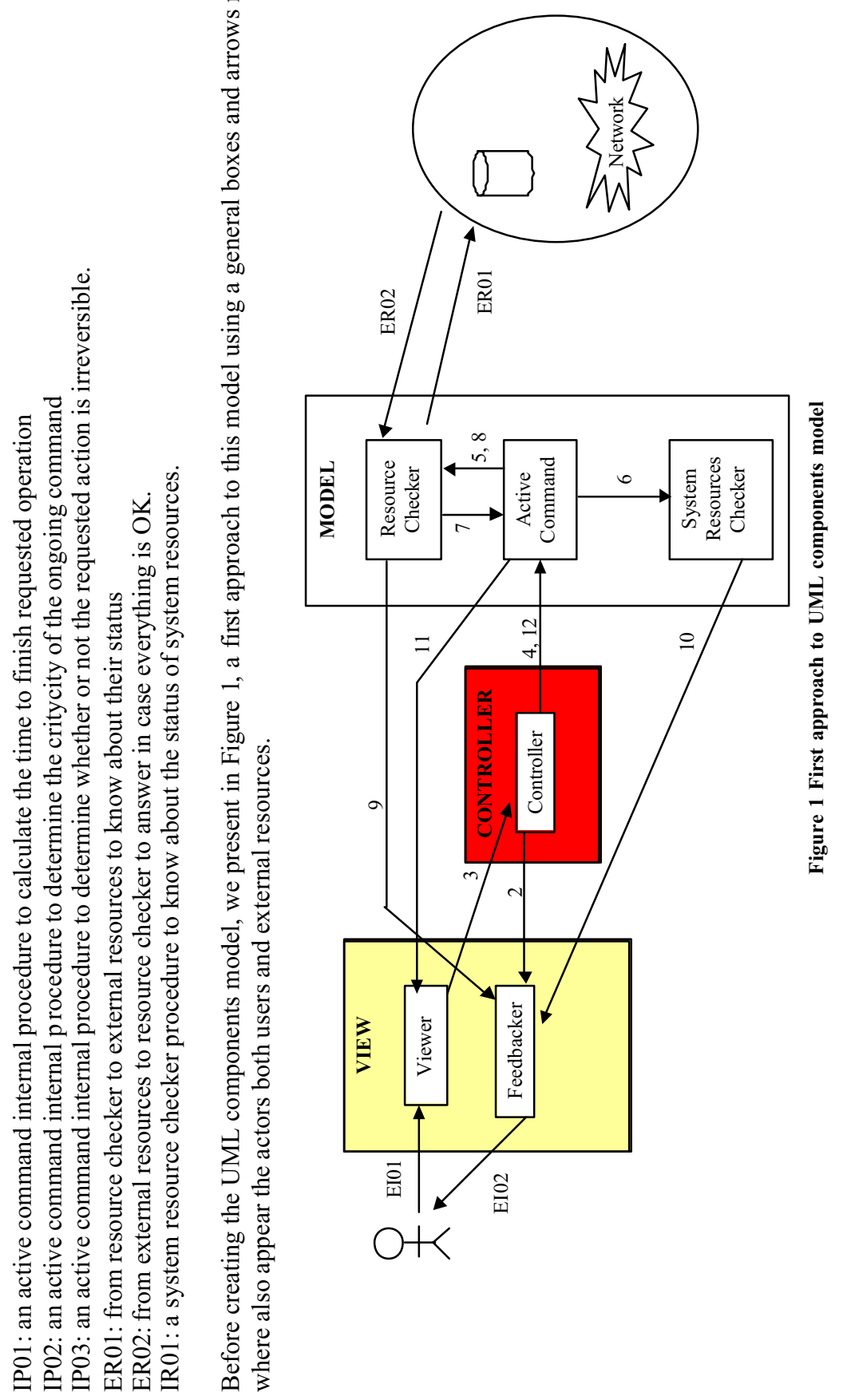


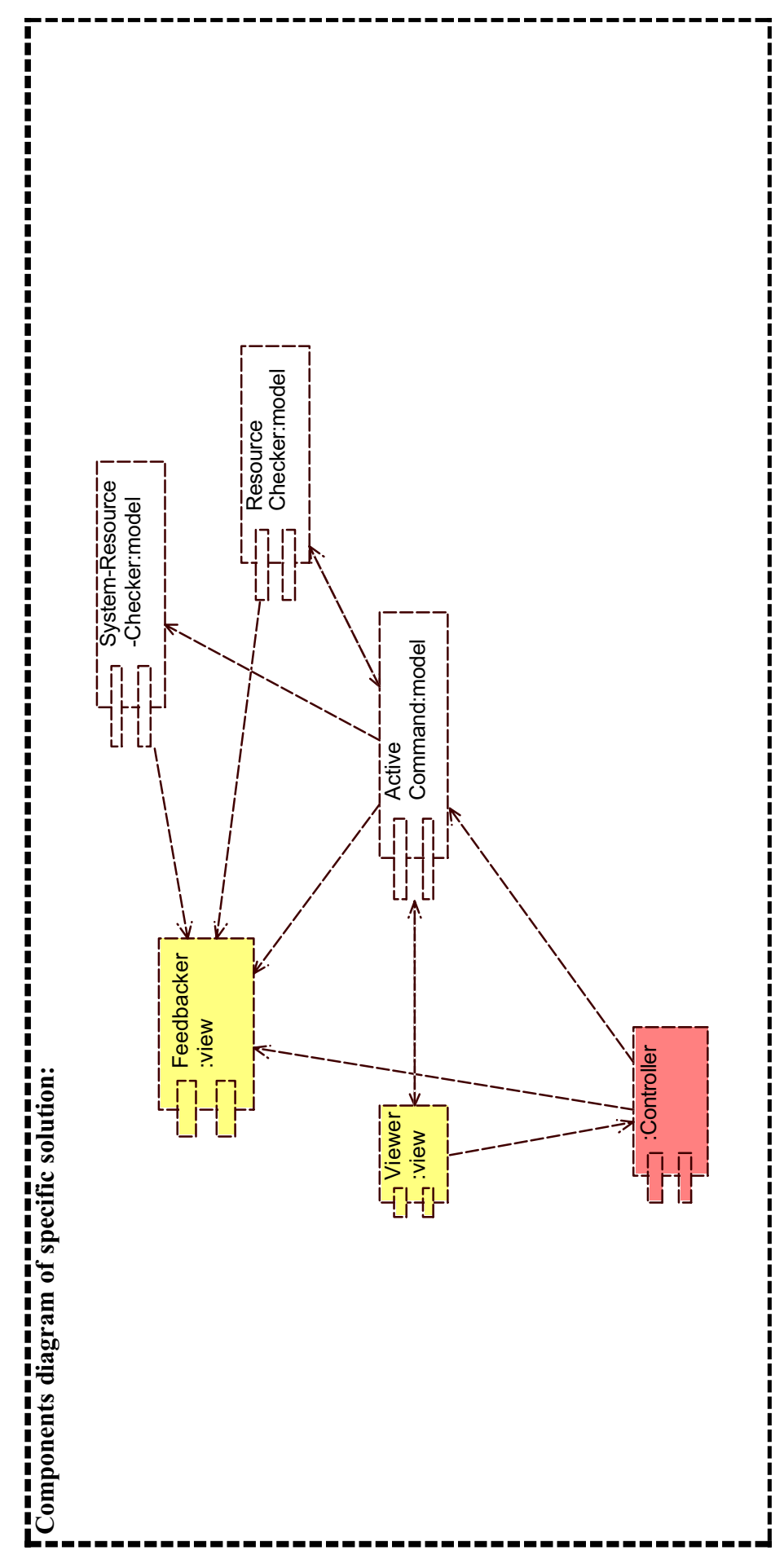




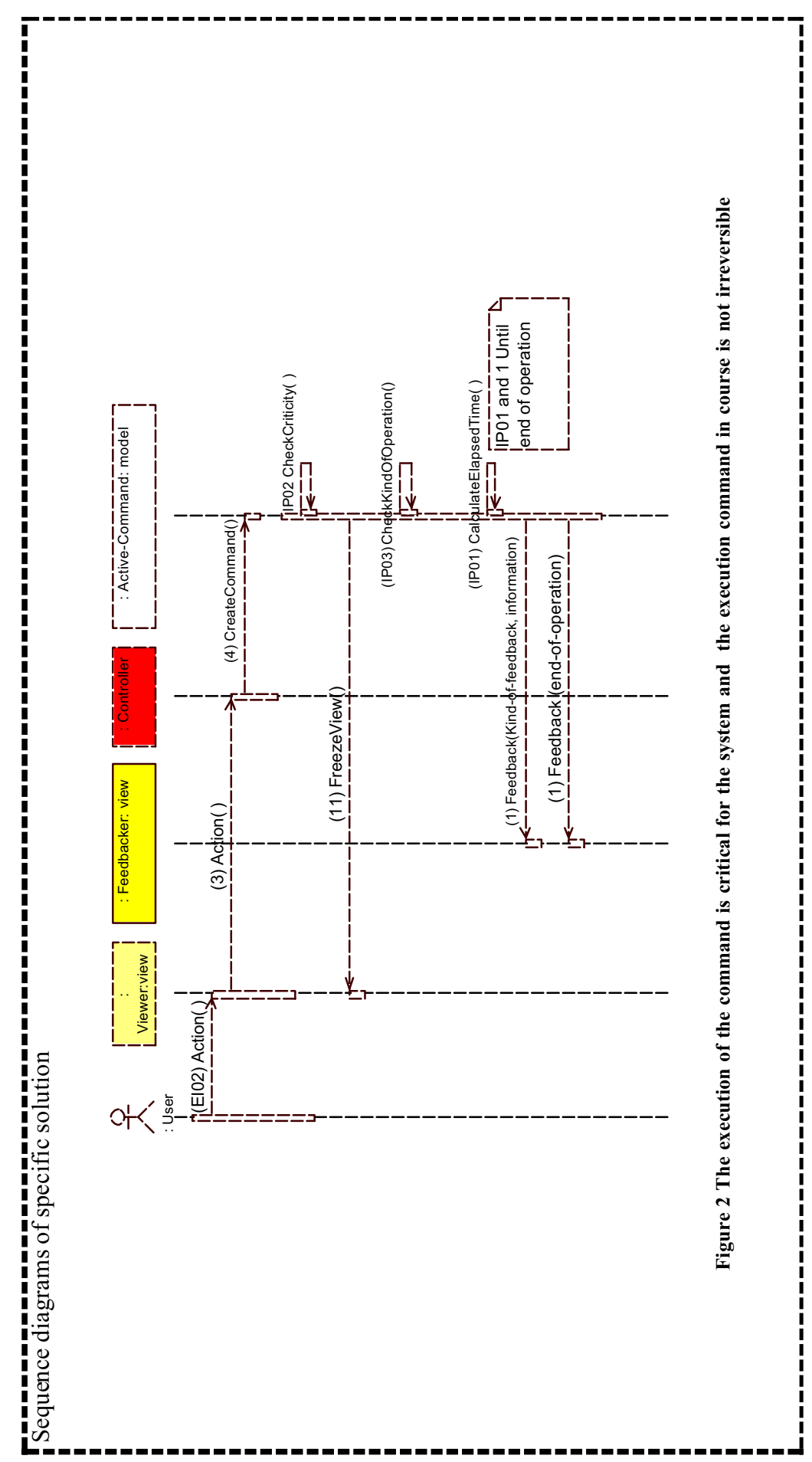




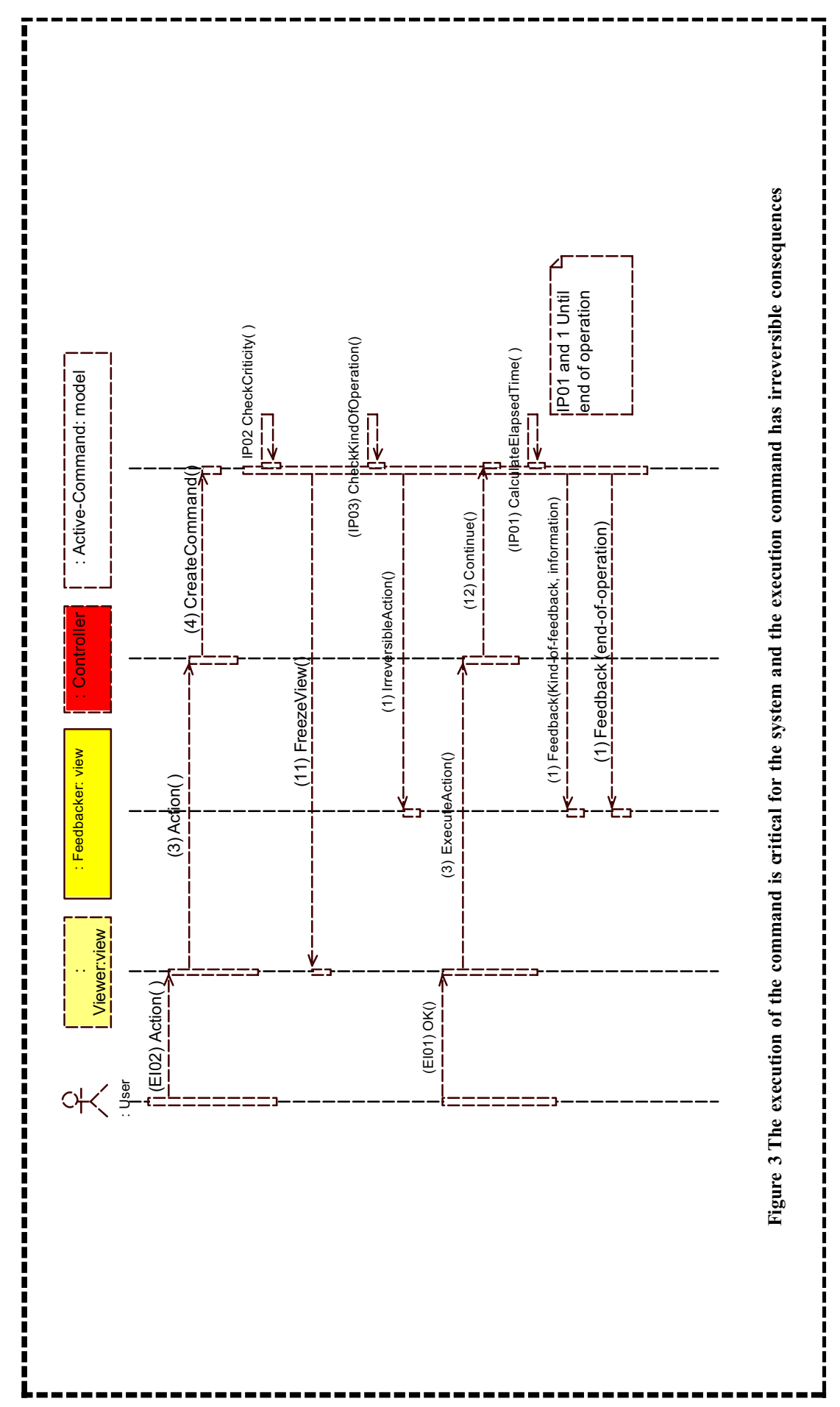




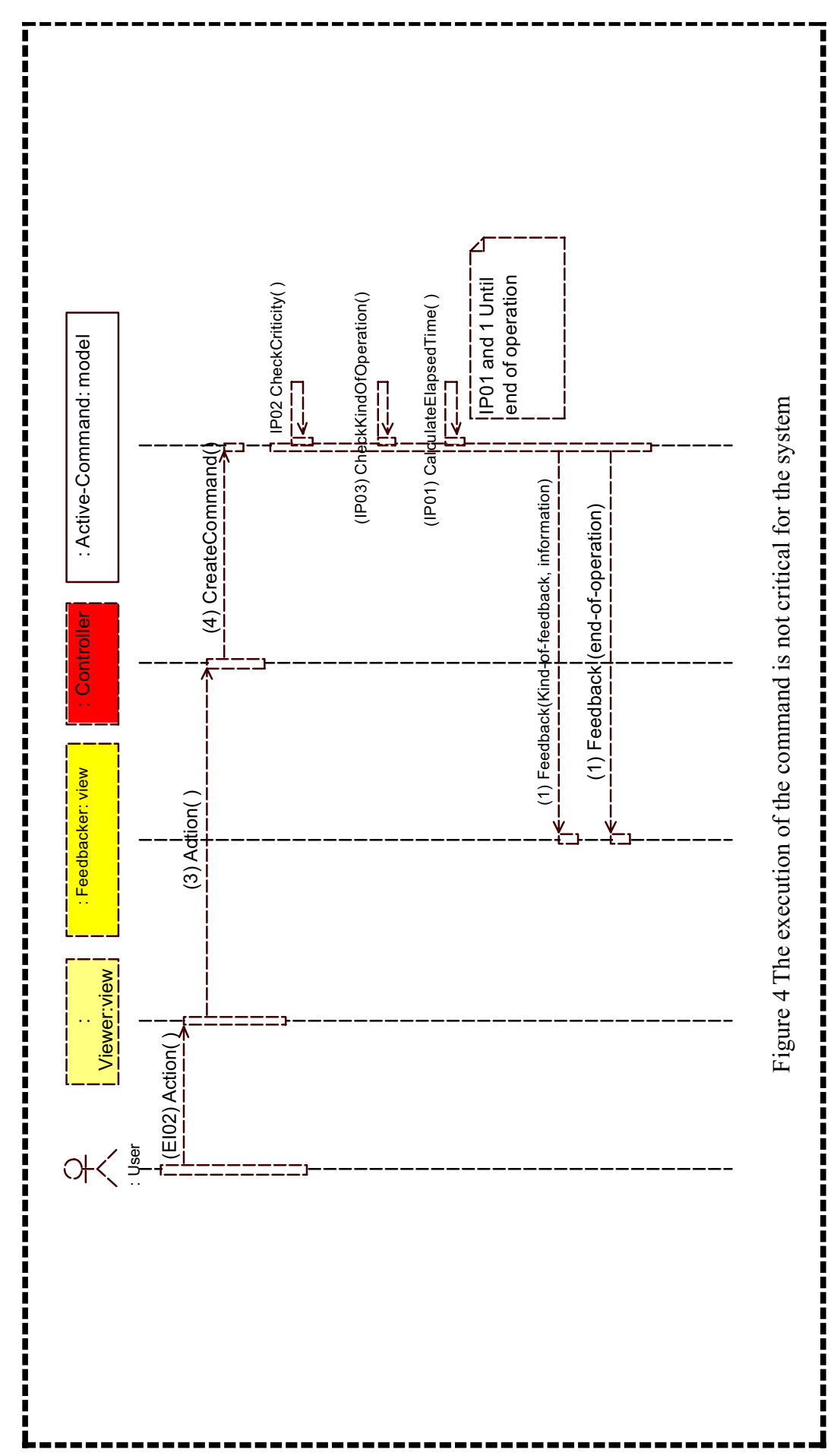




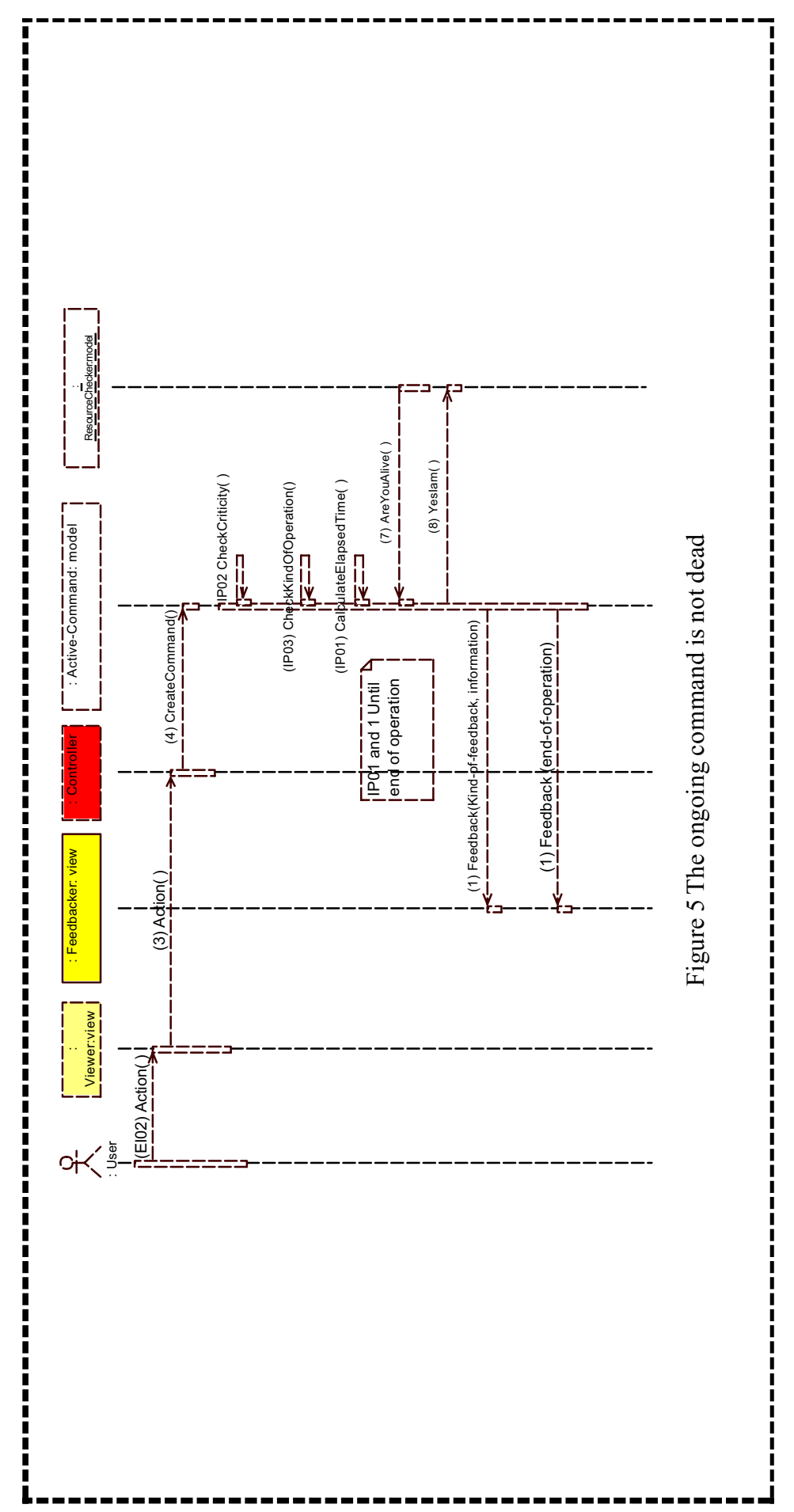




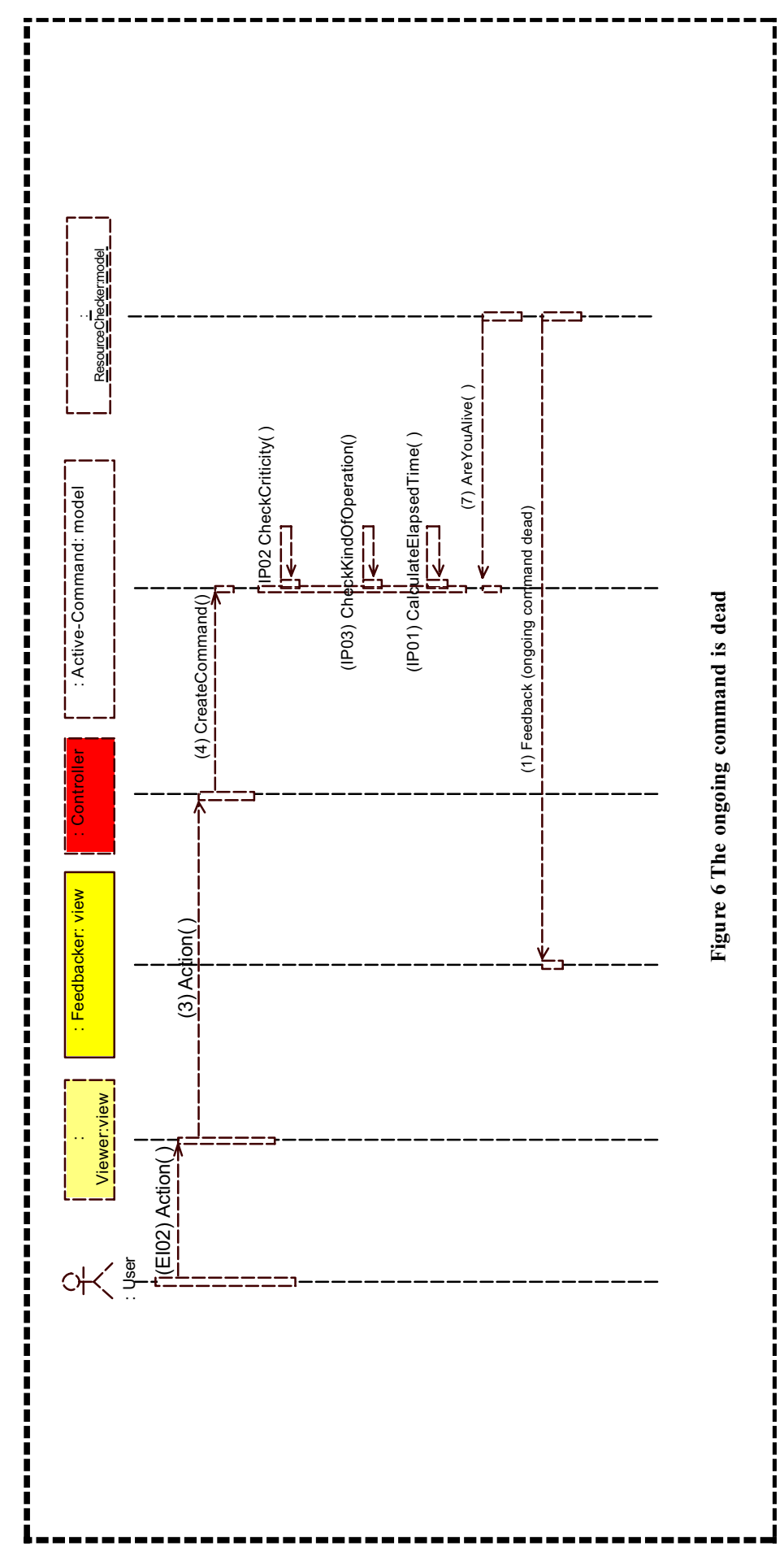

$=$ 


$$
\text { f }
$$




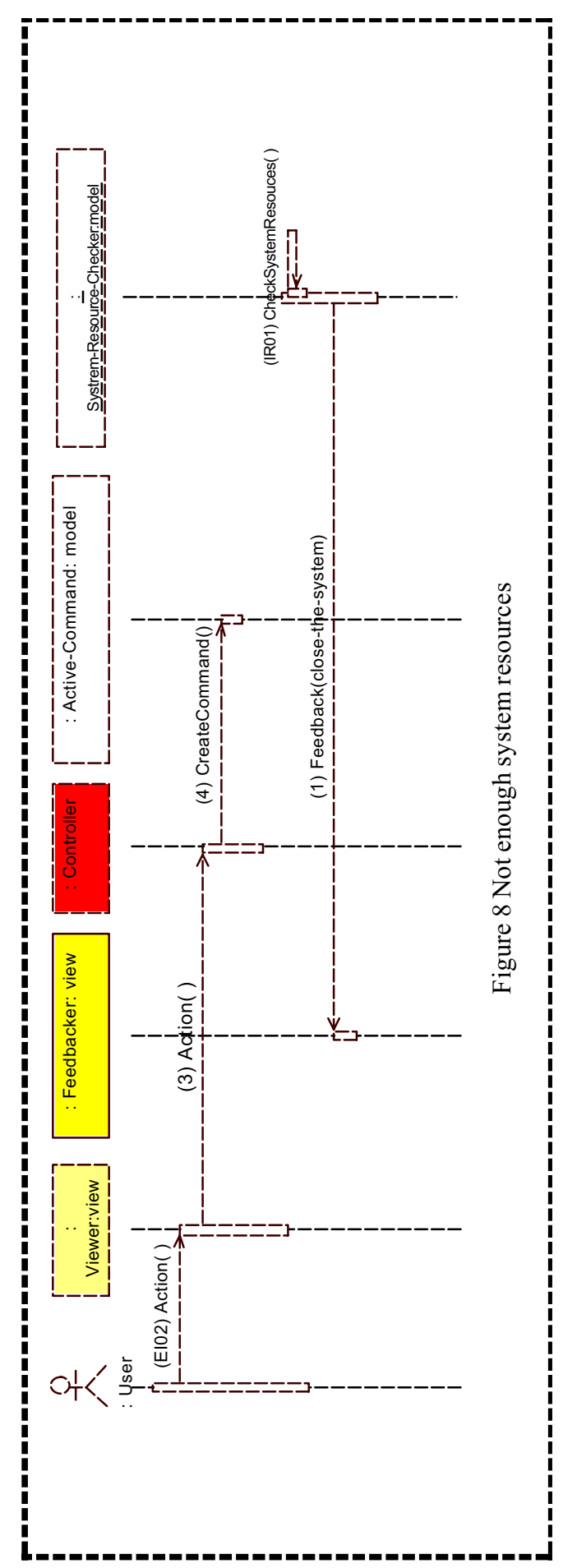




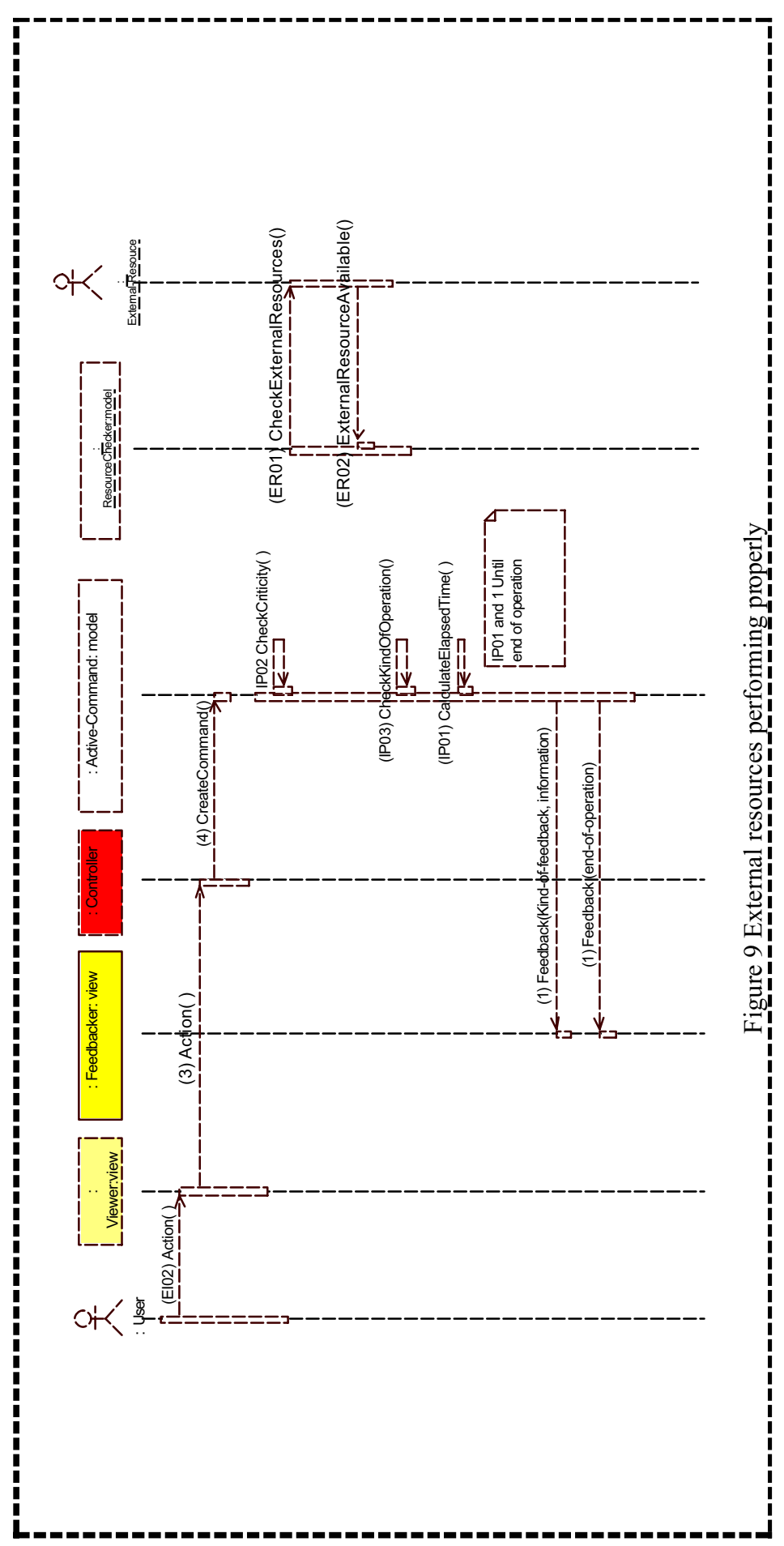




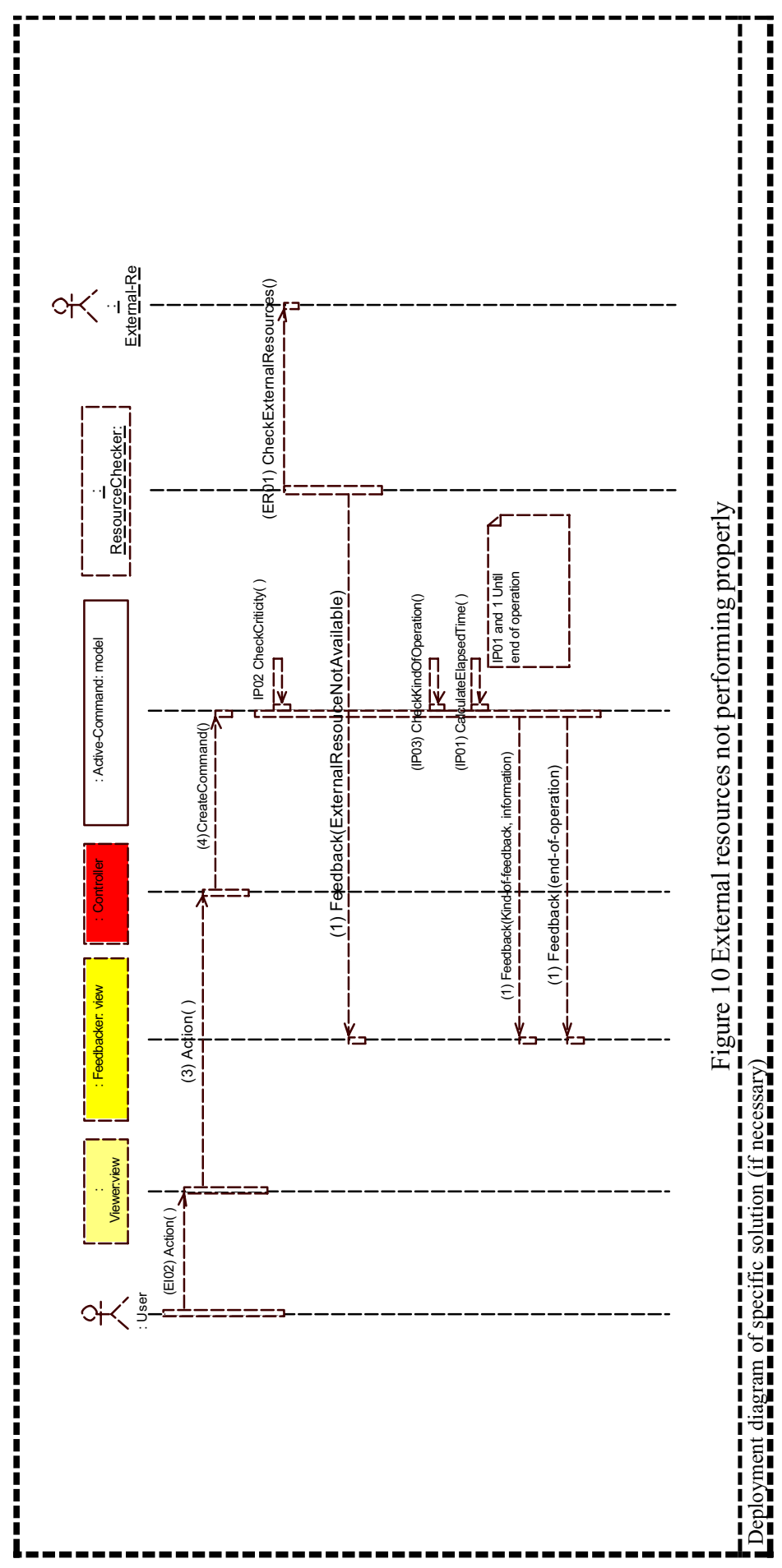




\section{REFERENCES}

Amgi, October 28, 2003 http://www.greta-web-desing-tips.com/web-usability/96.html

Baeker, R. M, Gruding, J, Buxton W, Greenberg, S. Readings in human computer interaction: toward the year 2000. Morgan Kaufmann. 1995

Benson, C, Elman, A., et al., October, 28 2003. GNOME Human Interface Guidelines http://developer.gnome.org/projects/gup/hig/

Brighton, October, 23 2003. Usability Pattern Collection. http://www.cmis.brighton.ac.uk/research/patterns/

Constantine, L., Lockwood, L. (1999). Software for Use : A Practical Guide to the Models and Methods of Usage-Centered Design . Addison-Wesley.

Coram T, Lee J, October 23, 2003 Experiences: A Pattern Language for User Interface Design. http://www.maplefish.com/todd/papers/experiences/Experiences.html

Heckel, P. (1991) The elements of friendly software design. (2nd ed.) CA: Sybex Inc.

Hix, D., Harston, H. (1993). Developing user interface: ensuring usability trough product and process. Wiley and Sons.

Matthews, W. November 10 2003, http://c2.com/cgi-bin/wiki?WebsitePatterns

Nielsen, J. (1993) Usability Engineering . Academic Press, Inc.

Perzel D., Kane D. (1999) Usability Patterns for Applications to the World Wide Web. PloP'99: The 6th Annual Conference on the Pattern Languages of Programs . August 15-18, 1999, Robert Allerton Park and Conference Center, University of Illinois at Urbana-Champaign. Urbana, IL, USA .

Rubinstein, R, Hersh, H. (1984). "The Human Factor", Digital Press, Bedford, MA .

Shneiderman, B. (1998). Designing the User Interface: Strategies for Effective HumanComputer Interaction. (3rd ed. ed.). Menlo Park, CA: Addison Wesley.

Tidwell, October, 22 2003. The Case for HCI Design Patterns. http://www.mit.edu/ jdidwell/common_ground_onefile.htm

Welie M. Amsterdam Collection of Patterns in User Interface Design. October 232003. http://www.welie.com/

Welie, M.Traetteberg. Interaction Patterns in User Interfaces. PloP'00 :7th. Pattern Languages of Programs Conference,August 13 to 16, 2000 Allerton Park. Monticello, Illinois, USA. http://jerry.cs.uiuc.edu/ plop/plop2k/. 


\section{APPENDIX}

Experts in human-computer interaction, software system design or networks, who can give their view on the usability aspect in question, should be involved in this.

C1. The system sometimes jams up because a given command does not respond; it then is important to alert users to the fact that this command has jammed.

C2. The system gives a warning that a given resource, be it the network, a database, etc., is not operational.

C3. When a web agent finds something users are looking for on the web, it returns feedback to users or delivers a new email, etc., that is, this point includes all the information that the system wants to supply to users, while the system is operating on other tasks.

C4. The system alerts users to the fact that they have to do a given previously programmed task.

C5. The system alerts users to the fact that they should save what they are doing, as the system will switch off in 1 minute because the battery is low and users will lose everything that is open.

C6. Users sometimes run several processes at the same time and want feedback to know that it finished.

C7. The system informs users how much longer it will take to complete a task, while allowing multitasking if the task in question can be performed at the same time as others. On the other hand, for example, when installing an operating system, users will only be informed of the progress of the task and will not be allowed to execute any other command in parallel.

C8. The system has to alert users to the fact that it has heard the interaction that they requested so that they not request the same service again because they think the system has not heard them.

C9. The system should warn users if they decide to invoke an action whose consequences are irreversible.

C10. The system, especially hypermedia navigational systems, should tell users where they are to assure that they do not get lost.

This section has been described according to the different types of feedback that have been identified in the literature. 


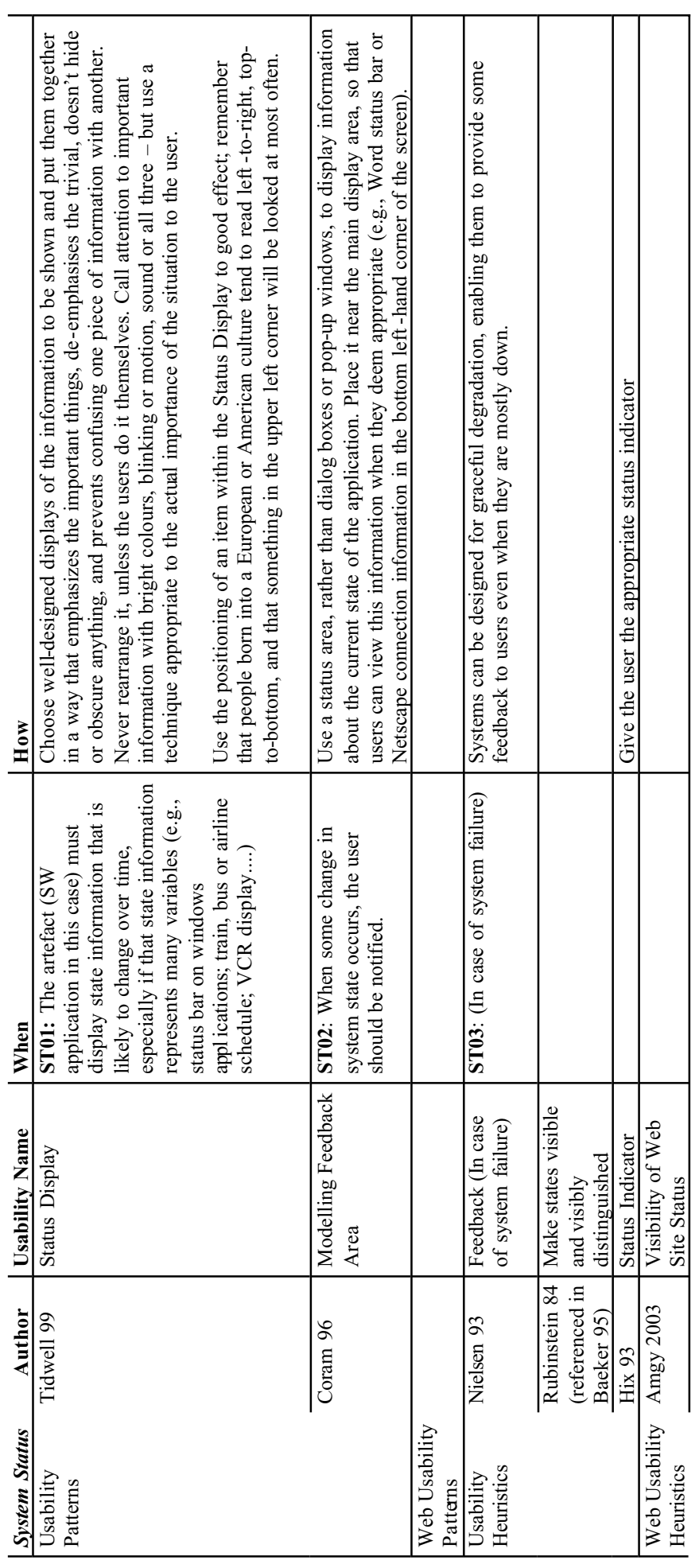




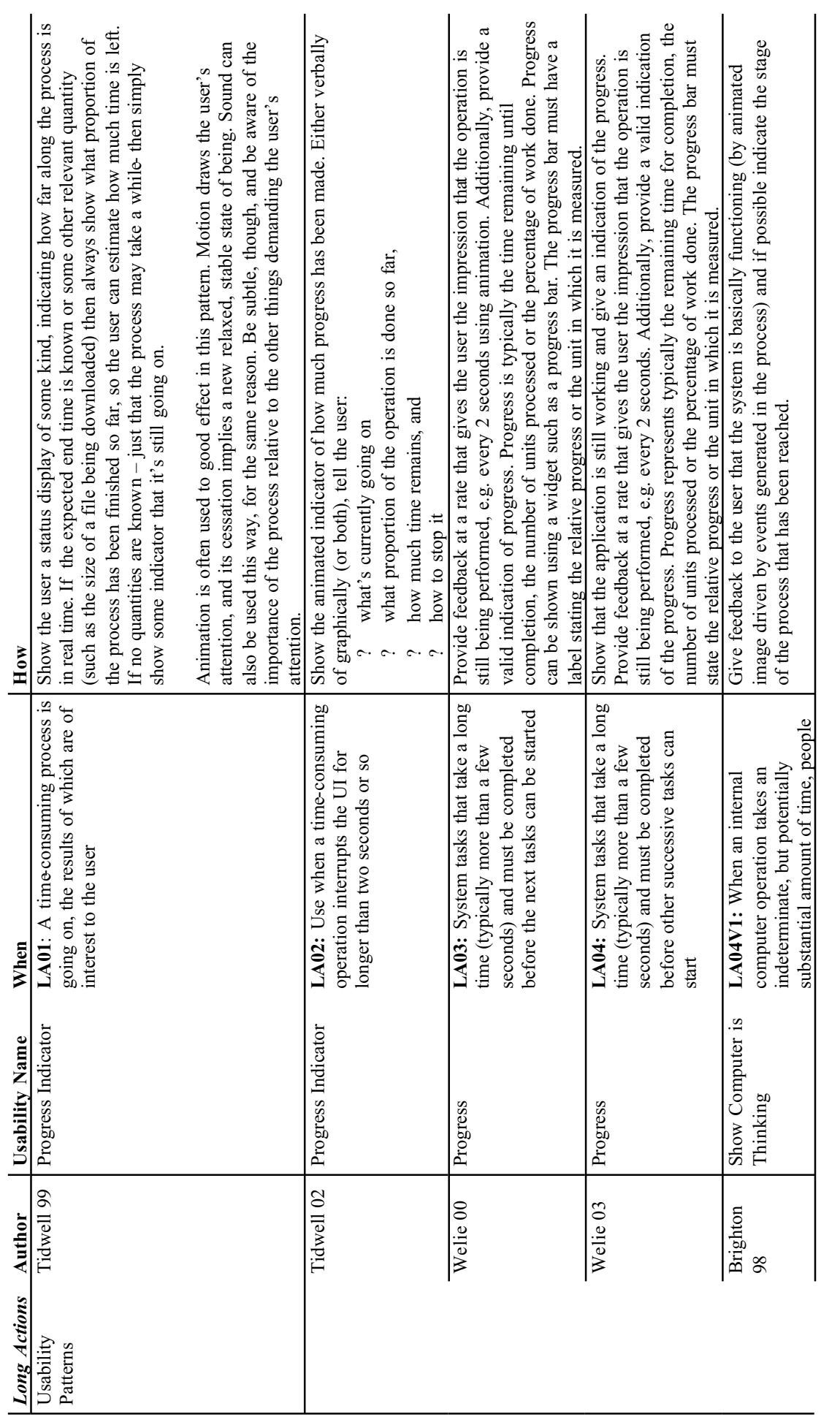

i 


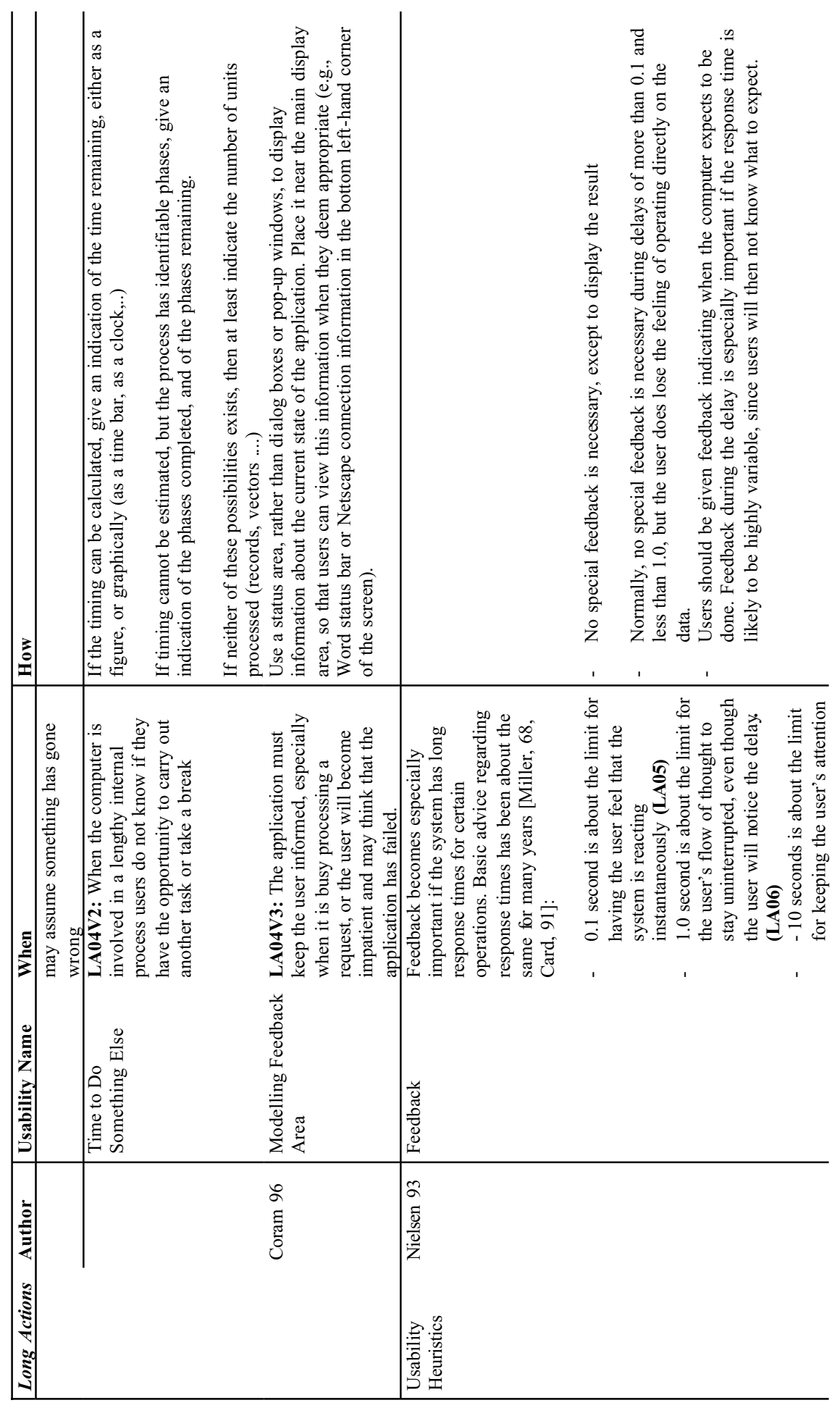

ㄴ 


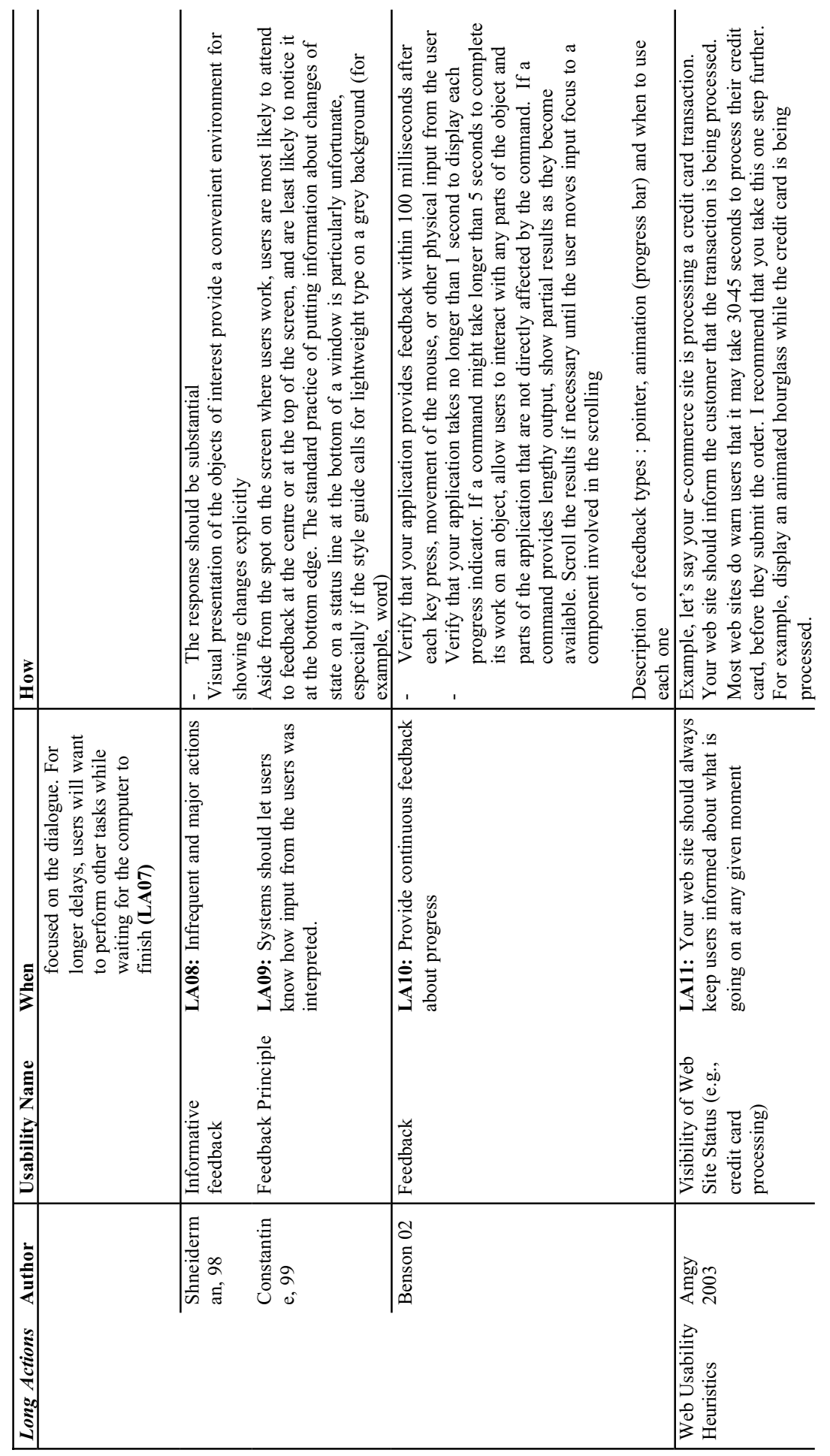

$\grave{\sim}$ 


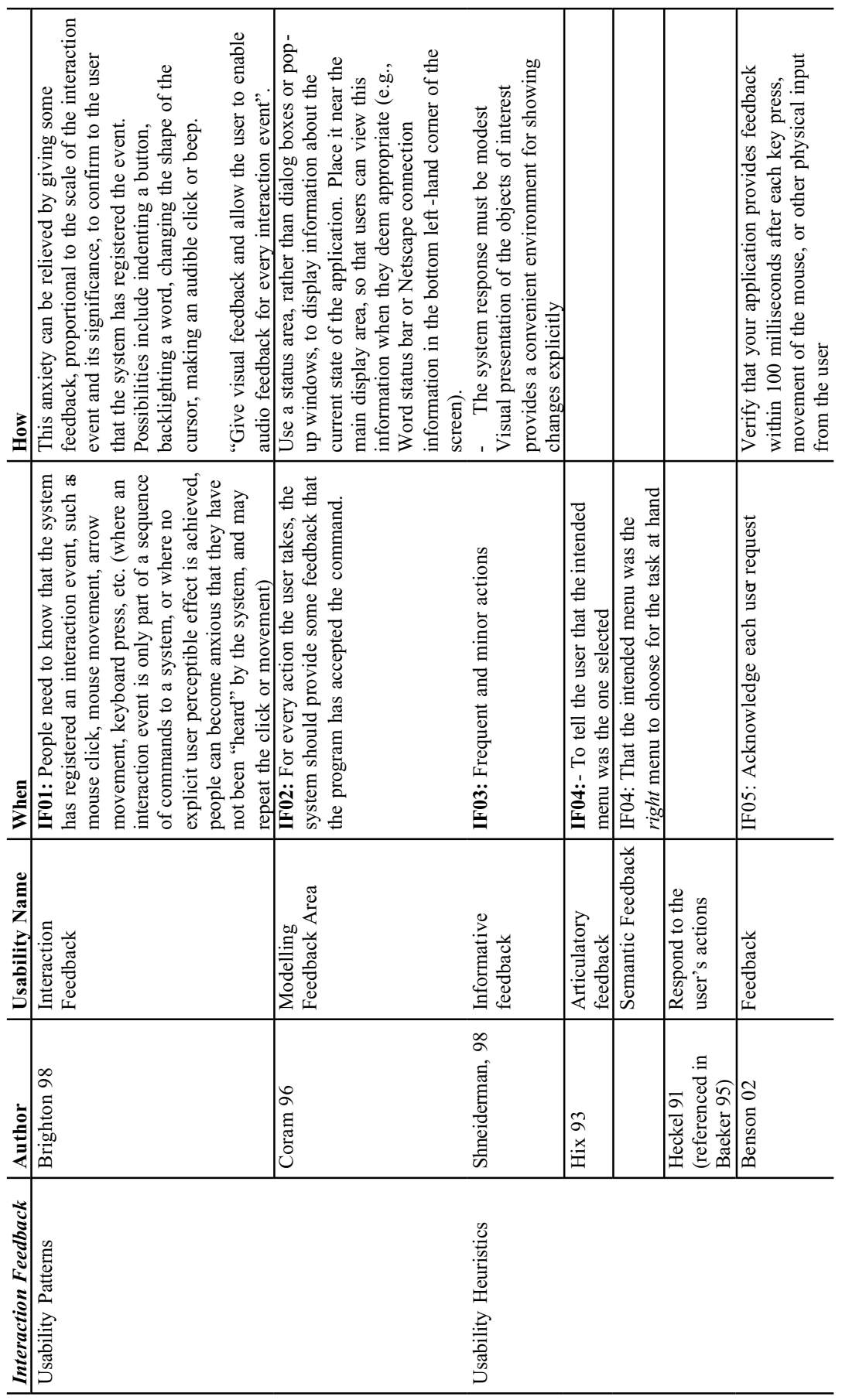




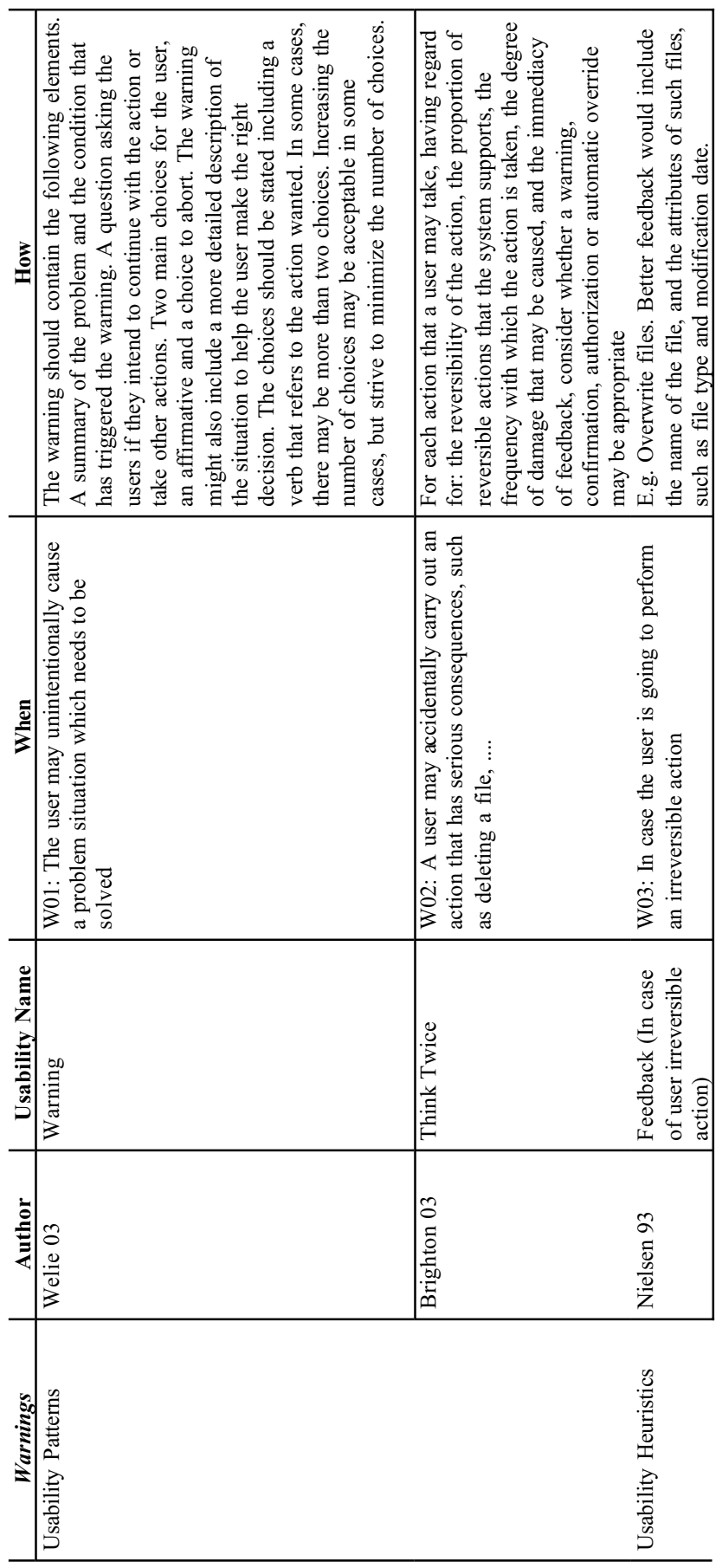




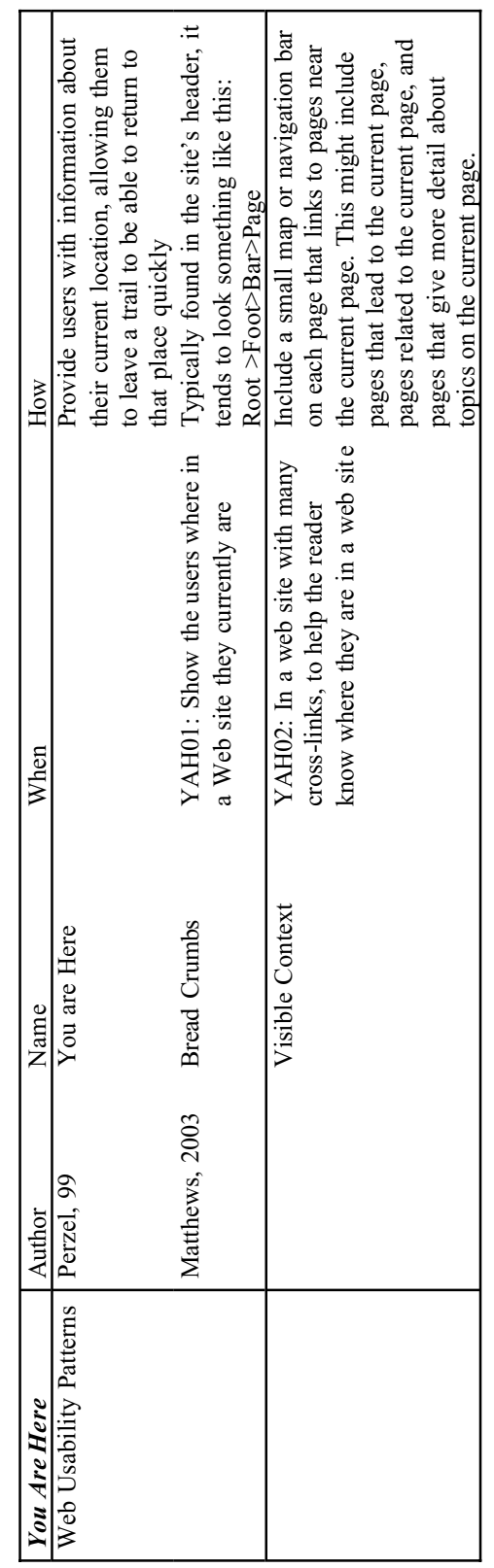




\section{CATALOGUING INFORMATION}

System status (ST): to inform users of the internal system state and state changes (including system failures)

? ST01: The artefact (SW application in this case) must display state information that is likely to change over time, especially if that state information represents variables (e.g., status bar on window application, train, bus or airline schedule, VCR displays...)

? ST02: When some change in system state occurs, the user should be notified.

? ST03: If the system fails, the user should be notified.

Long Actions (LA): to inform users that the system is processing an action that will take some time to complete.

? LA01: When a time-consuming process is going on, the results of which are of interest to the user, the user must be informed:

$\circ$ If the on-going process is critical, users should not be allowed to do anything else until this task is completed. (LA03: System tasks that take a long time (typically more than a few seconds) and must be completed before the next tasks can be started,

- LA07: If the on-going task is not critical and takes over 10 seconds, users should be allowed to run another operation if they so wish. Users should be informed when the on-going operation finishes.

? LA02: Use when a time-consuming operation interrupts the $\mathrm{UI}$ for longer than two seconds or so.

? LA04: is equivalent to LA03

? LA04V1: is equivalent to LA01

? LA04V2: is equivalent to LA01

? LA04V3: redundant

? LA05: The system response to user actions should arrive with at the latest 0.1 second after user interaction.

? LA06: redundant

? LA08: redundant

? LA09: Systems should let users know how input from the users was interpreted.

? LA10: The software must provide continuous feedback about progress.

? LA11: For web systems, the web site should always keep users informed about what is going on at any given moment.

LA11, has been ignored because represents a specific kind of software systems, while the solution for the USAP must be a general solution.

Interaction Feedback (IF): to inform users that the system has registered user interaction, that is, that the system has heard users.

? IF01: The feedback must be provided within $100 \mathrm{~ms}$.

? IF02: is equivalent to IF01 
? IF03: redundant

? IF04: This feedback is covered in the error or critical cases, because it does not make sense to provide this type of feedback in all cases.

? IF05: is equivalent to IF01

Warning $(W)$ : To inform users of any irreversible action.

? W01: The system must be provided with the ability to ask the user before executing the irreversible action.

? W02: is equivalent to W01

? W03: is equivalent to W01

You are here (YAH): to inform users where they are in the application (mainly for web sites).

? YAH01: In a web site with many cross-links, a feedback procedure must be developed to help users to know where they currently are.

? YAH02: is equivalent to YAH01

These two cases have been ignored because they are refered to a specific kind of software system while the solution for the USAP should be indeoendent of the kind of software to be developed. 